\title{
Open issues and next challenges in transcatheter mitral valve intervention
}

Citation for published version (APA):

Taramasso, M. (2017). Open issues and next challenges in transcatheter mitral valve intervention. [Doctoral Thesis, Maastricht University]. Datawyse / Universitaire Pers Maastricht. https://doi.org/10.26481/dis.20171026mt

Document status and date:

Published: 01/01/2017

DOI:

10.26481/dis.20171026mt

Document Version:

Publisher's PDF, also known as Version of record

\section{Please check the document version of this publication:}

- A submitted manuscript is the version of the article upon submission and before peer-review. There can be important differences between the submitted version and the official published version of record.

People interested in the research are advised to contact the author for the final version of the publication, or visit the DOI to the publisher's website.

- The final author version and the galley proof are versions of the publication after peer review.

- The final published version features the final layout of the paper including the volume, issue and page numbers.

Link to publication

\footnotetext{
General rights rights.

- You may freely distribute the URL identifying the publication in the public portal. please follow below link for the End User Agreement:

www.umlib.nl/taverne-license

Take down policy

If you believe that this document breaches copyright please contact us at:

repository@maastrichtuniversity.nl

providing details and we will investigate your claim.
}

Copyright and moral rights for the publications made accessible in the public portal are retained by the authors and/or other copyright owners and it is a condition of accessing publications that users recognise and abide by the legal requirements associated with these

- Users may download and print one copy of any publication from the public portal for the purpose of private study or research.

- You may not further distribute the material or use it for any profit-making activity or commercial gain

If the publication is distributed under the terms of Article $25 \mathrm{fa}$ of the Dutch Copyright Act, indicated by the "Taverne" license above, 


\section{Open issues and next challenges in transcatheter mitral valve intervention}


(C) copyright Maurizio Taramasso, Maastricht 2017

Printing: Datawyse | Universitaire Pers Maastricht 


\title{
Open issues and next challenges in transcatheter mitral valve intervention
}

\author{
PROEFSCHRIFT \\ ter verkrijging van de graad van doctor \\ aan de Universiteit Maastricht, \\ op gezag van de Rector Magnificus, Prof. dr. Rianne M. Letschert, \\ volgens het besluit van het College van Decanen, \\ in het openbaar te verdedigen \\ op 26 oktober om 10.00 uur
}

door

Maurizio Taramasso 


\section{Promotor}

Prof. dr. H.P. Brunner-La Rocca

Co-Promotor

Dr. P. Sardari Nia

\section{Beoordelingscommissie}

Prof. dr. J.G. Maessen (voorzitter)

Prof. dr. R. Chitwood (East Carolina University, Greenville, USA)

Prof. dr. J. Pomar (University of Barcelona, Spain)

Dr. C. Knackstedt

Dr. V. van Ommen 


\section{Contents}

Chapter 1 Introduction

Chapter 2 MitraClip therapy in high-risk and elderly patients with Degenerative Mitral Regurgitation: mid-term outcomes in a single center experience

Chapter 3 Clinical outcomes of MitraClip for the treatment of functional mitral regurgitation

Chapter 4 Transcatheter direct mitral annuloplasty with Cardioband: feasibility and efficacy trial in an acute preclinical model

Chapter 5 Cardioband, a transcatheter surgical-like direct mitral valve annuloplasty system: early results of the feasibility trial

Chapter 6 Transcatheter mitral valve interventions: Pathophysiological considerations in choosing reconstruction versus transcatheter valve implantation

Chapter 7 Conventional surgery and transcatheter closure via surgical transapical approach for paravalvular leak repair in high-risk patients: results from a single center experience

Chapter 8 Discussion

Chapter 9 Summary

Samenvatting (Summary in Dutch)

Valorisation of research 

Chapter

Introduction 
The clinical impact and consequently the economic burden of heart valve disease (HVD) are constantly growing in the last years. Increasing longevity of the population is mostly responsible for the rise in incidence and prevalence of the "epidemic" HVD. Advancements in valve surgery and, more recently, in transcatheter valve interventions, are rapidly shifting therapeutic management by enabling less invasive options for patients.

The Euro Heart Survey conducted by the European Society of Cardiology (ESC) showed that up to $50 \%$ of patients with severe mitral regurgitation (MR) are today denied surgical treatment because they were felt to be at too high risk for surgery owing to advanced age or comorbidities(1). Therefore, over the past few years, new transcatheter techniques have been developed to treat MR with less invasive approaches. Different types of transcatheter procedures are becoming available. Currently, the device with the widest clinical use is the MitraClip System (Abbott Park, IL, USA). MitraClip can be used to treat both degenerative (DMR) and functional MR (FMR) and, according to the last European and American Guidelines for the management of heart valve disease, can be considered in high risk or inoperable patients with severe symptomatic $\operatorname{MR}(2,3)$. Beyond the MitraClip device, additional repair and replacement technologies are being developed to expand the transcatheter mitral intervention armamentarium. 


\subsection{Clinical background}

Mitral regurgitation (MR) is the most frequent valvular heart disease in developed countries(4). MR can be organic (resulting from primary anatomical alterations affecting the valve leaflets or subvalvular apparatus: primary MR) or functional [resulting from left ventricular (LV) dilatation and remodeling processes, causing papillary muscle dislocation and leaflet tethering, in the absence of structural abnormalities of the valve: secondary MR].

The natural history of severe MR is unfavourable, leading to worsening LV failure, pulmonary hypertension, atrial fibrillation, and death(5).

The most common etiology of organic MR in Western countries is degenerative MR (DMR), due to leaflet tissue alteration known as fibroelastic deficiency or myxomatous degeneration, leading to mitral valve (MV) prolapse or flail(6) (see Figure 1).

FED

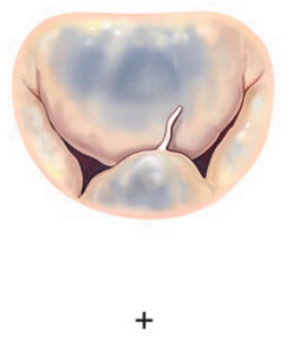

FED+

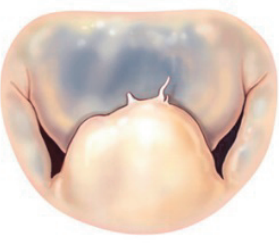

$++$
Forme fruste

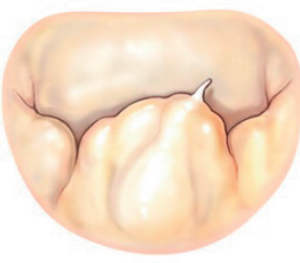

$+++$
Barlow's

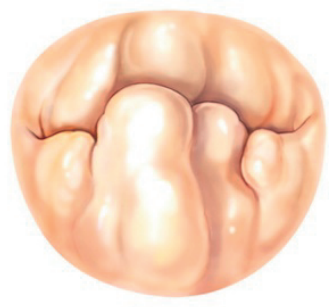

$++++$

\section{Leaflet tissue}

Figure 1. Spectrum of degenerative mitral disease. There is a spectrum of degenerative disease ranging from fibroelastic deficiency (FED) to Barlow's disease. In isolated FED there is a deficiency of collagen, with thin transparent leaflets and typically a ruptured thin chord. In long-standing prolapse, secondary myxomatous pathologic changes may occur in the prolapsing segment, resulting in leaflet thickening and expansion (FED+). Forme fruste designates degenerative disease with excess tissue with myxomatous changes in usually more than one leaflet segment, but usually does not involve a large valve size, distinguishing it from Barlow's disease. In the later, the hallmarks are large valve size, with diffuse myxomatous changes and excess leaflet tissue, with thickened, elongated, and often ruptured chordae (Eur Heart J. 2010 Aug;31(16):1958-66).

Secondary MR or functional MR (FMR) is the consequence of LV dysfunction and dilation due to the maladaptive process in the context of a post-ischemic or idiopathic dilated cardiomyopathy(7) (Figure 2).

Surgical repair represents the optimal treatment for severe DMR because of its welldocumented advantages over valve replacement in terms of perioperative mortality, preservation of postoperative LV function, and long-term survival(8, 9). Indeed, if performed before the onset of limiting symptoms or the development of LV dysfunction, $\mathrm{MV}$ repair is able to restore normal life expectancy and quality of life(10). By contrast, surgical correction of FMR is controversial, because the prognosis of the patient is more related to the cardiomyopathic process than to MR. Outcomes after surgical correction of FMR remain suboptimal and perioperative mortality is not negligible(11-14). 


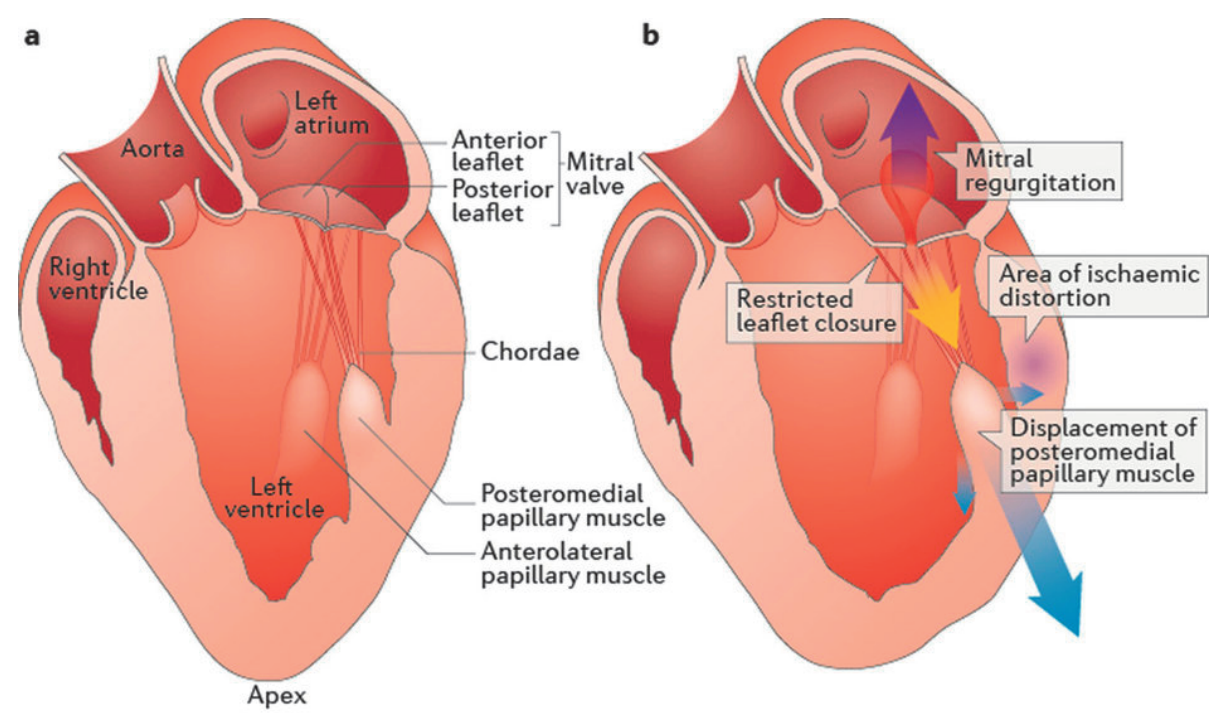

Figure 2. a) Normal mitral valve. B) In functional mitral regurgitation, displacement of the posteromedial papillary muscle and restricted closure of the mitral leaflets cause mitral regurgitation into the left atrium.

The Euro Heart Survey showed that up to $50 \%$ of patients with severe MR are today denied surgical treatment because they were felt to be at too high risk for surgery(1). Therefore, over the past few years, new transcatheter techniques have been developed to treat MR with less invasive approaches.

\subsection{Transcatheter mitral valve interventions}

Most transcatheter therapies for the mitral valve have been developed on the grounds of an established surgical procedure. Over the last years, multiple repair and replacement technologies and diversified approaches have been developed and are today under clinical study or in pre-clinical development. Conventionally, repair devices are classified according to the anatomical and pathophysiological addressed target: indirect and direct annuloplasty, leaflet and chordal repair procedures and LV remodeling devices.

The feasibility of transcatheter mitral valve implantation (TMVI) in native valves has been recently reported in very high-risk patients, with different devices and approaches(15-18).

Another challenging emerging field of mitral intervention is transcatheter treatment of paravalvular leak (PVL), which can occur after the surgical implantation of a prosthetic valve and it is associated with heart failure, haemolysis and increased mortality(19). While surgical closure of PVL remains the most common therapy, re-do surgery is often associated with high morbidity and mortality rates as well as a high-risk of 
recurrence(20). Percutaneous closure of PVL is an attractive and less invasive alternative to a surgical closure and has been found to alleviate the consequences and symptoms of PVLs in high-risk patients(21).

\subsubsection{The MitraClip therapy}

Currently, the device with the widest clinical use is the MitraClip System (Abbott Park, IL, USA). The MitraClip device is a transcatheter technology, which reproduces in close chest beating-heart condition, without cardiopulmonary bypass, the open surgical Alfieri edge-to-edge mitral repair technique (Figure 3)(22).
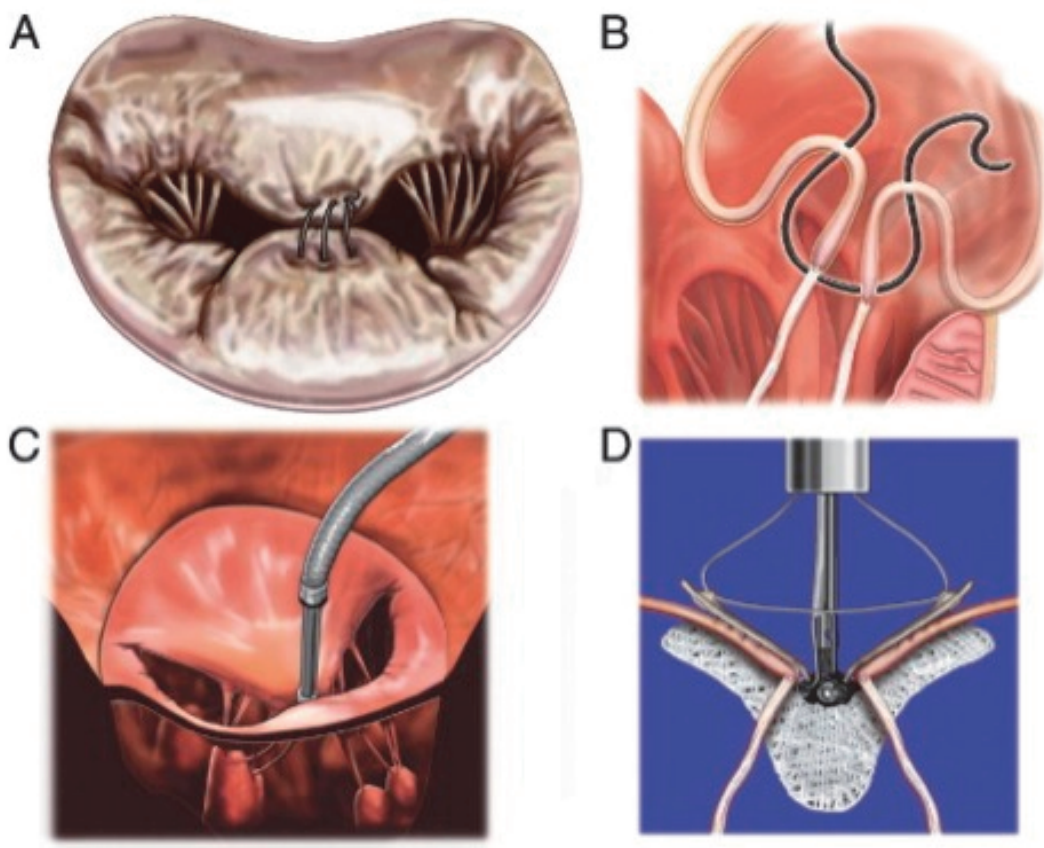

Figure 3. Surgical Edge-to-Edge Technique and MitraClip. (A) The surgical technique involves a continuous suture of the free edge of the leaflets at the site of the regurgitation. In case the lesion is in the A2-P2 area, a double orifice valve is created. (B) The sutures engage the free edge of the facing leaflets, suture bite depth depends on the amount of redundant tissue (larger in case of degenerative disease, and minimal in case of functional mitral regurgitation). (C) The MitraClip is implanted in the A2-P2 region, similarly to the surgical technique. The drawing illustrates the clip partially open, to demonstrate tissue penetration into the clip. Once proper leaflet grasping is confirmed, the clip is closed to enhance coaptation. (D) The free edges of the leaflets are engaged between the clip arms and the grippers. The clip is closed with leaflet facing. Compared with surgery where tissue is imbricated into the suture with no evidence of planar surface of coaptation, the MitraClip is designed to induce a linear apposition of leaflets to enhance coaptation (J Am Coll Cardiol. 2011 Nov 15;58(21):2174-82) 
The EVEREST study (Endovascular Valve Edge-to-Edge Repair of Mitral Regurgitation Study) comprises a series of trials, including the first randomized controlled trial in which percutaneous treatment was compared with surgical treatment in selected patients with MR (mainly of degenerative etiology)(23-25). The study results concluded that 1 year after the procedure, surgery was superior to percutaneous treatment in terms of efficacy (measured as freedom from recurrence of MR and survival), whereas the percutaneous treatment was associated with higher safety. In a post-hoc analysis, the MitraClip therapy has proven to be non-inferior to surgery in terms of effectiveness in three subgroups of patients: patients older than 70 years, those with LV dysfunction, and those with $\operatorname{FMR}(23)$.

Final results of the EVEREST II trial showed comparably low rates of surgery for MV dysfunction with either percutaneous or surgical therapy between 1- and 5-year followup after the initial procedure, endorsing durability of MR reduction with both repair techniques beyond the initial 6 months(26).

Safety and efficacy of the MitraClip therapy has been demonstrated in high-risk surgical patients different clinical setting, whit both degenerative and functional aetiology, even in the end-stage of the disease(27-33).

In this scenario, a multidisciplinary team approach is key in providing optimal individually tailored treatment for patients with MR.

\subsubsection{Direct mitral annuloplasty with the Cardioband System}

Mitral annuloplasty is largely performed during conventional mitral surgery, in order to restore the normal ratio between the leaflet surface area and the annular area and to improve leaflet coaptation. Moreover, it has been showed that mitral annuloplasty prevents progressive annular dilatation and consequent recurrent mitral regurgitation after surgery and reduces stress forces acting on the valve leaflet, therefore protecting from dehiscence of sutures $(34,35)$. While suture annuloplasty are nowadays very rarely performed, implantation of a prosthetic mitral ring is today the gold standard surgical technique for mitral annuloplasty.

In the context of DMR, where mitral leaflets are intrinsically diseased, annuloplasty is usually performed in association with leaflet repair techniques, in order to reduce MR recurrence due to further annular dilatation(36).

In FMR, undersized annuloplasty (2 sizes smaller than the size measured) is effectively performed as stand alone procedure ant it is associated with satisfactory results, when proper patient selection is carried out. Undersized annuloplasty is able to reduce the septo-lateral diameter of the mitral annulus, therefore forcing leaflet coaptation, balancing the copatation defect due to leaflet tethering(37).

The unavailability of a reliable annuloplasty device is reducing the overall chance of eligibility for transcatheter mitral interventions. Transcatheter annuloplasty has the potential either to improve outcomes either to increase therapeutic options. As soon as 
annuloplasty devices will become clinically available, percutaneous technique may potentially become a true alternative to surgery in selected patients.

Different catheter-based devices have made use of the coronary sinus to achieve indirect annuloplasty, whereas other devices achieve direct annuloplasty(38). Direct mitral valve annuloplasty is so far the most promising approach for transcatheter mitral valve annuloplasty, since it closely reproduces the conventional surgical approach.

The Valtech Cardioband (ValtechCardio, Inc. Or-Yehuda, Israel) is the closest transcatheter device to a surgical ring (Figure 4)(39). It is delivered from a transseptal approach and the implant is performed on the atrial side of the mitral annulus. An incomplete adjustable surgical-like Dacron band is implanted from commissure to commissure, under live echo and fluoroscopic guidance, using multiple anchors elements. The interaction with the cardiac function and the haemodynamic impact are minimal. After the implantation, Cardioband length may be shortened on the beating heart, under live echo guidance to improve leaflet coaptation and reduce MR. Safety and efficacy of the device have been first tested in acute and chronic large animal model and then confirmed in the first-in-man CE Mark trial(40, 41). The Cardioband device obtained CE mark in October 2015 for the treatment of high-risk patients with FMR.

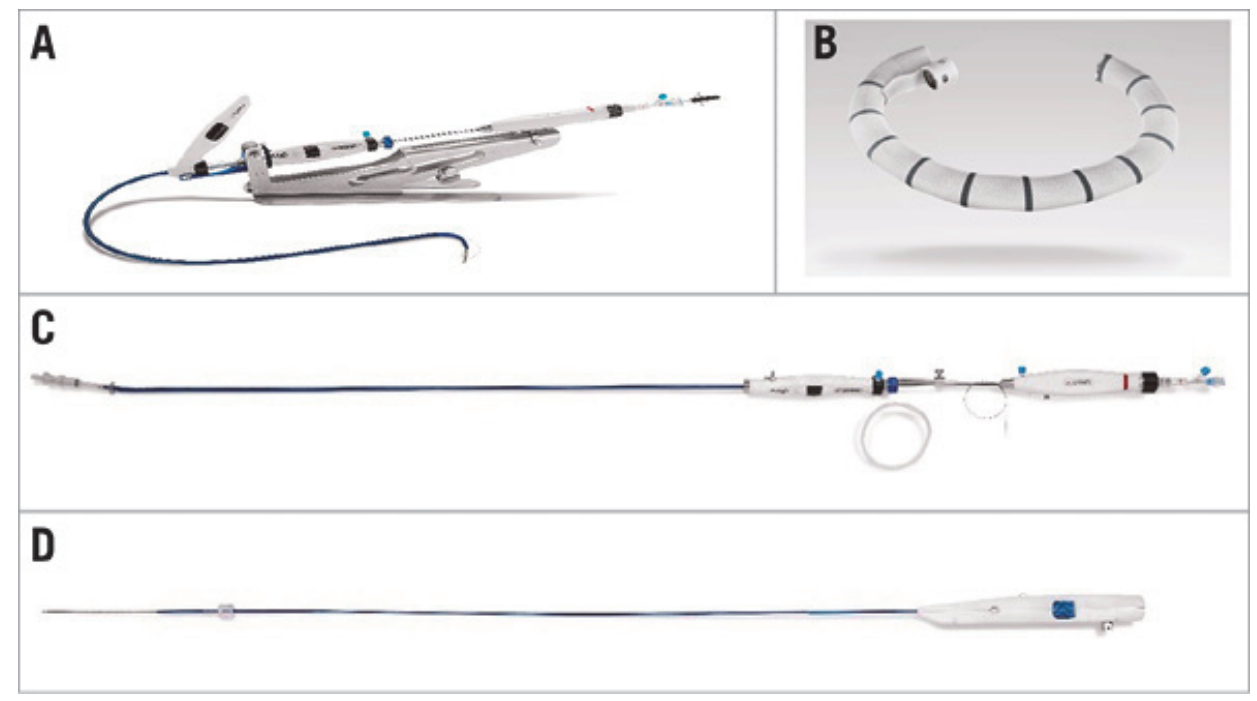

Figure 4. The Cardioband System. The Cardioband System (A) is composed of the implant (B), the delivery system (C) and the size adjustment tool (D) (Eurolntervention. 2015 Sep;11 Suppl W:W58-9) 
1.2.3 The future of transcatheter mitral valve interventions: competitive or complementary role of repair vs. replacement?

Transcatheter mitral valve implantation (TMVI) with transcatheter aortic valve implantation (TAVI) prostheses has been performed in patients with surgical degenerated bioprostheses or with recurrent MR following annuloplasty(42). Recently, feasibility of implantation of TAVI prostheses in calcified native valve has been reported(43). The feasibility of TMVI in native non-calcified valves has been reported in very high-risk patients, mainly with functional MR (FMR) (Table 1). Acknowledging the lack of scientific evidence to date, it is difficult to predict what the ultimate future role of transcatheter mitral valve interventions will be(44).

Whereas mitral valve repair is currently the most widely used approach for transcatheter interventions for MR, TMVI offers several theoretical advantages. Valve replacement is potentially applicable to a greater proportion of patients, with the hope that TMVI could provide the concept of 'one valve fits all'. MR reduction may be more predictable, and the procedure may be less technically demanding and easier to learn.

However, due to procedural and design challenges to TMVI, complications may be more

catastrophic and less forgiving, while transcatheter mitral valve repair may be associated with a superior safety profile as it involves a less marked change in valve anatomy and physiology. Repair does not entail a heterologous tissue implant, it does not require anti-coagulation, and it has been a general conclusion in the surgical experience that repair has advantages over valve replacement.

The major limitation of transcatheter repairs is that MR reduction is less predictable and MR may persist or reoccur. In addition, operators may need to master multiple transcatheter repair techniques to address the wide variability of mitral disease, and the need to combine different devices in selected patients to approximate a complete surgical repair. Given the advantages and disadvantages of these two approaches, a patient-specific decision-making algorithm for the optimal device choice will likely be required. 
Table 1. Preliminary results of transcatether mitral valve replacement in humans

\begin{tabular}{|c|c|c|c|c|c|}
\hline & $\begin{array}{l}\text { CardiAQ } \\
\text { (Edwards) }\end{array}$ & $\begin{array}{c}\text { Fortis } \\
\text { (Edwards) }\end{array}$ & $\begin{array}{c}\text { Tiara } \\
\text { (Neovasc) }\end{array}$ & $\begin{array}{l}\text { Tendyne } \\
\text { (Abbott) }\end{array}$ & $\begin{array}{l}\text { Twelve Intrepid } \\
\text { (Medtronic) }\end{array}$ \\
\hline Access / Nitinol frame & TF-TA / Yes & TA / Yes & TA / Yes & TA / Yes & TA-TF / Yes \\
\hline Pericardial leaflets & Bovine & Bovine & Bovine & Porcine & Bovine \\
\hline Symmetric leaflets & Yes & Yes & No & Yes & Yes \\
\hline Fixation System & $\begin{array}{c}\text { Barbs and tines } \\
+ \text { Tabs, clips and } \\
\text { paddles }\end{array}$ & $\begin{array}{l}\text { Atrial flange + } \\
\text { Tabs, clips and } \\
\text { paddles }\end{array}$ & $\begin{array}{c}\text { Atrial skirt + } \\
\text { Tabs, leaflet } \\
\text { anchors and } \\
\text { paddles }\end{array}$ & $\begin{array}{l}\text { Apical tether, } \\
\text { Atrial flange }\end{array}$ & Atrial flange \\
\hline $\begin{array}{l}\text { Clinical status } \\
\text { In humans and } \\
\text { patients treated (n) }\end{array}$ & $\begin{array}{c}\text { Compassionate } \\
\text { use } \\
n=12\end{array}$ & $\begin{array}{l}\text { Feasibility Trial } \\
\qquad N=13\end{array}$ & $\begin{array}{c}\text { TIARA -1 } \\
\text { Feasibility Study } \\
n=11\end{array}$ & $\begin{array}{c}\text { Currently } \\
\text { recruiting } \\
n=10\end{array}$ & $\begin{array}{c}\text { Currently } \\
\text { recruiting } \\
n=11\end{array}$ \\
\hline $\begin{array}{l}\text { Acute procedural } \\
\text { success }\end{array}$ & $83 \% 6$ & $76 \%$ & $\begin{array}{c}82 \% \\
\text { Two conversions }\end{array}$ & $\begin{array}{c}90 \% \\
\text { One retrieval }\end{array}$ & $\begin{array}{c}91 \% \\
\text { One unsuccessful }\end{array}$ \\
\hline In-hospital mortality & $17 \%$ & $31 \%$ & $27 \%$ & $0 \%$ & $18 \%$ \\
\hline Mitral PVL at discharge & $100 \%$ mild & $\begin{array}{l}89 \% \text { none } \\
11 \% \text { mild }\end{array}$ & $100 \%$ none & $\begin{array}{c}80 \% \text { none, } 10 \% \\
\text { mild, } 10 \% \text { NA }\end{array}$ & NA \\
\hline Mortality at 30-day & $50 \%$ (till day 36 ) & $38 \%$ & $27 \%$ & $0 \%$ & $18 \%$ \\
\hline
\end{tabular}

\subsubsection{The challenge of paravalvular leak treatment: the need for less invasive}

\section{options}

Paravalvular leak (PVL) is a well known complication after surgical valve replacement., with an incidence up to $17 \%$ after surgical valve replacement(19). Approximately $3 \%$ of the patients with PLV require treatment because of heart failure, haemolysis, or a combination of both. Re-operative surgery in this context is associated with high morbidity and mortality, as well as a high-risk of recurrence.

The suboptimal results from surgical repair of PVL suggest that, a less invasive solution should be considered the first-line therapy in these high-risk patients.

Percutaneous PVL closure, which was first described by Hourihan et al. in 1992, has emerged as an alternative to surgical closure and was found effective if successful(21). Transapical access is a safe alternative to transseptal approach for mitral transcatheter PVL closure. The potential advantage is that it is often less difficult to wire the defect and less resistance is encountered to cross the defect with the delivery sheath. We recently reported satisfactory acute results of a small series of 17 very high-risk patients who underwent mitral PVL closure through the transapical route. Notably, 30-day mortality was $0 \%$, with an acute procedural success of $94 \%$, and these results compared favorably with open heart surgery(45). 
With the availability of different technologies and devices, proper clinical and anatomical patient selection is the major challenge for the modern heart team, in order to offer the best patient-tailored therapeutic option. Careful analysis of the clinical outcomes of patients treated with the different devices is fundamental to assess the ideal candidate for each procedure. Moreover, especially for the new technologies, preclinical animal studies are propaedeutic to define and standardize the procedural steps before the introduction in the clinical practice.

I will try to address some aspects of these important issues in the following chapters.

In particular, in chapter 2 I will discuss the outcomes of MitraClip treatment in high risk and elderly patients with severe degenerative MR, focusing on optimal patient selection and results in a single high-volume centre experience. In chapter 3, outcomes of MitraClip in high-risk heart failure patients with functional MR will be addressed. Some relevant aspects regarding the optimal timing for MitraClip in heart failure patients will be discussed, in particular the role of baseline pro-BNP in patient selection.

Chapter 4 focuses on the preclinical experiences with the Cardioband transcatheter annuloplasty system, which has been instrumental to test safety and feasibility of this new device in a large animal model, and to set up the standardization of the procedural steps of the procedure for the first in man trial, which is the subject of Chapter 5 . Finally, in Chapters 6 and 7 I will focus on two challenging emerging topics in mitral valve intervention: transcatheter mitral valve replacement technologies, and its benefits and disadvantages compared to the repair techniques, and mitral paravalvalur leak closure, which represent at the moment one of the most demanding transcatheter therapies for interventionists. 


\section{References}

1. Mirabel M, lung B, Baron G, Messika-Zeitoun D, Detaint D, Vanoverschelde JL, et al. What are the characteristics of patients with severe, symptomatic, mitral regurgitation who are denied surgery? European heart journal. 2007;28(11):1358-65.

2. Nishimura RA, Otto CM, Bonow RO, Carabello BA, Erwin JP, 3rd, Guyton RA, et al. 2014 AHA/ACC guideline for the management of patients with valvular heart disease: executive summary: a report of the American College of Cardiology/American Heart Association Task Force on Practice Guidelines. Journal of the American College of Cardiology. 2014;63(22):2438-88.

3. Vahanian A, Alfieri O, Andreotti F, Antunes MJ, Baron-Esquivias G, Baumgartner H, et al. Guidelines on the management of valvular heart disease (version 2012). European heart journal. 2012;33(19):2451-96.

4. Nkomo VT, Gardin JM, Skelton TN, Gottdiener JS, Scott CG, Enriquez-Sarano M. Burden of valvular heart diseases: a population-based study. Lancet. 2006;368(9540):1005-11.

5. Ling LH, Enriquez-Sarano M, Seward JB, Tajik AJ, Schaff HV, Bailey KR, et al. Clinical outcome of mitral regurgitation due to flail leaflet. The New England journal of medicine. 1996;335(19):1417-23.

6. Anyanwu AC, Adams DH. Etiologic classification of degenerative mitral valve disease: Barlow's disease and fibroelastic deficiency. Seminars in thoracic and cardiovascular surgery. 2007;19(2):90-6.

7. Grigioni F, Enriquez-Sarano M, Zehr KJ, Bailey KR, Tajik AJ. Ischemic mitral regurgitation: long-term outcome and prognostic implications with quantitative Doppler assessment. Circulation. 2001;103(13):1759-64.

8. Olson LJ, Subramanian R, Ackermann DM, Orszulak TA, Edwards WD. Surgical pathology of the mitral valve: a study of 712 cases spanning 21 years. Mayo Clinic proceedings. 1987;62(1):22-34.

9. Yun KL, Miller DC. Mitral valve repair versus replacement. Cardiology clinics. 1991;9(2):315-27.

10. Detaint D, Sundt TM, Nkomo VT, Scott CG, Tajik AJ, Schaff HV, et al. Surgical correction of mitral regurgitation in the elderly: outcomes and recent improvements. Circulation. 2006;114(4):265-72.

11. Bax JJ, Braun J, Somer ST, Klautz R, Holman ER, Versteegh MI, et al. Restrictive annuloplasty and coronary revascularization in ischemic mitral regurgitation results in reverse left ventricular remodeling. Circulation. 2004;110(11 Suppl 1):li103-8.

12. Braun J, Bax JJ, Versteegh MI, Voigt PG, Holman ER, Klautz RJ, et al. Preoperative left ventricular dimensions predict reverse remodeling following restrictive mitral annuloplasty in ischemic mitral regurgitation. European journal of cardio-thoracic surgery : official journal of the European Association for Cardio-thoracic Surgery. 2005;27(5):847-53.

13. Crabtree TD, Bailey MS, Moon MR, Munfakh N, Pasque MK, Lawton JS, et al. Recurrent mitral regurgitation and risk factors for early and late mortality after mitral valve repair for functional ischemic mitral regurgitation. The Annals of thoracic surgery. 2008;85(5):1537-42; discussion 42-3.

14. De Bonis M, Taramasso M, Grimaldi A, Maisano F, Calabrese MC, Verzini A, et al. The GeoForm annuloplasty ring for the surgical treatment of functional mitral regurgitation in advanced dilated cardiomyopathy. European journal of cardio-thoracic surgery : official journal of the European Association for Cardio-thoracic Surgery. 2011;40(2):488-95.

15. Ussia GP, Quadri A, Cammalleri V, De Vico P, Muscoli S, Marchei M, et al. Percutaneous transfemoraltransseptal implantation of a second-generation CardiAQ mitral valve bioprosthesis: first procedure description and 30-day follow-up. Eurolntervention : journal of EuroPCR in collaboration with the Working Group on Interventional Cardiology of the European Society of Cardiology. 2016;11(10):112651.

16. Cheung A, Webb J, Verheye S, Moss R, Boone R, Leipsic J, et al. Short-term results of transapical transcatheter mitral valve implantation for mitral regurgitation. Journal of the American College of Cardiology. 2014;64(17):1814-9.

17. Moat N, Duncan A, Lindsay A, Quarto C, Blanke P, Leipsic J, et al. Transcatheter mitral valve replacement for the treatment of mitral regurgitation: in-hospital outcomes of an apically tethered device. Journal of the American College of Cardiology. 2015;65(21):2352-3. 
18. Abdul-Jawad Altisent O, Dumont E, Dagenais F, Senechal M, Bernier M, O'Connor K, et al. Initial Experience of Transcatheter Mitral Valve Replacement With a Novel Transcatheter Mitral Valve: Procedural and 6-Month Follow-Up Results. Journal of the American College of Cardiology. 2015;66(9):1011-9.

19. Genoni M, Franzen D, Vogt P, Seifert B, Jenni R, Kunzli A, et al. Paravalvular leakage after mitral valve replacement: improved long-term survival with aggressive surgery? European journal of cardio-thoracic surgery : official journal of the European Association for Cardio-thoracic Surgery. 2000;17(1):14-9.

20. Taramasso M, Maisano F, Denti P, Guidotti A, Sticchi A, Pozzoli A, et al. Surgical treatment of paravalvular leak: Long-term results in a single-center experience (up to 14 years). The Journal of thoracic and cardiovascular surgery. 2015;149(5):1270-5.

21. Hourihan M, Perry SB, Mandell VS, Keane JF, Rome JJ, Bittl JA, et al. Transcatheter umbrella closure of valvular and paravalvular leaks. Journal of the American College of Cardiology. 1992;20(6):1371-7.

22. Maisano F, La Canna G, Colombo A, Alfieri O. The evolution from surgery to percutaneous mitral valve interventions: the role of the edge-to-edge technique. Journal of the American College of Cardiology. 2011;58(21):2174-82

23. Feldman T, Foster E, Glower DD, Kar S, Rinaldi MJ, Fail PS, et al. Percutaneous repair or surgery for mitral regurgitation. The New England journal of medicine. 2011;364(15):1395-406.

24. Feldman T, Kar S, Rinaldi M, Fail P, Hermiller J, Smalling R, et al. Percutaneous mitral repair with the MitraClip system: safety and midterm durability in the initial EVEREST (Endovascular Valve Edge-to-Edge REpair Study) cohort. Journal of the American College of Cardiology. 2009;54(8):686-94.

25. Feldman T, Wasserman HS, Herrmann HC, Gray W, Block PC, Whitlow P, et al. Percutaneous mitral valve repair using the edge-to-edge technique: six-month results of the EVEREST Phase I Clinical Trial. Journal of the American College of Cardiology. 2005;46(11):2134-40.

26. Feldman T, Kar S, Elmariah S, Smart SC, Trento A, Siegel RJ, et al. Randomized Comparison of Percutaneous Repair and Surgery for Mitral Regurgitation: 5-Year Results of EVEREST II. Journal of the American College of Cardiology. 2015;66(25):2844-54.

27. Attizzani GF, Ohno Y, Capodanno D, Cannata S, Dipasqua F, Imme S, et al. Extended use of percutaneous edge-to-edge mitral valve repair beyond EVEREST (Endovascular Valve Edge-to-Edge Repair) criteria: 30day and 12-month clinical and echocardiographic outcomes from the GRASP (Getting Reduction of Mitral Insufficiency by Percutaneous Clip Implantation) registry. JACC Cardiovascular interventions. 2015;8(1 Pt A):74-82.

28. D'Ascenzo F, Moretti C, Marra WG, Montefusco A, Omede P, Taha S, et al. Meta-Analysis of the Usefulness of Mitraclip in Patients With Functional Mitral Regurgitation. The American journal of cardiology. 2015.

29. Glower DD, Kar S, Trento A, Lim DS, Bajwa T, Quesada R, et al. Percutaneous mitral valve repair for mitral regurgitation in high-risk patients: results of the EVEREST II study. Journal of the American College of Cardiology. 2014;64(2):172-81.

30. Maisano F, Franzen O, Baldus S, Schafer U, Hausleiter J, Butter C, et al. Percutaneous mitral valve interventions in the real world: early and 1-year results from the ACCESS-EU, a prospective, multicenter, nonrandomized post-approval study of the MitraClip therapy in Europe. Journal of the American College of Cardiology. 2013;62(12):1052-61.

31. Nickenig G, Estevez-Loureiro R, Franzen O, Tamburino C, Vanderheyden M, Luscher TF, et al. Percutaneous mitral valve edge-to-edge repair: in-hospital results and 1-year follow-up of 628 patients of the 2011-2012 Pilot European Sentinel Registry. Journal of the American College of Cardiology. 2014;64(9):875-84.

32. Taramasso M, Maisano F, Denti P, Latib A, La Canna G, Colombo A, et al. Percutaneous edge-to-edge repair in high-risk and elderly patients with degenerative mitral regurgitation: midterm outcomes in a single-center experience. The Journal of thoracic and cardiovascular surgery. 2014;148(6):2743-50.

33. Taramasso M, Maisano F, Latib A, Denti P, Buzzatti N, Cioni M, et al. Clinical outcomes of MitraClip for the treatment of functional mitral regurgitation. Eurolntervention : journal of EuroPCR in collaboration 
with the Working Group on Interventional Cardiology of the European Society of Cardiology. 2014;10(6):746-52.

34. Maisano F, La Canna G, Grimaldi A, Vigano G, Blasio A, Mignatti A, et al. Annular-to-leaflet mismatch and the need for reductive annuloplasty in patients undergoing mitral repair for chronic mitral regurgitation due to mitral valve prolapse. The American journal of cardiology. 2007;99(10):1434-9.

35. Kunzelman KS, Reimink MS, Cochran RP. Annular dilatation increases stress in the mitral valve and delays coaptation: a finite element computer model. Cardiovascular surgery (London, England). 1997;5(4):42734.

36. Gillinov AM, Cosgrove DM, Blackstone EH, Diaz R, Arnold JH, Lytle BW, et al. Durability of mitral valve repair for degenerative disease. The Journal of thoracic and cardiovascular surgery. 1998;116(5):734-43.

37. Bolling SF, Pagani FD, Deeb GM, Bach DS. Intermediate-term outcome of mitral reconstruction in cardiomyopathy. The Journal of thoracic and cardiovascular surgery. 1998;115(2):381-6; discussion 7-8.

38. Taramasso M, Maisano F. Transcatheter mitral valve repair--transcatheter mitral valve annuloplasty. Eurolntervention : journal of EuroPCR in collaboration with the Working Group on Interventional Cardiology of the European Society of Cardiology. 2014;10 Suppl U:U129-35.

39. Maisano F, Taramasso M. The Cardioband transcatheter direct mitral valve annuloplasty system. Eurolntervention : journal of EuroPCR in collaboration with the Working Group on Interventional Cardiology of the European Society of Cardiology. 2015;11 Suppl W:W58-9.

40. Maisano F, Taramasso M, Nickenig G, Hammerstingl C, Vahanian A, Messika-Zeitoun D, et al. Cardioband, a transcatheter surgical-like direct mitral valve annuloplasty system: early results of the feasibility trial. European heart journal. 2016;37(10):817-25.

41. Taramasso M, Guidotti A, Cesarovic N, Denti P, Addis A, Candreva A, et al. Transcatheter direct mitral annuloplasty with Cardioband: feasibility and efficacy trial in an acute preclinical model. Eurolntervention : journal of EuroPCR in collaboration with the Working Group on Interventional Cardiology of the European Society of Cardiology. 2015;11(7).

42. Bouleti C, Fassa AA, Himbert D, Brochet E, Ducrocq G, Nejjari M, et al. Transfemoral implantation of transcatheter heart valves after deterioration of mitral bioprosthesis or previous ring annuloplasty. JACC Cardiovascular interventions. 2015;8(1 Pt A):83-91.

43. Fassa AA, Himbert D, Brochet E, Depoix JP, Cheong AP, Alkhoder S, et al. Transseptal transcatheter mitral valve implantation for severely calcified mitral stenosis. JACC Cardiovascular interventions. 2014;7(6):696-7.

44. Maisano F, Alfieri O, Banai S, Buchbinder M, Colombo A, Falk V, et al. The future of transcatheter mitral valve interventions: competitive or complementary role of repair vs. replacement? European heart journal. 2015;36(26):1651-9.

45. Taramasso M, Maisano F, Latib A, Denti P, Guidotti A, Sticchi A, et al. Conventional surgery and transcatheter closure via surgical transapical approach for paravalvular leak repair in high-risk patients: results from a single-centre experience. European heart journal cardiovascular Imaging. 2014;15(10):1161-7. 



\section{Chapter}

\section{MitraClip therapy in high-risk and elderly patients with Degenerative Mitral Regurgitation: mid-term outcomes in a single center experience}

Maurizio Taramasso MD, Francesco Maisano MD, Paolo Denti MD, Azeem Latib MD, Giovanni La Canna MD, Antonio Colombo MD, Ottavio Alfieri MD 


\section{Abstract}

Background: To report mid-term outcomes of MitraClip implantation in inoperable or high-risk surgical candidates with degenerative mitral regurgitation (DMR).

Methods: From October 2008, data of all high-risk or elderly patients with severe DMR who underwent MitraClip implantation were prospectively collected.

Results: Forty-eight high-risk consecutive patients with severe DMR underwent MitraClip implantation (mean age $78.5 \pm 10.8$ years; $56.6 \%$ of the patients $\geq 80$ year-old). Mean STS score was $12 \pm 10 \%$ and $71 \%$ were in NYHA class III-IV. Mean LVEF was $57 \pm 11 \%$. The device was successfully implanted in $47 / 48$ patients (98\%). In-hospital mortality was 2 $\%$. Median stay in intensive care unit was 22 hours; patients were discharged from the hospital an average of $4.5 \pm 2.4$ days. Pre-discharge echocardiography showed an MR reduction to grade $\leq 2+$ in $43 / 47$ patients (91.5\%). Actuarial survival was $89 \pm 5.2 \%$ and $70.2 \pm 9 \%$ at 1 and 2 years ( $82 \pm 9 \%$ in patients $<80$-year-old and $95 \pm 4.4 \%$ in patients $\geq 80$ year-old at 1 year; $p=0.9$ ). Freedom from $M R \geq 3+$ was $80 \pm 7 \%$ at 1 year and $76.6 \pm 7 \%$ at 2 years. At 1 year, 93\% of survivors were in NYHA class I-II (100\% of patients $<80$-year-old and $88 \%$ of $\geq 80$-year-old patients; $p=0.4$ ). Significant quality of life improvements were documented. A significant improvement in 6MWT performance was observed.

Conclusions: MitraClip therapy is a valuable alternative to surgery in high-risk and elderly patients with DMR. Clinical benefits are obtained also in octogenarians. 


\section{Introduction}

Surgical repair represents the optimal treatment for severe degenerative mitral regurgitation (DMR) due to its well-documented advantages over valve replacement in terms of perioperative mortality, preservation of postoperative LV function, and long-term survival (1-2). Indeed, if performed before the onset of limiting symptoms or the development of LV dysfunction, MV repair is able to restore normal life expectancy and quality of life (3). Currently, more than $90 \%$ of degenerative lesions can be repaired successfully in high-volume centers, with very low morbidity and fast recovery (4-6). Considering those results, elective mitral valve repair may be indicated even in asymptomatic patients with severe DMR (7).

However, in the real world clinical practice a large number of patients with severe MR are denied surgery: the Euro Heart Survey conducted by the European Society of Cardiology showed that up to $50 \%$ of the patients with severe MR is today denied surgical treatment because they were felt to be at too high risk for surgery due to advanced age or comorbidities (8). Moreover, prevalence of DMR increases in elderly (9) and advanced age is one of the main risk factors of mortality and major morbidity after cardiac surgery (10). Therefore, over the past years, new transcatheter techniques have been developed to treat MR with less invasive approaches. Although less effective in reducing MR compared with surgical repair (11-12), MitraClip therapy (Abbott Vascular Inc. Menlo Park, CA, USA) has been showed to improve functional and clinical outcome in inoperable or high-risk patients (13-18). Few data are today available on mid-term clinical outcomes of high-risk patients with DMR after MitraClip implantation.

The aim of this study is to report mid-term clinical and echocardiographic results of MitraClip therapy to treat symptomatic high-risk or elderly patients with severe DMR in a single high-volume center experience, in order to validate the use of MitraClip treatment in this specific setting.

\section{Materials and methods}

We retrospectively analyzed the clinical and echocardiographic data of a cohort of consecutive patients who underwent MitraClip therapy between October 2008 and July 2013 for severe or moderately severe symptomatic DMR. All the patients underwent preoperative coronary angiography and transesophageal Doppler echocardiography (TEE). Clinical, Doppler echocardiographic, operative, and outcome data were prospectively collected in a dedicated database. The study protocol was performed in accordance with the institutional ethics committee, and all patients gave written informed consent for the procedures and data collection. 


\section{Description of the procedure}

The procedure was performed under general anesthesia in a hybrid operating room, under TEE and fluoroscopic guidance. Transeptal puncture was performed using a Brockenbrough needle through peripheral venous access at the right groin. Live realtime 3-D echocardiography was used to improve the conduct of the implantation. A steerable guide catheter was advanced in the left atrium through the transeptal puncture. The delivery system was inserted and the MitraClip device was implanted in correspondence of the origin of the regurgitation jet, perpendicularly to the coaptation line. If the effect of the implant was satisfactory, the clip was deployed. When necessary, more than 1 clip was implanted. The comprehensive description of the procedure is reported elsewhere (19).

\section{Patient selection}

Patients were selected if they met basic criteria for intervention from the European Society of Cardiology Task Force recommendation on the management of valvular heart disease (7). Indication to MitraClip therapy was given according to local institutional practice in consideration of current CE-mark approved labeling. Eligible patients included those with symptomatic moderate-to-severe $(3+)$ or severe $(4+)$ mitral regurgitation. Transthoracic and transesophageal echocardiograms studies were evaluated at baseline to assess patient eligibility.

All the patients underwent a multimodality decision making process by a dedicated multidisciplinary Heart Team, including evaluation of surgical risk by Logistic EuroSCORE (http://www.euroscore.org/) and STS score (http://riskcalc.sts.org/STSWebRiskCalc273/) as well as adjunctive risk evaluation such as the presence of advanced liver cirrhosis, severe neurological impairment. Frailty and biological status were evaluated by the institutional Heart Team after collegial discussion, according to the so-called "eyeball test". Quality of Life (QoL) of all the patients was evaluated by Minnesota Living with Heart Failure Questionnaire (MLHFQ) and the 36 Item Short-Form Health Survey (SF-36); the 6 minute walking test (6MWT) was used to evaluate functional capacity.

\section{Follow-up}

All the patients were followed-up after discharge in a dedicated outpatient clinic with physical examination, ECG, TTE and arrhythmology consultation whenever indicated. Follow-up visits were performed at 1-month, 6-months and then yearly. 


\section{Statistical Analysis}

Statistical analysis were conducted using the JMP 11.0 software (SAS Institute Inc, NC, USA). Continuous variables are presented as mean \pm SD or as median (IQR, Q1-Q3) and categorical variables are expressed as percentages. Univariable comparisons were performed with Student's unpaired or paired t-test for continuous normally distributed data, which were tested by the Shapiro-Wilk normality test. Mann-Whitney rank sum test was used for comparisons of non parametric continuous data and the chi-square test for categorical data. Survival and freedom from $\geq 3+M R$ were presented using the Kaplan-Meier method; comparisons were performed with Log-Rank test. A p-value $<0.05$ was considered statistically significant, and all reported $p$-values are 2 -sided.

\section{Results}

\section{Patient characteristics}

The study population consisted of 48 high-risk consecutive patients with severe or moderate to severe DMR underwent MitraClip implantation between October 2008 and July 2013 in our Institution. During the same period, 2370 patient underwent surgical mitral repair (with or without associated procedure) and 116 patients underwent MitraClip implantation for functional MR.

Mean age of the study population was $78.5 \pm 10.8$ years; $56.6 \%$ of the patients were $\geq 80$ year-old. The mean logistic EuroSCORE at baseline was $15.7 \pm 11.2$; mean STS score was $12 \pm 10 \%$ (range 2-36\%; IQR 4-18\%); 40\% and $45.5 \%$ of patients had a baseline logistic EuroSCORE $\geq 20 \%$ and STS score $\geq 10 \%$, respectively. Patients presented multiple comorbidities. Baseline characteristics of all the patients are summarized in Table 1 (including also data from ACCESS-EU phase I DMR cohort for comparison) (13). Stratification into $<80$-year-old and $\geq 80$-year-old patients revealed important demographic differences (mean Logistic EuroSCORE $12.1 \pm 8.5 \%$ and $18.5 \pm 12$ respectively, $p=0.04$ ).

The majority of the patients had severe symptoms of heart failure at baseline, with $60.5 \%$ in NYHA Functional Class III and $10.5 \%$ in Class IV.

Quality of life questionnaire revealed an important impairment in perceived quality of life in all the patients (MLHFQ was $35.4 \pm 12$; SF-36 physical domain was 38.6 \pm 7.9 ; SF36 mental domain was $42.5 \pm 8.7$ ). A tendency towards worst perceived quality of life was observed in patients $\geq 80$-year-old (MLHFQ $33 \pm 14$ vs. $36 \pm 8-p=0.3$; SF-36 physical domain $40.6 \pm 6$ vs. $42.4 \pm 8-p=0.06$; SF-36 mental domain $42.7 \pm 9$ vs $42.4 \pm 8 ; p=0.4$ ). Patients older than 80 years had worst performance at 6MWT $(262.3 \pm 110.4 \mathrm{~m}$ vs. 180.1 $\pm 64.7 \mathrm{~m} ; \mathrm{p}=0.004)$.

Preoperative median pro-BNP value was 1026 pg/ml (IQR 346-1895pg/ml), without any difference according to age. 


\section{Chapter 2}

Table 1. Baseline demographics and comorbidities

\begin{tabular}{|c|c|c|c|c|c|}
\hline Characteristic & $\begin{array}{l}\text { Overall } \\
(n=48)\end{array}$ & $\begin{array}{l}\text { Age }<80 \text { years } \\
(n=21)\end{array}$ & $\begin{array}{l}\text { Age } \geq 80 \text { years } \\
(n=27)\end{array}$ & p-value & $\begin{array}{l}\text { ACCESS-EU DMR } \\
(\mathrm{n}=117)\end{array}$ \\
\hline Age (years) & $78.5 \pm 10.8$ & $70.2 \pm 11$ & $84.8 \pm 3$ & $<0.0001$ & $75.6 \pm 12.1$ \\
\hline Female ( $n, \%)$ & $22(46)$ & $9(42)$ & $13(48)$ & 0.7 & $59(50.4)$ \\
\hline Logistic EuroScore (\%) & $15.7 \pm 12.2$ & $12.1 \pm 8.5$ & $18.5 \pm 12$ & 0.04 & $15.5 \pm 13.3$ \\
\hline STS-PROM (\%) & $12 \pm 10$ & $8.3 \pm 6$ & $15.1 \pm 11$ & 0.02 & na \\
\hline Previous cardiac surgery (n, \%) & $10(21)$ & $6(28)$ & $4(14)$ & 0.2 & $28(23.9)$ \\
\hline $\begin{array}{l}\text { Previous percutaneous } \\
\text { intervention }(n, \%)\end{array}$ & $7(14.5)$ & $3(14)$ & $4(14)$ & 0.9 & $32(27.6)$ \\
\hline Coronary Artery Disease (n, \%) & 19 (39.5) & $9(42)$ & $10(37)$ & 0.7 & $48(41)$ \\
\hline Atrial Fibrillation (n, \%) & $25(52)$ & $7(33)$ & $18(66)$ & 0.02 & $67(58.8)$ \\
\hline Baseline serum creatinine $(\mathrm{mg} / \mathrm{dl})$ & $1.1 \pm 0.4$ & $0.9 \pm 0.2$ & $1.3 \pm 0.3$ & 0.006 & na \\
\hline COPD (\%) & $14(29)$ & $6(28)$ & $8(29)$ & 0.3 & $17(14.7)$ \\
\hline Cerebrovascular disease (n, \%) & $5(10.5)$ & $1(4)$ & $4(14)$ & 0.2 & $12(10.3)$ \\
\hline NYHA class III-IV (n, \%) & $34(70.8)$ & $14(66)$ & $20(74)$ & 0.5 & $113(96.4)$ \\
\hline Previous ICD-CRT (n, \%) & $1(2)$ & 0 & $1(3.7)$ & 0.3 & $2(1.7)$ \\
\hline
\end{tabular}

STS-PROM= Society of Thoracic Surgeons Predicted Risk of Mortality; COPD= Chronic Obstructive Pulmonary Disease; NYHA= New York Heart Association; ICD-CRT= Implantable Cardioverter Defibrillator-Cardiac Resynchronization Therapy; na=not available.

Table 2 shows in detail preoperative echocardiography of the study population. All the patients had a MR grade $3+$ of $4+$ at baseline; mean LVEF was $57 \pm 11 \%$.

Table 2. Preoperative echocardiography.

\begin{tabular}{|c|c|c|c|c|c|}
\hline \multirow{2}{*}{$\begin{array}{l}\text { Characteristic } \\
\text { LV Ejection fraction (\%) }\end{array}$} & \multirow{2}{*}{$\begin{array}{l}\begin{array}{l}\text { Overall } \\
(n=48)\end{array} \\
57.9 \pm 11\end{array}$} & \multicolumn{3}{|c|}{$\begin{array}{l}\text { Age }<80 \text { years } A g e \geq 80 \text { years } p \text {-value } \\
(n=21) \quad(n=27)\end{array}$} & \multirow{2}{*}{$\begin{array}{l}\text { ACCESS-EU DMR } \\
(n=117) \\
\text { na }\end{array}$} \\
\hline & & $55.3 \pm 13$ & $59.9 \pm 8$ & 0.1 & \\
\hline $\begin{array}{l}\text { LV Ejection Fraction } \\
<40 \%(n, \%)\end{array}$ & $6(12.5)$ & $4(19)$ & $2(7.4)$ & 0.2 & $11(9.4)$ \\
\hline LVEDD (mm) & $56.9 \pm 8$ & $60.4 \pm 9$ & $54.4 \pm 6$ & 0.01 & na \\
\hline LVESD (mm) & $35.3 \pm 7$ & $37 \pm 8.7$ & $34 \pm 6.7$ & 0.2 & $35 \pm 9$ \\
\hline $\mathrm{sPAP}(\mathrm{mmHg})$ & $46.4 \pm 14$ & $42.1 \pm 13$ & $49.7 \pm 14.8$ & 0.03 & na \\
\hline TR 3-4+ (n, \%) & $9(19.5)$ & $2(10)$ & $7(27)$ & 0.1 & na \\
\hline Central lesion (n, \%) & $44(92)$ & $19(90)$ & $25(93)$ & 0.3 & na \\
\hline Flail width (mm) & $12 \pm 2$ & $12.8 \pm 3$ & $12.4 \pm 2.3$ & 0.8 & na \\
\hline Flail gap (mm) & $4.6 \pm 1.4$ & $5.5 \pm 1.6$ & $4.1 \pm 1$ & 0.04 & na \\
\hline
\end{tabular}

LV= Left Ventricle; LVEDD= Left Ventricle End Diastolic Diameter; LVESD= Left Ventricle End Systolic Diameter; SPAP: systolic Pulmonary Artery Pressure; TR: Tricuspid Regurgitation; na: not available. 


\section{Procedural and in-hospital outcomes}

The device was successfully implanted in 47/48 patients (98\%); one patient was converted to conventional surgical mitral valve replacement because of clip entanglement in the subvalvular apparatus in the commissural region, with impossibility to retrieve the device.

One clip was implanted in 16 patients (33.3\%), 2 clips were implanted in 29 patients (60.4\%) and 3 clips were implanted in 2 patients (4.1\%). Median procedural time (defined as the time from start of the transseptal procedure until the removal of the Steerable Guide Catheter) was 94 min (IQR 69-130 min; 6 minutes shorter compared to ACCESS-EU DMR) (13).

Safety outcomes at 30-days are presented in Table 3; 30-days mortality was $2 \%$ (1/48 patient died from septic shock and multiorgan failure after conversion to open mitral surgery). There was no incidence of acute myocardial infarction, stroke, major vascular complication or cardiac tamponade at 30 days. In 2 patients (4\%) blood transfusion was required; severe acute renal failure occurred in 1 patients (2\%). Median stay in intensive care unit was 22 hours (IQR 18-24 hours); in 75\% of the cases (36/48 patients) stay in intensive care unit was less than 1 day. Patients were discharged from the hospital an average of $4.5 \pm 2.4$ days $(4.3 \pm 3$ days and $4.7 \pm 1.5$ days for patients $<80$-yearold and $\geq 80$-year-old respectively- $p=0.7$ ) with a median of 4 days following the MitraClip procedure. Only a minority of the patients were transferred to a cardiopulmonary rehabilitation facility ( 2 patients $<80$-year-old and 2 patients $\geq 80$-year-old; $p=0.8$ ): $91.5 \%$ of hospital survivors (43/47 patients) were discharged directly home.

Table 3. Thirty-day safety outcomes

\begin{tabular}{llllll}
\hline 30-day outcome & $\begin{array}{l}\text { Overall } \\
(n=48)\end{array}$ & \multicolumn{2}{l}{$\begin{array}{l}\text { Age<80 years Age } 280 \text { years } p \text {-value } \\
(n=21)\end{array}$} & $\begin{array}{l}\text { ACCESS-EU DMR } \\
(n=117)\end{array}$ \\
\hline Death (n, \%) & $1(2)$ & 0 & $1(3)$ & 0.3 & $7(6)$ \\
Conversion to surgery (n, \%) & $1(2)$ & 0 & $1(3)$ & 0.3 & $2(1.7)$ \\
Stroke (n, \%) & 0 & 0 & 0 & - & $1(0.9)$ \\
AMI (n, \%) & 0 & 0 & 0 & - & $1(0.9)$ \\
Renal failure (n, \%) & $1(2)$ & 0 & $1(3)$ & 0.3 & $3(2.6)$ \\
Bleeding complications (n, \%) & $2(4)$ & 0 & $2(8)$ & 0.2 & $4(3.4)$ \\
Cardiac tamponade (n, \%) & 0 & 0 & 0 & - & $1(0.9)$ \\
ICU stay <24 hours (n, \%) & $36(75)$ & $18(81)$ & $18(70)$ & & na \\
\hline
\end{tabular}

$\mathrm{AMI}=$ acute myocardial infarction; ICU= intensive care unit; na=not available.

Pre-discharge echocardiography showed an MR reduction to grade $\leq 2+$ in 43/47 patients (91.5\%); 29/47 patients (61.7\%) achieved an MR reduction to grade $\leq 1+$. No differences in MR grade reduction were observed according to age group (Figure 1). No cases of mitral stenosis were observed: post-procedural median MV area was $3 \mathrm{~cm} 2$ 
(IQR 2.7- $3.1 \mathrm{~cm} 2)$; pre-discharge sPAP was $37.8 \pm 10 \mathrm{mmHg}(p=0.03$ compared to baseline.)

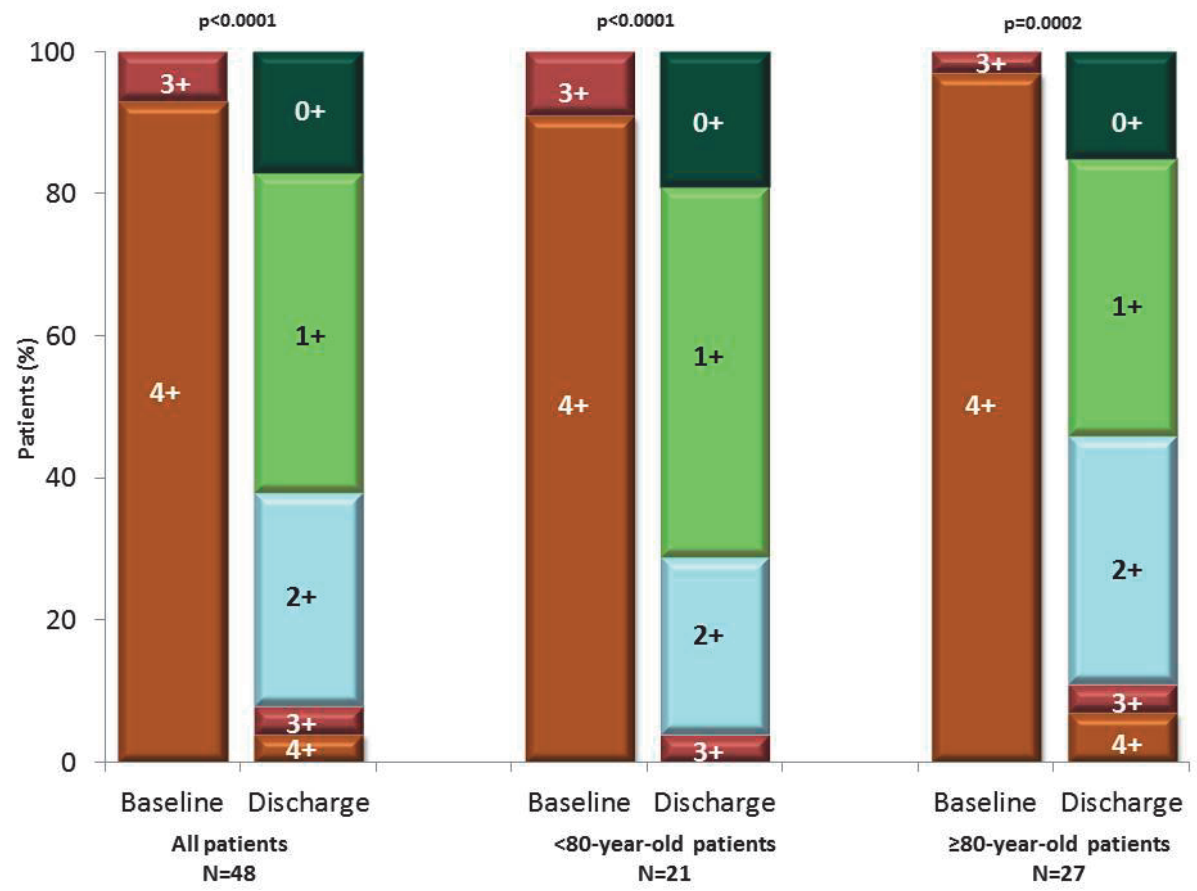

Figure 1. Mitral regurgitation at baseline and at discharge echocardiography.

\section{Follow-up}

Median follow-up was 16 months (IQR 2- 23 months). Overall actuarial survival was $89 \pm 5.2 \%$ and $70.2 \pm 9 \%$ at 1 and 2 years respectively for the entire study populations; no differences were observed between patients $<80$-year-old and patients $\geq 80$-year-old $(82 \pm 9 \%$ and $95 \pm 4.4 \%$ at 1 year respectively; $p=0.9)$ (Figure 2). Causes of death were classified as cardiac in 33\% of the cases. After discharge, 1 patient (2\%) underwent mitral surgery 2 years after the procedure; 1 patient (2\%) repeated MitraClip procedure 1 month after the index procedure.

Actuarial freedom from $M R \geq 3+$ was $80 \pm 7 \%$ at 1 year and $76.6 \pm 7 \%$ at 2 years (Figure $3)$. There were no statistically significant differences in $<80$-year-old patients compared with $\geq 80$-year-old patients ( $86.5 \pm 8 \%$ and $75 \pm 9 \%$ respectively; $p=0.5$ ).

At 1 year, 93\% of survivors were in NYHA class I-II (100\% of patients < 80 -year-old and $88 \%$ of $\geq 80$-year-old patients; $p=0.4$ ) (Figure 4 ).

A significant improvement was documented with all the quality of life assessments: MLHFQ was $18.1 \pm 10$, SF-36 physical domain was $44.3 \pm 7$ and SF-36 mental domain was $49 \pm 8.3$ ( $p<0.0001, p=0.005$ and $p=0.01$ compared to preoperative values respectively). 
A significant improvement in 6MWT performance was observed $(262 \pm 91 \mathrm{~m}$; mean improvement $48 \mathrm{~m} ; \mathrm{p}=0.005)$. Significant improvements in perceived quality of life and performance with 6MWT were observed in both patients group (Figures $5 \mathrm{~A}$ and B).

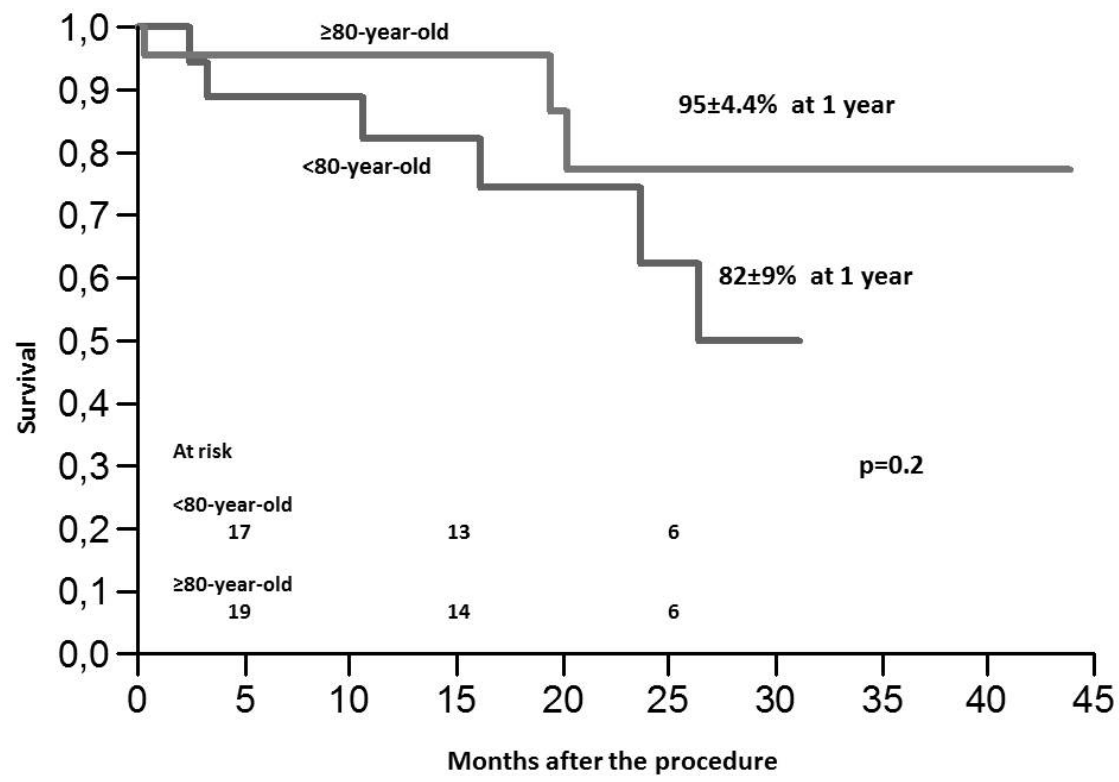

Figure 2. Actuarial survival at follow-up in patients $<80$-year-old and $\geq 80$-year-old.

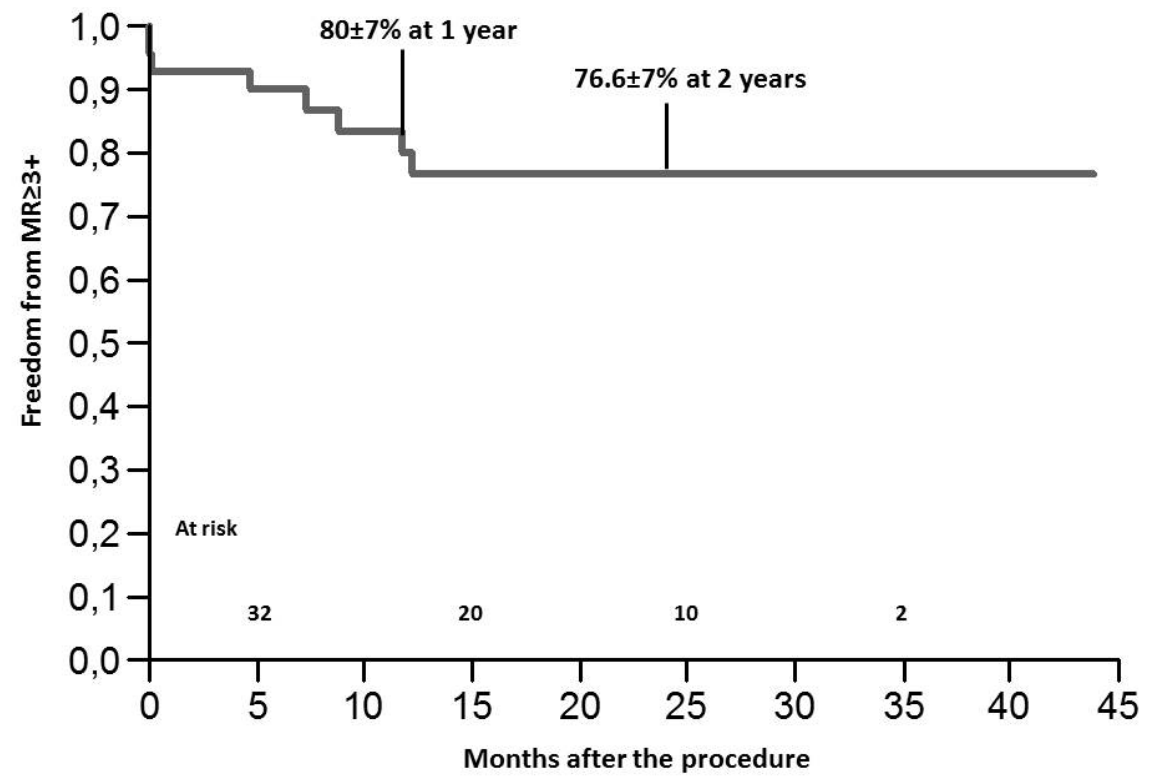

Figure 3. Actuarial freedom from $M R \geq 3+$ at follow-up ( $M R=$ mitral regurgitation) 


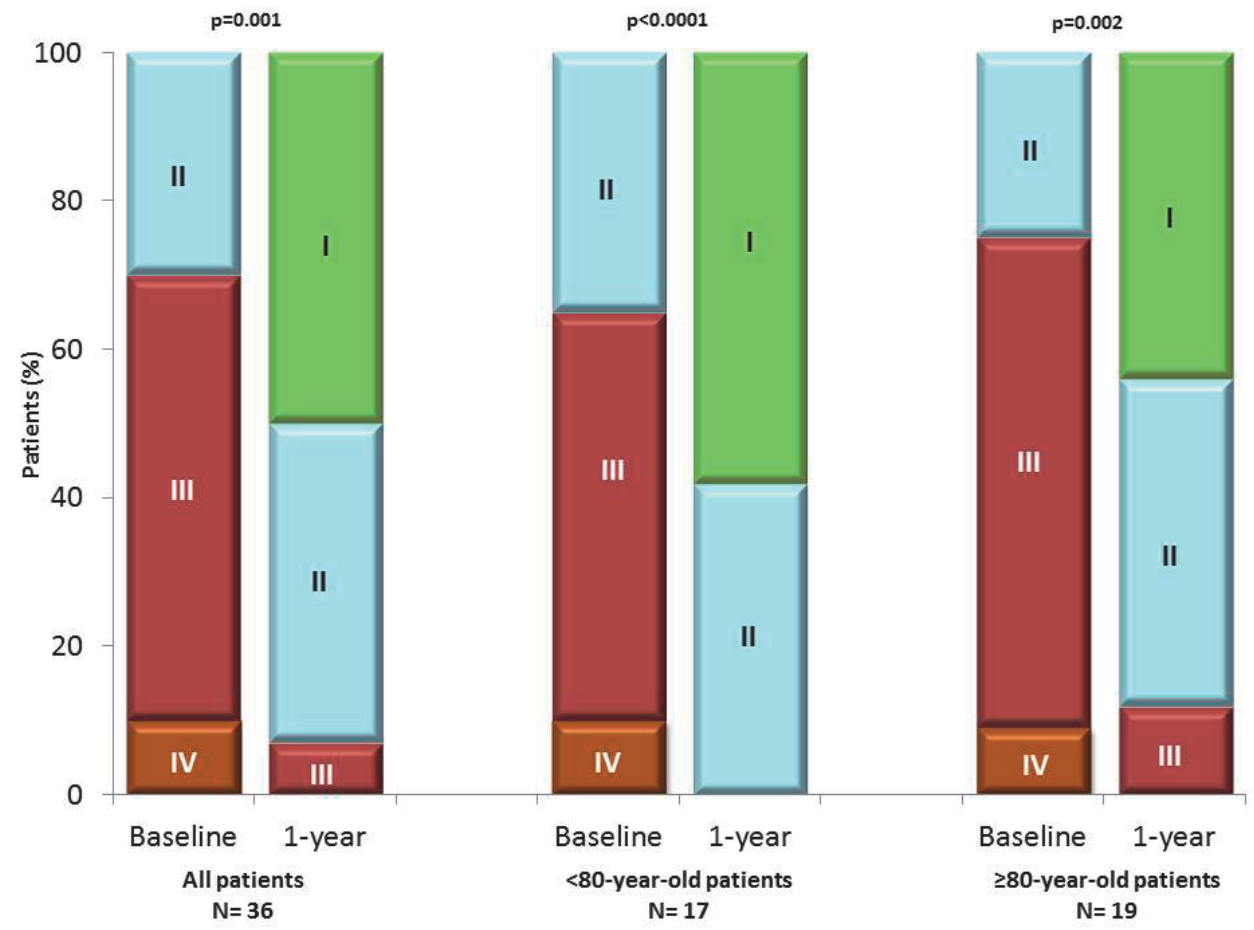

Figure 4. New York Heart Association Functional Class at baseline and 1 year. 


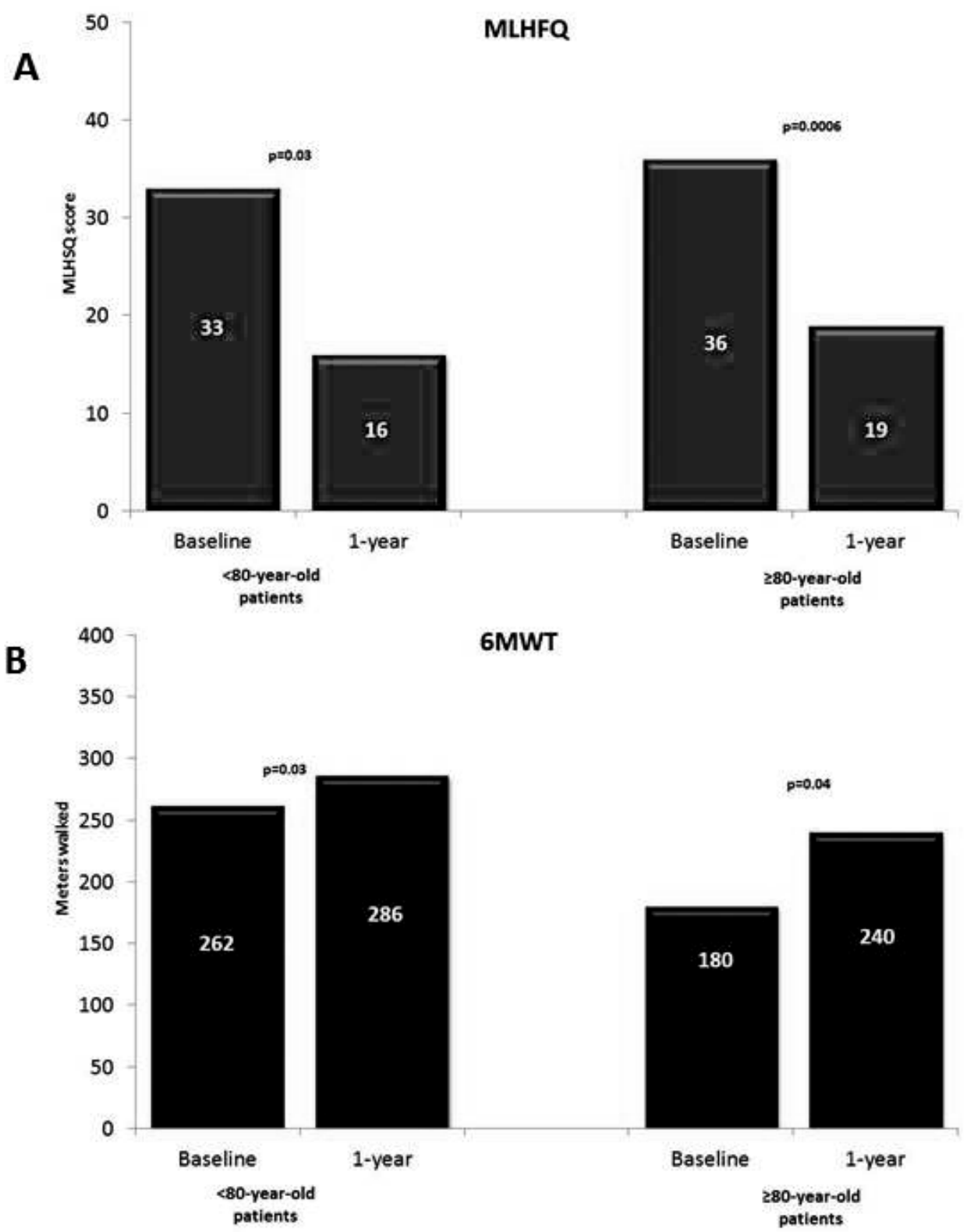

Figure 5. (A) Results of MLHFQ in patients <80-year-old and $\geq 80$-year-old (MLHFQ= Minnesota Living with Heart Failure Questionnaire); (B) results of 6MWT in patients $<80$-year-old and $\geq 80$-year-old $(6 \mathrm{MWT}=$ six minutes walking test). 


\section{Discussion}

Surgical MV repair is the treatment of choice for patients with severe DMR (20-21). Therefore, modern mitral valve surgery is today the benchmark for any new technique, including MitraClip therapy.

However, MR is a frequent condition in elderly (especially degenerative etiology) $(9,22)$. Advanced age is one of the main risk factors of mortality and morbidity after cardiac surgery (about 78\% of the major complications after cardiac surgery and deaths occurred in elderly patients) (23). Although favorable outcomes are reported even in elderly patients after isolated mitral repair (3), operative mortality and morbidity is high in elderly patients in presence of copathologies and associated surgical procedures (22).

Badhawar et al. (24) recently reported the outcomes after mitral valve repair in 14604 patients older than 65 years. In patients with more than 80 years with advanced heart failure symptoms (NYHA class III-IV) operative mortality was 5.3\% and 5-year survival was $68 \%$. The 5 -year rates of recurrence of heart failure, major bleeding and stroke were $28.8 \%, 12.3 \%$ and $11.7 \%$ respectively.

Seeburger et al. (25) reported the single centre experience with 2053 elderly (70 years or older) patients who underwent MV surgical procedures with or without associated procedures. Seventy-seven patients (3.1\%) died within 30 days after the operation. Cerebrovascular accidents, occurred in 4.2\%; incidence of acute renal failure was $16.7 \%$. Concomitant CABG was a significant risk factor for increased early mortality. Five-year survival for patients older than 80 years was $47.9 \%$ and associated comorbidities were associated with an increased risk of late death.

Chikwe et al. (26) reported the results of a consecutive series of 322 octogenarians operated over a period of 10 years. About half of the patients had mitral valve surgery combined with coronary artery by-pass grafting. Only in patients treated with an isolated elective repair the surgical risk was apparently acceptable, with a mortality of about $5 \%$ at 30 days. However, mortality at 3 months was about 13\%, indicating that octogenarians are not likely to recover easily from the trauma of open heart surgery.

Currently, up to $50 \%$ of the patients with severe MR are not referred for surgery because high predicted surgical risk or advanced age (8). According to the ESC 2012 Guidelines (7), percutaneous edge-to-edge procedure may be considered in patients with symptomatic severe DMR who fulfill the echo criteria of eligibility, are judged inoperable or at high surgical risk by a 'heart team', and have a life expectancy greater than 1 year (Class IIb, level of evidence C).

Data from the EVEREST trials and from registries in Europe and the USA showed that MitraClip procedure has a procedural success rate (postprocedural MR $\leq 2+$ ) of around $75 \%$, is relatively safe and generally well-tolerated, even by patients in poor clinical condition (10-18). Patients currently treated in the real world with MitraClip therapy for DMR are very different from those enrolled in the EVEREST II randomized trial, which included surgical low risk candidates. The High Risk Registry Study, an arm of the EVER- 
EST II trial, enrolled symptomatic patients with moderate to severe or severe MR for whom surgical risk for perioperative mortality rate was estimated to be higher than $12 \%$ with STS score. In this series, $88.5 \%$ of the patients had 5 or more associated copathologies and $83 \%$ of the patients were more than 75 years old (17). A degenerative etiology was present in 62 patients. By 30-days, 4 of 62 (6.5\%) DMR patients treated with MitraClip died.

The results of DMR cohort of ACCESS-EU Phase I study showed satisfactory clinical outcomes in selected high-risk patients (13): 117 patients (mean age 75.6 \pm 12 years; mean Logistic EuroSCORE $15.5 \pm 13.3 \%$ ) with DMR underwent the MitraClip procedure. However, a 30 -day mortality of $6.0 \%$ was reported. In a subgroup of patients with particularly high risk (mean Logistic EuroSCORE 33 $\pm 11 \%$ ), observed mortality was $9.1 \%$. Similarly, Lim et al. reported a 6.3\% 30-day mortality in 141 high-risk DMR patients (mean age 82 year) (18).

The major finding of the present study concerns the very high level of safety of MitraClip therapy in high-risk and elderly patients with DMR if appropriate patients selection is performed. In our experience, 30-day mortality was remarkably low (2\% overall; $3 \%$ in patients older than 80 years). Although patients treated in our Institution were older compared to ACCESS-EU DMR, they had similar baseline risk profile (Logistic EurOSCORE 15.7 \pm 12.2 ). The relative higher 30 -day mortality reported in the registries may reflect the fact that they are real world registries, in which many procedures, at least at the beginning of the enrollment, were done in very sick patients as compassionate and probably futile treatment. The low mortality and extremely low morbidity reported in our experience points out the importance of careful patients selection to identify a patient who could really beneficiate from the procedure and to reduce procedural risk.

It is important to point out that patient selection is fundamental also to obtain successful procedural results: in our experience we observed a procedural success of $98 \%$, which is extremely satisfactory, especially in degenerative etiology, and favorably compares with other large real-world MitraClip series of patients with DMR ( $94 \%$ in ACCESSEU DMR (13), about $80 \%$ reported by Rudolf et al. in DMR patients (14)).

At follow-up, we observed an actuarial survival of $89 \pm 5.2 \%$ and $70.2 \pm 9 \%$ at 1 and 2 years respectively, without differences were observed between patients $<80$-year-old and patients $\geq 80$-year-old, which favorably compare with other MitraClip series (1 year mortality ranging from 6 to 24\%) and with the abovementioned surgical reports.

Regarding echocardiographic outcome, our experience showed an acute reduction of $M R$ to grade $\leq 2+$ in $91.5 \%$, and in $61.7 \%$ an MR reduction to grade $\leq 1$ was achieved. These results are consistent to those ones reported in ACCESS DMR registry (reduction of MR to grade $\leq 2+$ in $88.7 \%$ ) and favorably compared with the EVEREST II trial (77\%) $(10,13)$. Freedom from $M R \geq 3+$ was $80 \pm 7 \%$ and $76.6 \pm 7 \%$ at 1 and 2 years, respectively. If compared to reparative mitral surgery, these results are inferior, confirming that surgery is so far the gold standard therapy for DMR. However, it should be considered that the patients included in the present study, like the majority of the patients currently 
treated with MitraClip, are high-risk surgical candidates or inoperable patients. Although estimated surgical risk was high, meaningful clinical improvements were documented. In fact, besides intra- and early-postoperative risks, it would appear equally or even more important, especially in elderly patients, integrated evaluation of the quality of life and functional status, to judge whether a certain procedure could lead to the expected functional improvement. Maisano et al. (27) in a retrospective study including 225 older than 70 years patients who underwent mitral surgery for severe DMR demonstrated that quality of life following surgery is suboptimal in more than half of the patients, even if the patient survives after the operation.

Remarkably, important clinical benefits were documented at 1 year even in patients older than 80 years, in term of NYHA class, quality of life and functional status tested by walk test improvements. In our experience, MLHFQ scores, SF-36 scores and 6MWT performance improved significantly at 12 months compared with baseline ( $p=0.03$ and $p<0.0001$, respectively). Significant improvements were observed also in patients older than 80 years. This is consistent with the ACCESS-EU DMR results at 1 year and with other reports in different clinical settings $(10,12,17,28)$.

\section{Conclusions}

The results of this single center experience confirm that MitraClip therapy is a valuable alternative to surgery in high-risk and elderly patients with DMR. Clinical benefits are evident at 1 year and are obtained also in octogenarians. Although patients treated in current practice are high-risk, the procedure remains very safe and effective in selected patients. Durability of MR reduction as well as clinical benefit warrant further monitoring of patients after MitraClip implantation during long-term follow-up.

\section{Limitations of the study}

This study was an observational, retrospective single center study; therefore the sample size is too small to make strong conclusions. Moreover, the results include an initial learning curve. 


\section{References}

1. Yun KL, Miller DC. Mitral valve repair versus replacement. Cardiol Clin. 1991;9:315-327.

2. Olson LJ, Subramanian R, Ackermann DM, Orszulak TA, Edwards WD. Surgical pathology of the mitral valve: a study of 712 cases spanning 21 years. Mayo Clin Proc. 1987;62:22-34.

3. Detaint D, Sundt TM, Nkomo VT, Scott CG, Tajik AJ, Schaff HV, et al. Surgical correction of mitral regurgitation in the elderly: outcomes and recent improvements. Circulation. 2006;114:265-272.

4. Gillinov AM, Blackstone EH, Nowicki ER, Slisatkorn W, Al-Dossari G, Johnston DR, et al. Valve repair versus valve replacement for degenerative mitral valve disease. J Thorac Cardiovasc Surg. 2008;135:885893.

5. Adams DH, Anyanwu AC, Rahmanian PB, Abascal V, Salzberg SP, Filsoufi F. Large annuloplasty rings facilitate mitral valve repair in Barlow's disease. Ann Thorac Surg. 2006;82:2096-2100.

6. Flameng $W$, Herijgers $P$, Bogaerts $K$. Recurrence of mitral valve regurgitation after mitral valve repair in degenerative valve disease. Circulation. 2003;107:1609-1613.

7. Vahanian A, Alfieri O, Andreotti F, Antunes MJ, Barón-Esquivias G, Baumgartner H, et al. Guidelines on the management of valvular heart disease (version 2012). Eur Heart J. 2012;33:2451-2496.

8. Mirabel M, lung B, Baron G, Messika-Zeitoun D, Détaint D, Vanoverschelde JL, et al. What are the characteristics of patients with severe, symptomatic, mitral regurgitation who are denied surgery? Eur Heart J. 2007;28:1358-1365.

9. Nkomo VT, Gardin JM, Skelton TN, Gottdiener JS, Scott CG, Enriquez-Sarano M. Burden of valvular heart diseases: a population-based study. Lancet. 2006;368:1005-1011.

10. O'Brien SM, Shahian DM, Filardo G, Ferraris VA, Haan CK, Rich JB, et al. The Society of Thoracic Surgeons 2008 cardiac surgery risk models: part 2--isolated valve surgery. Ann Thorac Surg. 2009;88:S23-42.

11. Feldman T, Foster E, Glower DD, Kar S, Rinaldi MJ, Fail PS, et al. Percutaneous repair or surgery for mitral regurgitation. N Engl J Med. 2011;364:1395-1406.

12. Writing Committee Members, O'Gara PT, Calhoon JH, Moon MR, Tommaso CL. Transcatheter therapies for mitral regurgitation: A professional society overview from the American College of Cardiology, The American Association for Thoracic Surgery, Society for Cardiovascular Angiography and Interventions Foundation, and The Society of Thoracic Surgeons. J Thorac Cardiovasc Surg. 2014;147:837-49.

13. Reichenspurner H, Schillinger W, Baldus S, Hausleiter J, Butter C, Schäefer U, et al. Clinical outcomes through 12 months in patients with degenerative mitral regurgitation treated with the MitraClip(R) device in the ACCESS-EUrope Phase I trial. Eur J Cardiothorac Surg. 2013;44:e280-288

14. Rudolph V, Knap M, Franzen O, Schlüter M, de Vries T, Conradi L, et al. Echocardiographic and clinical outcomes of MitraClip therapy in patients not amenable to surgery. J Am Coll Cardiol. 2011;58:21902195.

15. Schillinger W, Hünlich M, Baldus S, Ouarrak T, Boekstegers P, Hink U, et al. Acute outcomes after MitraClip therapy in highly aged patients: results from the German TRAnscatheter Mitral valve Interventions (TRAMI) Registry. Eurolntervention. 2013;9:84-90.

16. Maisano F, Franzen O, Baldus S, Schäfer U, Hausleiter J, Butter C, et al. Percutaneous Mitral Valve Interventions in the Real World: Early and One Year Results From the ACCESS-EU, a Prospective, Multicenter, Non-Randomized Post-Approval Study of the MitraClip ${ }^{\circledR}$ Therapy in Europe. J Am Coll Cardiol. 2013 17;62:1052-1061.

17. Whitlow PL, Feldman T, Pedersen WR, Lim DS, Kipperman R, Smalling R, et al. Acute and 12-month results with catheter-based mitral valve leaflet repair: the EVEREST II (Endovascular Valve Edge-to-Edge Repair) High Risk Study. J Am Coll Cardiol. 2012;59:130-139.

18. Lim DS, Reynolds MR, Feldman T, Kar S, Herrmann HC, Wang A, et al. Improved Functional Status and Quality of Life in Prohibitive Surgical Risk Patients With Degenerative Mitral Regurgitation Following Transcatheter Mitral Valve Repair with the MitraClip ${ }^{\circledR}$ System. J Am Coll Cardiol. 2013 Oct 24.

19. Maisano F, Denti P, Michev I, La Canna G, Arendar I, Colombo A, et al. Percutaneous mitral valve repair with the edge-to-edge technique. MMCTS, 2010. doi:10.1510/mmcts. 2009.004002. 
20. Gammie JS, O'Brien SM, Griffith BP, Ferguson TB, Peterson ED. Influence of hospital procedural volume on care process and mortality for patients undergoing elective surgery for mitral regurgitation. Circulation 2007;115, 881-887.

21. Savage EB, Ferguson TB Jr, DiSesa VJ. Use of mitral valve repair: analysis of contemporary United States experience reported to the Society of Thoracic Surgeons National Cardiac Database. Ann. Thorac. Surg. $2003 ; 75,820-825$.

22. Iung B, Baron G, Butchart EG, Delahaye F, Gohlke-Bärwolf C, Levang OW, et al. A prospective survey of patients with valvular heart disease in Europe: The Euro Heart Survey on Valvular Heart Disease. Eur Heart J. 2003;24:1231-1243.

23. Mehta RH, Eagle KA, Coombs LP, Peterson ED, Edwards FH, Pagani FD, et al. Influence of age on outcomes in patients undergoing mitral valve replacement. Ann Thorac Surg. 2002;74:1459-1467.

24. Badhwar V, Peterson ED, Jacobs JP, He X, Brennan JM, O'Brien SM, et al. Longitudinal outcome of isolated mitral repair in older patients: results from 14,604 procedures performed from 1991 to 2007. Ann Thorac Surg. 2012;94:1870-1877.

25. Seeburger J, Falk V, Garbade J, Noack T, Kiefer P, Vollroth M, et al. Mitral valve surgical procedures in the elderly. Ann Thorac Surg. 2012;94:1999-2003.

26. Chikwe J, Goldstone AB, Passage J, Anyanwu AC, Seeburger J, Castillo JG, et al. A propensity scoreadjusted retrospective comparison of early and mid-term results of mitral valve repair versus replacement in octogenarians. Eur Heart J. 2011;32:618-626.

27. Maisano F, Viganò G, Calabrese C, Taramasso M, Denti P, Blasio A, et al. Quality of life of elderly patients following valve surgery for chronic organic mitral regurgitation. Eur J Cardiothorac Surg. 2009;36:261266.

28. Treede H, Schirmer J, Rudolph V, Franzen O, Knap M, Schluter M, et al. A heart team's perspective on interventional mitral valve repair: percutaneous clip implantation as an important adjunct to a surgical mitral valve program for treatment of high-risk patients. J Thorac Cardiovasc Surg. 2012;143:78-84. 
Chapter

\section{Clinical outcomes of MitraClip for the treatment of functional mitral regurgitation}

Maurizio Taramasso MD, Francesco Maisano MD, Azeem Latib MD, Paolo Denti MD, Nicola Buzzatti MD, Micaela Cioni MD, Giovanni La Canna MD, Antonio Colombo MD,

Ottavio Alfieri MD

Eurolntervention. 2014;10:746-52 


\section{Abstract}

AIMS: The aim of this study was to report medium-term outcomes of MitraClip implantation in inoperable or high-risk surgical candidates with functional mitral regurgitation (FMR) in our single-centre experience.

METHODS and RESULTS: From October 2008, 109 consecutive patients with FMR underwent MitraClip implantation (mean age 69 \pm 9 years; $82 \%$ NYHA Class III-IV). Logistic EuroSCORE was $22 \pm 16 \%$. Comorbidities included: chronic renal failure $(47 \%)$, diabetes (22\%), COPD (28\%). Mean EF was $28 \pm 11 \%$; LVEDD was $68 \pm 8 \mathrm{~mm}$. Procedural success was $99 \%$ and 30 -day mortality was $1.8 \%$. At discharge, $87 \%$ patients had MR $\leq 2+$. At 12 months, EF was $34.7 \pm 10.4 \%$ ( $p=0.002$ compared to preoperative value). Actuarial survival at three years was $74.5 \pm 7 \%$. Actuarial freedom from $M R \geq 3+$ at 2.5 years was $70 \pm 6 \%$. At one-year follow-up, $86 \%$ of patients were in NYHA Class I-II. Preoperative pro-BNP level $\geq 1,600 \mathrm{pg} / \mathrm{ml}$ was identified as an independent risk factor of mortality at follow-up.

CONCLUSIONS: MitraClip therapy for FMR is a valuable alternative to surgery in high-risk patients. Higher preoperative pro-BNP level is a risk factor for mortality at follow-up. Although patients treated in current practice are high-risk, the procedure remains safe and effective in selected patients. 


\section{Introduction}

Surgical repair of severe functional mitral regurgitation (FMR) in patients with postischaemic or idiopathic dilated cardiomyopathy and left ventricle (LV) systolic dysfunction has been demonstrated to improve symptoms and quality of life (1-4). However, perioperative mortality after surgery for FMR is not negligible, and a large number of patients with FMR are not referred for open heart surgery because of high surgical risk or comorbidities $(5,6)$. New percutaneous techniques have recently been developed to treat MR with less invasive approaches. The MitraClip ${ }^{\mathrm{TM}}$ (Abbott Vascular Inc., Santa Clara, CA, USA) is a device reproducing the Alfieri surgical technique (7) with a percutaneous approach, which has been used to decrease the invasiveness of treating both degenerative and functional MR in high-risk patients (8-14). The aim of this study was to report the clinical outcomes of MitraClip therapy to treat symptomatic high-risk patients with severe FMR and severe LV dysfunction in our single-centre experience.

\section{Methods}

We retrospectively analysed the clinical and echocardiographic data of a cohort of consecutive patients who underwent MitraClip therapy for severe or moderately severe symptomatic FMR refractory to medical therapy. All the patients underwent preoperative coronary angiography and transoesophageal Doppler echocardiography (TEE). The study protocol was performed in accordance with the protocol of the institutional ethics committee, and all patients gave written informed consent for the procedures and data collection.

\section{Description of the procedure}

The procedure was performed under general anaesthesia in a hybrid operating room, under TEE and fluoroscopic guidance. Transseptal puncture was performed using a Brockenbrough needle through peripheral venous access at the right groin. Live realtime 3D echocardiography was used to improve the conduct of the implantation. A steerable guide catheter was advanced in the left atrium through the transseptal puncture. The delivery system was inserted and the MitraClip device was implanted corresponding to the origin of the regurgitation jet, perpendicularly to the coaptation line. If the effect of the implant was satisfactory, the clip was deployed. When necessary, more than one clip was implanted. A comprehensive description of the procedure is reported elsewhere (15). 


\section{Patient selection}

Patients were selected if they met the basic criteria for intervention of the European Society of Cardiology Task Force recommendations on the management of valvular heart disease16. All the patients underwent transthoracic echocardiography followed by transoesophageal (TEE) examination at baseline. The severity of FMR was graded as: mild, 1+ (jet area/left atrial area $<10 \%)$; moderate, $2+$ (jet area/left atrial area $10-20 \%$ ); moderately severe, $3+$ (jet area/left atrial area 20-45\%); and severe, $4+$ (jet area/left atrial area $>45 \%$ ). In addition, the vena contracta width at the narrowest portion of the regurgitant jet was measured as follows: $\leq 0.3 \mathrm{~cm}, 1-2+$; between $0.3 \mathrm{~cm}$ and $0.5 \mathrm{~cm}, 3+$; and $\geq 0.5 \mathrm{~cm}, 4+$. All the patients underwent a multimodality decision-making process including evaluation of surgical risk by logistic EuroSCORE (http://www.euroscore.org/) as well as adjunctive risk evaluation, such as the presence of advanced liver cirrhosis, severe neurological impairment and frailty. Frailty was defined by the Heart Team after collegial discussion, according to the so-called "eyeball test". Quality of life (QoL) was evaluated using the Minnesota Living with Heart Failure Questionnaire (MLHFQ) and 36item short-form health survey (SF-36); the six-minute walking test (6MWT) was used to evaluate functional capacity.

Patient selection was partially based on the EVEREST criteria for FMR (central MR with a basal area $>4 \mathrm{~cm} 2$, coaptation length of at least $2 \mathrm{~mm}$, and coaptation depth $<11$ $\mathrm{mm}$ ) (8). However, several patients with criteria beyond EVEREST recommendations were treated. The absolute exclusion criteria that we used to determine ineligibility from the procedure were leaflet calcification in the target zone, excessive leaflet retraction, total and irreversible lack of leaflet coaptation, and small valve area with risk of mitral stenosis after clip implantation.

\section{Follow-up}

All the patients were followed up after discharge in a dedicated outpatient clinic with physical examination, ECG, TTE and arrhythmology consultation whenever indicated. Follow-up visits were performed at one month, six months and then yearly.

\section{Statistical analysis}

Statistical analysis was conducted using JMP 8.0 software (SAS Institute Inc., Cary, NC, USA). Continuous variables are presented as mean \pm SD or as median (IQR, Q1-Q3) and categorical variables are expressed as percentages. Univariable comparisons were performed with the Student's unpaired or paired t-test for continuous normally distributed data, which was tested by the Shapiro-Wilk normality test. The Mann-Whitney rank sum test was used for comparisons of non-parametric continuous data and the chi-square test for categorical data. The threshold of $1,600 \mathrm{pg} / \mathrm{ml}$ for preoperative pro-BNP levels 
was set according to the inclusion criteria of the ongoing COAPT trial (17). Survival and freedom from $\geq 3+M R$ were reported using the Kaplan-Meier method; comparisons were performed using the log-rank test. A p-value $<0.05$ was considered statistically significant, and all reported p-values are two-sided. Univariate analysis of predictors of death at follow-up was performed with Cox proportional hazard regression. Variables with a $p$-value $<0.2$ were then inserted in a multivariable model.

\section{Patient characteristics}

A total of 109 high-risk consecutive patients with severe FMR underwent MitraClip implantation between October 2008 and April 2013 at our institution (75\% ischaemic aetiology; 25\% idiopathic dilated cardiomyopathy). Demographic and clinical features of the patients are shown in Table 1. A logistic EuroSCORE $\geq 20 \%$ was documented in $48 \%$ of the patients. The quality of life questionnaire revealed an important impairment in perceived quality of life in all the patients (MLHFQ was $40 \pm 15$; SF-36 physical domain

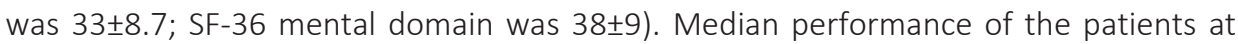
6MWT was $190 \mathrm{~m}$ (IQR 120-252 m). The preoperative median pro-BNP value was 3,238 $\mathrm{pg} / \mathrm{ml}$ (IQR 1,452-5,500 pg/ml); $72.3 \%$ of the patients had a preoperative pro-BNP value $\geq 1,600 \mathrm{pg} / \mathrm{ml}$. Table 2 shows the preoperative echocardiography of the study population in detail; $88 \%$ of the patients had severe or moderate to severe LV systolic dysfunction (EF <40\%). EVEREST criteria were totally fulfilled in only $37 \%$ of the patients.

Table 1. Preoperative clinical features $(n=109)$.

\begin{tabular}{|l|c|}
\hline Age (years) & $69 \pm 9$ \\
\hline Female gender, n (\%) & $18(16.5)$ \\
\hline Previous AMI, n (\%) & $71(65)$ \\
\hline Log EuroSCORE (\%) & $22 \pm 16.5$ \\
\hline Log EuroSCORE $\geq 20 \%$ (\%) & $50(48)$ \\
\hline MR ischaemic aetiology, n (\%) & $82(75)$ \\
\hline Previous cardiac surgery, n (\%) & $34(31)$ \\
\hline Coronary artery disease, n (\%) & $82(75)$ \\
\hline Atrial fibrillation, $\mathrm{n}$ (\%) & $38(34)$ \\
\hline Chronic renal failure, $\mathrm{n}$ (\%) & $52(47)$ \\
\hline COPD, $\mathrm{n}$ (\%) & $30(28)$ \\
\hline Diabetes, $\mathrm{n}$ (\%) & $24(22)$ \\
\hline NYHA Class III-IV, $\mathrm{n}$ (\%) & $90(82)$ \\
\hline Previous ICD-CRT & $37(34)$ \\
\hline $\begin{array}{l}\text { AMI: acute myocardial infarction; COPD: chronic obstructive pulmonary } \\
\text { disease; ICD-CRT: implantable cardioverter defibrillator-cardiac } \\
\text { resynchronisation therapy; NYHA: New York Heart Association }\end{array}$ \\
\hline
\end{tabular}


Table 2. Preoperative echocardiography $(n=109)$.

\begin{tabular}{|l|c|}
\hline LV ejection fraction (\%) & $28 \pm 11$ \\
\hline LV ejection fraction <40\%, $\mathrm{n}(\%)$ & $96(88)$ \\
\hline LVEDD (mm) & $68 \pm 8$ \\
\hline SPAP (mmHg) & $49 \pm 15$ \\
\hline TR 3-4+, $\mathrm{n}(\%)$ & $28(26)$ \\
\hline Tented area (cm $\left.{ }^{2}\right)$ & $3.1 \pm 1.9$ \\
\hline Coaptation depth (cm) & $1.5 \pm 1$ \\
\hline $\begin{array}{l}\text { LV: left ventricle; LVEDD: left ventricle end-diastolic diameter; } \\
\text { LVESD: left ventricle end-systolic diameter; SPAP: systolic pulmonary } \\
\text { artery pressure; TR: tricuspid regurgitation }\end{array}$ \\
\hline
\end{tabular}

\section{Procedural and in-hospital outcomes}

The procedural success rate was 99\%: one patient was converted to conventional surgical mitral valve replacement because of posterior leaflet laceration after clip implantation. One clip was implanted in 33 patients (30.2\%), two clips were implanted in 71 patients (65.1\%), and three clips were implanted in five patients (4.7\%). Procedural time was $95.5 \pm 41 \mathrm{~min}$.

Thirty-day mortality was 1.8\% (2/109 patients: one from acute cardiogenic shock and multiorgan failure seven days after the procedure; one from haemothorax due to emphysematous bulla rupture 10 days after the procedure). Perioperative results are summarised in Table 3.

In $57.7 \%$ of the patients (63/109), high inotropic support was required in the intensive care unit (defined as adrenaline dosage $>0.5 \mathrm{\gamma} / \mathrm{kg} / \mathrm{min}$ or association of two or more i.v. inotropic drugs); in $13 \%$ of the patients (14/109), an intra-aortic balloon pump (IABP) was required. One patient who underwent conversion to open heart surgery due to structural damage of the mitral valve required transient circulatory support with ECMO because of particularly severe preoperative LV dysfunction; incidence of postoperative new onset acute renal failure (defined as stage 2 or 3 of the modified RIFLE criteria) 18 was $21 \%$ (23/109 patients) and renal replacement therapy was required in $6 \%(7 / 109)$.

Globally, 63\% of the patients had an intensive care unit stay of less than 24 hours. Median postoperative length of stay (LOS) was five days (IQR 3.8-7.6 days). The majority of the in-hospital survivors were discharged directly home (71/107 patients, $66.3 \%$ of the total); the rest of the patients were transferred to a cardiopulmonary rehabilitation facility. Pre-discharge echocardiography showed residual MR $\leq 2+$ in $87 \%$ of the patients. 
Table 3. Perioperative outcome $(n=109)$.

\begin{tabular}{|l|c|}
\hline 30-day mortality, $\mathrm{n}(\%)$ & $2(1.8)$ \\
\hline Conversion to surgery, $\mathrm{n}(\%)$ & $1(1)$ \\
\hline Acute kidney injury, $\mathrm{n}(\%)$ & $23(21)$ \\
\hline Need for CVVH, $\mathrm{n}(\%)$ & $7(6)$ \\
\hline Need for IABP, $\mathrm{n}(\%)$ & $14(13)$ \\
\hline Major infection/sepsis, $\mathrm{n}(\%)$ & $4(3.6)$ \\
\hline New onset AF, $\mathrm{n}(\%)$ & $5(4)$ \\
\hline Stroke, $\mathrm{n}(\%)$ & 0 \\
\hline AMI, $\mathrm{n}(\%)$ & 0 \\
\hline Median LOS (days) & 5 \\
\hline Discharged home, $\mathrm{n}(\%)$ & $71(65)$ \\
\hline Discharge MR $\leq 2+, \mathrm{n}(\%)$ & $94(87)$ \\
\hline $\begin{array}{l}\text { AF: atrial fibrillation; AMl: acute myocardial infarction; } \\
\text { CVVH: continuous venovenous haemofiltration; IABP: intra-aortic balloon } \\
\text { pump; LOS: length of stay; MR: mitral regurgitation }\end{array}$ \\
\hline
\end{tabular}

\section{Follow-up}

Median follow-up was 13 months (IQR 7-25 months). Overall actuarial survival was $74.5 \pm 7 \%$ at three years (Figure 1). Patients with a preoperative logistic EuroSCORE $\geq 20 \%$ ( $71.9 \pm 8 \%$ vs. $89.8 \pm 5.7 \%$ at two years; $p=0.01$ ), patients with new onset postoperative acute renal failure $(67.1 \pm 11 \%$ vs. $95.7 \pm 2 \%$ at one year; $p=0.003)$, and patients who required post-procedural IABP $(70.1 \pm 12 \%$ vs. $96.1 \pm 2.2 \%$ at six months; $p=0.009)$ had a significantly reduced actuarial survival at follow-up.

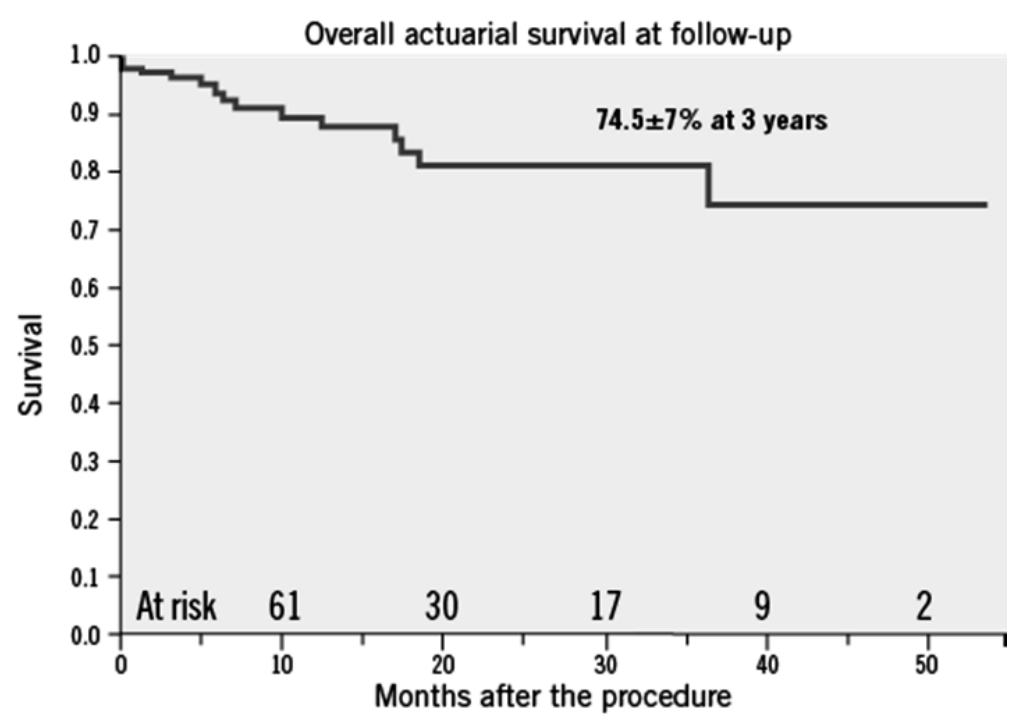

Figure 1. Overall actuarial survival at follow-up 
Cumulative cardiovascular death was 9.1\% (10/109 patients: five patients with residual moderate to severe MR died from refractory heart failure, and the causes of death in the other five patients were haemorrhagic stroke, acute myocardial infarction, acute pulmonary oedema with superimposed pulmonary infection, ventricular arrhythmia, and sudden death). One patient underwent heart transplantation because of refractory heart failure 12 months after the procedure; two patients with residual severe MR underwent successful repeat MitraClip implantation 12 and 18 months after the initial procedure, respectively, and two patients ineligible for repeat MitraClip underwent uneventful surgical mitral valve replacement nine and 15 months after the procedure, respectively (logistic EuroSCORE $11.1 \%$ and $21.8 \%$, respectively).

Overall actuarial freedom from $M R \geq 3+$ at follow-up was $70 \pm 6 \%$ at 2.5 years (Figure 2 ). Freedom from $M R \geq 3+$ at one year was significantly reduced in patients with preoperative TR $\geq 3+(65.5 \pm 10 \%$ vs. $81.7 \pm 5 \% ; p=0.01)$ while no differences were observed according to the adherence to EVEREST criteria ( $72 \pm 6 \%$ vs. $87.7 \pm 5.8 \% ; p=0.09$ ).

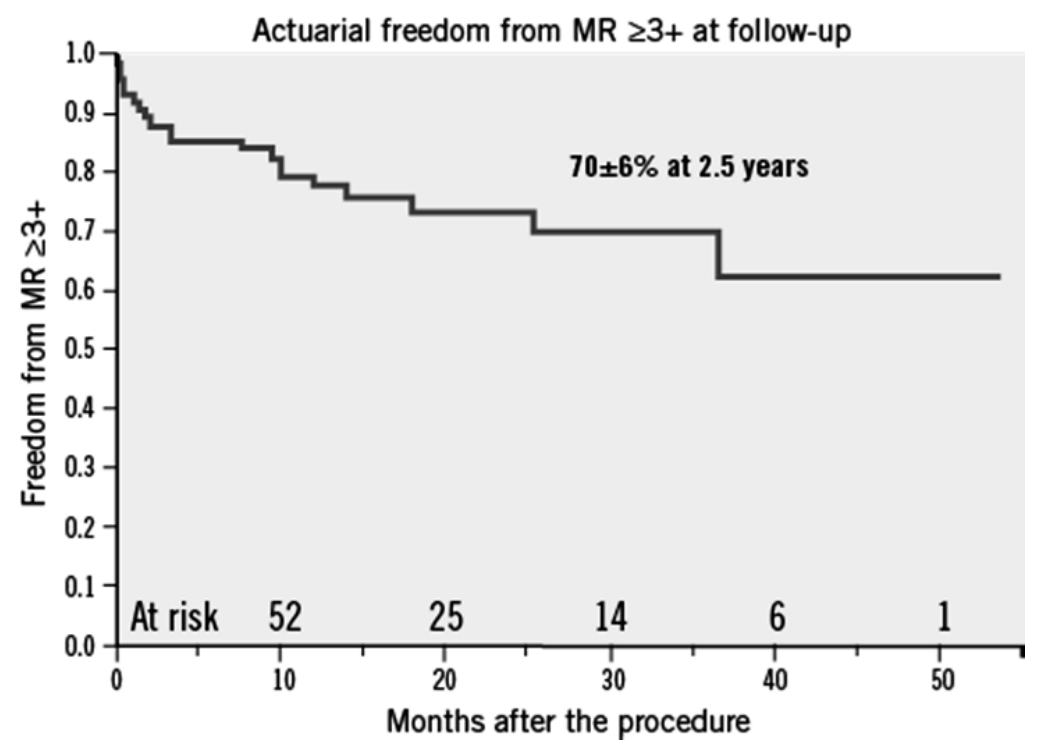

Figure 2. Actuarial freedom from $M R \geq 3+$ at follow-up.

At univariate analysis (Table 4), preoperative logistic EuroSCORE $\geq 20 \%$ (HR 4.4; $p=0.01$ ), preoperative level of pro-BNP $>1,600 \mathrm{pg} / \mathrm{ml}$ (HR 21.2; $\mathrm{p}=0.01)$, need for postoperative support with IABP (HR 3.8; $p=0.02$ ) and occurrence of postoperative AKI (HR 4.1; $\mathrm{p}=0.01$ ) were significant risk factors for mortality at follow-up. The multivariate analysis identified a preoperative level of pro-BNP $\geq 1,600 \mathrm{pg} / \mathrm{ml}$ as an independent predictor of mortality at follow-up $(H R=4.5 ; p=0.03)$. 
Table 4. Predictors of mortality at follow-up.

\begin{tabular}{|l|c|c|c|c|}
\hline \multirow{2}{*}{} & \multicolumn{2}{|c|}{ Univariate } & \multicolumn{2}{c|}{ Multivariate } \\
\cline { 2 - 5 } & $\begin{array}{c}\text { Hazard ratio } \\
(95 \% \mathrm{CI})\end{array}$ & $p$-value & $\begin{array}{c}\text { Hazard ratio } \\
(95 \% \mathrm{CI})\end{array}$ & $p$-value \\
\hline Logistic ES $\geq 20 \%$ & $4.4(1.8-9.5)$ & 0.01 & $4(1.6-7.8)$ & 0.06 \\
\hline Need for IABP & $4.8(1.2-13.5)$ & 0.02 & $0.9(0.3-4)$ & 0.9 \\
\hline Post-op AKI & $4.1(2-16)$ & 0.01 & $3.9(1.2-12)$ & 0.1 \\
\hline Pro-BNP $\geq 1,600 \mathrm{pg} / \mathrm{mI}$ & $21(2.5-38)$ & 0.01 & $4.5(1.8-15)$ & 0.03 \\
\hline TR 3-4+ & $1.3(0.7-3)$ & 0.6 & & \\
\hline Discharge MR $\geq 3+$ & $2(0.5-3.6)$ & 0.4 & & \\
\hline LVEF & $0.1(0.1-1.5)$ & 0.2 & & \\
\hline sPAP & $1.5(1-4)$ & 0.7 & & \\
\hline Ischaemic aetiology & 0.7 (0.5-5) & 0.6 & & \\
\hline $\begin{array}{l}\text { AKI: acute kidney injury; ES: EuroSCORE; IABP: intra-aortic balloon pump; LVEF: left } \\
\text { ventricle ejection fraction; MR: mitral regurgitation; sPAP: systolic pulmonary artery } \\
\text { pressure; TR: tricuspid regurgitation }\end{array}$ & & & \\
\hline
\end{tabular}

Actuarial survival at one year was $100 \%$ for patients with a preoperative level of pro$\mathrm{BNP}<1,600 \mathrm{pg} / \mathrm{ml}$ and $83.9 \pm 5.7 \%$ for patients who did not $(p=0.05)$ (Figure 3 ).

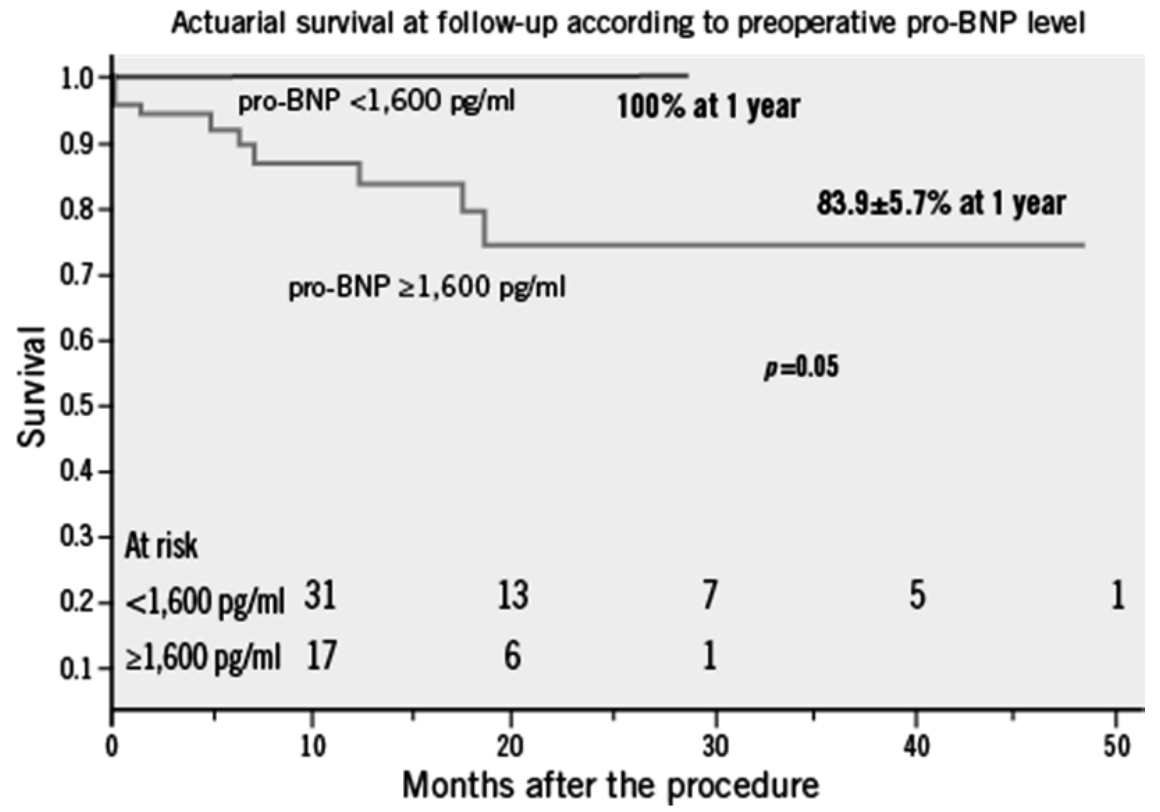

Figure 3. Actuarial survival at follow-up according to preoperative pro-BNP level. 
At one-year follow-up, a significant improvement in EF was documented (from $27 \pm 9.8 \%$ to $34.7 \pm 10.4 \% ; p=0.002$ ). Echocardiography showed a significant reduction in LV dimensions: LV end-diastolic diameter decreased from $70 \pm 7.8 \mathrm{~mm}$ to $64 \pm 7.8 \mathrm{~mm}(p=0.003)$ and LV end-diastolic volume from $202.3 \pm 63.8 \mathrm{ml}$ to $174.3 \pm 59.4 \mathrm{ml}(p=0.003)$; sPAP decreased from $49 \pm 15 \mathrm{mmHg}$ to $44 \pm 2.6 \mathrm{mmHg}(p=0.08)$ and $86 \%$ of the patients were in NYHA Class I-II at one-year follow-up. A significant improvement was documented with all the quality of life assessments: MLHFQ was $22 \pm 18.5$, SF-36 physical domain was 41.9 \pm 10.6 , and SF-36 mental domain was 46.4 $\pm 10.7(p<0.000, p<0.0001$ and $p=0.002$ compared to preoperative values, respectively). A significant improvement in 6MWT

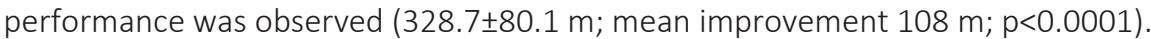

\section{Discussion}

Functional MR is associated with a poor prognosis in heart failure patients with postischaemic or idiopathic dilated cardiomyopathy $(19,20)$. Surgical mitral valve repair may be considered in severely symptomatic patients with severe FMR despite optimal medical therapy and cardiac resynchronisation therapy (21). Although several studies have reported reverse LV remodelling and improvements in symptoms and quality of life after surgical mitral repair $(4,22)$, operative mortality is not negligible, ranging from $8.8 \%$ to $21 \%$ (23-25). Moreover, the number of patients with severe FMR who are not referred for surgery because of high surgical risk, advanced age and comorbidities is increasing (6). On the basis of the good results that have been reported with the surgical treatment of FMR with the edge-to-edge technique (26), percutaneous edge-toedge with MitraClip implantation has been used for FMR in high-risk patients with favourable safety and efficacy results (10-14,27).

The safety and efficacy of the percutaneous edge-to-edge with MitraClip has been initially tested in the EVEREST I trial (8), and then compared to surgery in the randomised EVEREST II trial (9). However, most of the patients enrolled in the EVEREST trials had degenerative MR and all patients were surgical candidates.

The real-world setting is very different from the original EVEREST trials: most of the patients treated with MitraClip are at high surgical risk and MR is more often functional rather than degenerative. Several clinical experiences with satisfactory acute and midterm results have now been reported in the literature (10-14,27).

Recently, the new European guidelines included the MitraClip as a treatment option in high-risk and inoperable patients with FMR and severe symptoms despite optimal medical therapy (class IIb indication with evidence $\mathrm{C}$ ), reflecting that there is still a scarcity of data to make stronger recommendations (16).

In this study, the single-centre experience with the percutaneous treatment of FMR in selected high-risk patients was reported. The results observed in the present study compare favourably to those reported in the largest real-world registries: in the AC- 
CESS-EU study (13), 30-day mortality in patients with FMR (393 patients; logistic EurOSCORE $24.8 \pm 18.9 \%$; $67 \%$ of the patients with EF <40\%) was $2.8 \%$; in the TRAMI registry (1,064 patients, 590 with FMR; logistic EuroSCORE about 20\%) (14), observed 30-day mortality was $6.7 \%$ and $4.7 \%$ in patients younger than 76 years and patients older than 76 years, respectively.

In our experience, MitraClip therapy is associated with very low hospital mortality (1.8\%), short postoperative LOS (median five days) and the postoperative course was smooth in the majority of the patients, despite the high-risk profile at baseline ( $48 \%$ of the patients had a logistic EuroSCORE $\geq 20 \%$, with a mean EF of $28 \pm 11 \%$ ). Procedural success was $99 \%$. Moreover, $65 \%$ of the patients were discharged directly home. The relatively higher 30-day mortality reported in the ACCESS and TRAMI registries may reflect the fact that they are real-world registries, in which many procedures, at least at the beginning of the enrolment, were done in very sick patients as a compassionate and probably futile treatment. The low mortality and extremely low morbidity reported in our experience point out the importance of careful patient selection to identify patients who could really benefit from the procedure and to reduce procedural risk.

Midterm follow-up confirmed the clinical benefit of MitraClip therapy in this setting: $86 \%$ of the patients were in NYHA Class I-II one year after the procedure, and a significant improvement in perceived quality of life and functional capacity was documented (mean improvement at 6MWT performance of $120 \mathrm{~m}$ ). These results are consistent with those reported in the ACCESS-EU study13. Similar to other recent reports (27), left ventricular reverse remodelling was observed at one-year echocardiography, which has been associated with favourable outcome in the surgical experience (4).

Surgical experience showed that residual MR after surgical repair is associated with poor outcome $(4,24)$. Recently, Paranskaya et al showed that residual MR grade is a predictor of one-year adverse events after MitraClip treatment (28). In our experience, all the patients who underwent MitraClip therapy had an acute reduction in MR grade after the procedure, with pre-discharge echocardiography showing residual $M R \leq 2+$ in $87 \%$ of the patients.

In our study, a preoperative level of pro-BNP $\geq 1,600 \mathrm{pg} / \mathrm{ml}$ was identified as an independent predictor of death at follow-up. Plasma levels of pro-BNP are a useful tool to predict mortality and readmission in heart failure patients and may be used for risk stratification in this setting $(29,30)$. Recently, Hwang et al reported that elevated preoperative plasma BNP levels in patients with chronic severe MR undergoing surgery predict poor postoperative outcome (31).

Neuss et al showed that the preprocedural pro-BNP level was a powerful predictor of poor outcome (composite primary endpoint of all-cause mortality, LV assist device implantation, mitral valve surgery, and unsuccessful implantation), suggesting that in patients with end-stage heart failure and dramatically increased pro-BNP level $(>10,000$ $\mathrm{pg} / \mathrm{ml}$ ) MitraClip treatment was not able to improve the clinical course (32). 
In our experience, we also found that a lower threshold of pro-BNP level $(\geq 1,600$ $\mathrm{pg} / \mathrm{ml}$ ) was an independent predictor of reduced survival after MitraClip treatment in patients with FMR, suggesting that pro-BNP measurement should be considered for assessing postprocedural outcome and might be useful for defining the appropriate timing decision of the procedure, which should ideally be performed earlier, before the end-stage phase of the disease. Our finding confirms the important role of pro-BNP dosage for proper patient selection.

We observed a higher risk of recurrence of significant MR in patients with preoperative TR 3-4+. In all the patients with preoperative TR $\geq 3+$ who had MR recurrence at follow-up, the mechanism of MR recurrence was recurrent leaflet tethering due to ongoing LV remodelling. Although this finding may suggest a possible prognostic role of preoperative TR grade in patients with functional MR undergoing MitraClip treatment, no differences in terms of survival were observed. The adherence to the EVEREST criteria (which were totally fulfilled in fewer than $50 \%$ of the patients) was not associated with the anatomical results, suggesting that new specific criteria are required. However, longer follow-up would be required to determine the real clinical impact of residual MR.

\section{Limitations}

This study was an observational, retrospective single-centre study. Therefore, the sample size was too small to make firm conclusions. Moreover, the results include an initial learning curve.

\section{Conclusions}

In conclusion, this study shows that MitraClip therapy is a safe procedure in selected high-risk patients with FMR and can be accomplished with low morbidity and mortality. Moreover, MitraClip treatment is associated with an improvement in functional status and quality of life at one year as well as significant LV reverse remodelling. Although an acute reduction of MR can be obtained in the majority of patients after MitraClip, further studies are needed to determine the clinical impact of residual MR after MitraClip implantation. Thus, MitraClip is a valuable clinical option in patients with adequate anatomy who are considered inoperable or with a high surgical risk and should be considered as an important therapeutic modality in the multidisciplinary treatment of heart failure. 


\section{References}

1. Yiu SF, Enriquez-Sarano M, Tribouilloy C, Seward JB, Tajik AJ. Determinants of the degree of functional mitral regurgitation in patients with systolic left ventricular dysfunction: a quantitative clinical study. Circulation. 2000;102:1400-6.

2. Acker MA, Bolling S, Shemin R, Kirklin J, Oh JK, Mann DL, Jessup M, Sabbah HN, Starling RC, Kubo SH; Acorn Trial Principal Investigators and Study Coordinators. Mitral valve surgery in heart failure: insights from the Acorn Clinical Trial. J Thorac Cardiovasc Surg. 2006;132:568-77.

3. Bax JJ, Braun J, Somer ST, Klautz R, Holman ER, Versteegh MI, Boersma E, Schalij MJ, van der Wall EE, Dion RA. Restrictive annuloplasty and coronary revascularization in ischemic mitral regurgitation results in reverse left ventricular remodeling. Circulation. 2004;110:II103-8.

4. De Bonis M, Lapenna E, Verzini A, La Canna G, Grimaldi A, Torracca L, Maisano F, Alfieri O. Recurrence of mitral regurgitation parallels the absence of left ventricular reverse remodeling after mitral repair in advanced dilated cardiomyopathy. Ann Thorac Surg. 2008;85:932-9.

5. Wu AH, Aaronson KD, Bolling SF, Pagani FD, Welch K, Koelling TM. Impact of mitral valve annuloplasty on mortality risk in patients with mitral regurgitation and left ventricular systolic dysfunction. J Am Coll Cardiol. 2005;45:381-7.

6. Mirabel M, lung B, Baron G, Messika-Zeitoun D, Détaint D, Vanoverschelde JL, Butchart EG, Ravaud P, Vahanian $A$. What are the characteristics of patients with severe, symptomatic, mitral regurgitation who are denied surgery? Eur Heart J. 2007;28:1358-65.

7. Alfieri O, Maisano F, De Bonis M, Stefano PL, Torracca L, Oppizzi M, La Canna G. The double-orifice technique in mitral valve repair: a simple solution for complex problems. J Thorac Cardiovasc Surg. 2001;122:674-81.

8. Feldman T, Kar S, Rinaldi M, Fail P, Hermiller J, Smalling R, Whitlow PL, Gray W, Low R, Herrmann HC, Lim S, Foster E, Glower D; EVEREST Investigators. Percutaneous mitral repair with the MitraClip system: safety and midterm durability in the initial EVEREST (Endovascular Valve Edge-to-Edge REpair Study) cohort. J Am Coll Cardiol. 2009;54:686-94.

9. Feldman T, Foster E, Glower DD, Kar S, Rinaldi MJ, Fail PS, Smalling RW, Siegel R, Rose GA, Engeron E, Loghin C, Trento A, Skipper ER, Fudge T, Letsou GV, Massaro JM, Mauri L; EVEREST II Investigators. Percutaneous repair or surgery for mitral regurgitation. N Engl J Med. 2011;364:1395-406.

10. Rudolph V, Lubos E, Schlüter M, Lubs D, Goldmann B, Knap M, de Vries T, Treede H, Schirmer J, Conradi L, Wegscheider K, Reichenspurner H, Blankenberg S, Baldus S. Aetiology of mitral regurgitation differentially affects 2-year adverse outcomes after MitraClip therapy in high-risk patients. Eur J Heart Fail. 2013;15:796-807.

11. Pleger ST, Mereles D, Schulz-Schönhagen M, Krumsdorf U, Chorianopoulos E, Rottbauer W, Katus HA, Bekeredjian R. Acute safety and 30-day outcome after percutaneous edge-to-edge repair of mitral regurgitation in very high-risk patients. Am J Cardiol. 2011;108:1478-82.

12. Franzen O, van der Heyden J, Baldus S, Schlüter M, Schillinger W, Butter C, Hoffmann R, Corti R, Pedrazzini G, Swaans MJ, Neuss M, Rudolph V, Sürder D, Grünenfelder J, Eulenburg C, Reichenspurner H, Meinertz T, Auricchio A. MitraClip ${ }^{\circledR}$ therapy in patients with end-stage systolic heart failure. Eur J Heart Fail. 2011;13:569-76.

13. Maisano F, Franzen O, Baldus S, Schäfer U, Hausleiter J, Butter C, Ussia GP, Sievert H, Richardt G, Widder JD, Moccetti T, Schillinger W. Percutaneous mitral valve interventions in the real world: early and one year results from the ACCESS-EU, a prospective, multicenter, non-randomized post-approval study of the MitraClip ${ }^{\circledR}$ therapy in Europe. J Am Coll Cardiol. 2013;62: 1052-61.

14. Schillinger W, Hünlich M, Baldus S, Ouarrak T, Boekstegers P, Hink U, Butter C, Bekeredjian R, Plicht B, Sievert H, Schofer J, Senges J, Meinertz T, Hasenfuß G. Acute outcomes after MitraClip therapy in highly aged patients: results from the German TRAnscatheter Mitral valve Interventions (TRAMI) Registry. EuroIntervention. 2013;9:84-90. 
15. Maisano F, Denti P, Michev I, La Canna G, Arendar I. Colombo A, Alfieri O. Percutaneous mitral valve repair with the edge-to-edge technique. MMCTS. Published online January 1, 2010.

16. Vahanian A, Alfieri O, Andreotti F, Antunes MJ, Barón-Esquivias G, Baumgartner H, Borger MA, Carrel TP, De Bonis M, Evangelista A, Falk V, lung B, Lancellotti P, Pierard L, Price S, Schäfers HJ, Schuler G, Stepinska J, Swedberg K, Takkenberg J, Von Oppell UO, Windecker S, Zamorano JL, Zembala M. Guidelines on the management of valvular heart disease (version 2012): The Joint Task Force on the Management of Valvular Heart Disease of the European Society of Cardiology (ESC) and the European Association for Cardio-Thoracic Surgery (EACTS). Eur Heart J. 2012;33:2451-96.

17. Stone G, Mack M. Clinical Outcomes Assessment of the MitraClip Therapy Percutaneous Therapy for High Surgical Risk Patients (COAPT). http://clinicaltrials.gov/ct2/show/NCT01626079

18. Mehta RL, Kellum JA, Shah SV, Molitoris BA, Ronco C, Warnock DG, Levin A; Acute Kidney Injury Network. Acute kidney injury network: report of an initiative to improve outcomes in acute kidney injury. Crit Care. 2007;11:R31.

19. Trichon BH, Felker GM, Shaw LK, Cabell CH, O'Connor CM. Relation of frequency and severity of mitral regurgitation to survival among patients with left ventricular systolic dysfunction and heart failure. Am J Cardiol. 2003;91:538-43.

20. Grigioni F, Enriquez-Sarano M, Zehr KJ, Bailey KR, Tajik AJ. Ischemic mitral regurgitation: long-term outcome and prognostic implications with quantitative Doppler assessment. Circulation. 2001;103:175964.

21. Bolling SF, Deeb GM, Brunsting LA, Bach DS. Early outcome of mitral valve reconstruction in patients with end-stage cardiomyopathy. J Thorac Cardiovasc Surg. 1995;109:676-82.

22. Bach DS, Bolling SF. Early improvement in congestive heart failure after correction of secondary mitral regurgitation in end-stage cardiomyopathy. Am Heart J. 1995;129:1165-70.

23. Braun J, Bax JJ, Versteegh MI, Voigt PG, Holman ER, Klautz RJ, Boersma E, Dion RA. Preoperative left ventricular dimensions predict reverse remodeling following restrictive mitral annuloplasty in ischemic mitral regurgitation. Eur J Cardiothorac Surg. 2005;27:847-53.

24. Crabtree TD, Bailey MS, Moon MR, Munfakh N, Pasque MK, Lawton JS, Moazami N, Aubuchon KA, AlDadah AS, Damiano RJ Jr. Recurrent mitral regurgitation and risk factors for early and late mortality after mitral valve repair for functional ischemic mitral regurgitation. Ann Thorac Surg. 2008;85:1537-42.

25. De Bonis M, Taramasso M, Grimaldi A, Maisano F, Calabrese MC, Verzini A, Ferrara D, Alfieri O. The GeoForm annuloplasty ring for the surgical treatment of functional mitral regurgitation in advanced dilated cardiomyopathy. Eur J Cardiothorac Surg. 2011;40:488-95.

26. De Bonis M, Lapenna E, La Canna G, Ficarra E, Pagliaro M, Torracca L, Maisano F, Alfieri O. Mitral valve repair for functional mitral regurgitation in end-stage dilated cardiomyopathy: role of the "edge-toedge" technique. Circulation. 2005;112:1402-8.

27. Scandura S, Ussia GP, Capranzano P, Caggegi A, Sarkar K, Cammalleri V, Mangiafico S, Chiarandà M, Immè S, Di Pasqua F, Pistritto AM, Millan G, Tamburino C. Left cardiac chambers reverse remodeling after percutaneous mitral valve repair with the MitraClip system. J Am Soc Echocardiogr. 2012;25: 1099105.

28. Paranskaya L, D’Ancona G, Bozdag-Turan I, Akin I, Kische S, Turan GR, Rehders T, Ortak J, Nienaber CA, Ince $\mathrm{H}$. Residual mitral valve regurgitation after percutaneous mitral valve repair with the MitraClip ${ }^{\circledR}$ system is a risk factor for adverse one-year outcome. Catheter Cardiovasc Interv. 2013;81:609-17.

29. Mueller C, Scholer A, Laule-Kilian K, Martina B, Schindler C, Buser P, Pfisterer M, Perruchoud AP. Use of B-type natriuretic peptide in the evaluation and management of acute dyspnea. N Engl J Med. 2004;350:647-54.

30. Logeart D, Thabut G, Jourdain P, Chavelas C, Beyne P, Beauvais F, Bouvier E, Solal AC. Predischarge Btype natriuretic peptide assay for identifying patients at high risk of re-admission after decompensated heart failure. J Am Coll Cardiol. 2004;43:635-41.

31. Hwang IC, Kim YJ, Kim KH, Lee SP, Kim HK, Sohn DW, Oh BH, Park YB. Prognostic value of B-type natriuretic peptide in patients with chronic mitral regurgitation undergoing surgery: mid-term follow-up results. Eur J Cardiothorac Surg. 2013;43:e1-6. 
32. Neuss M, Schau T, Schoepp M, Seifert M, Hölschermann F, Meyhöfer J, Butter C. Patient selection criteria and midterm clinical outcome for MitraClip therapy in patients with severe mitral regurgitation and severe congestive heart failure. Eur J Heart Fail. 2013;15:786-95. 



\section{Chapter}

\section{Transcatheter direct mitral annuloplasty with Cardioband: feasibility and efficacy trial in an acute preclinical model}

Maurizio Taramasso MD, Andrea Guidotti, Nikola Cesarovic DVM, PhD, Paolo Denti MD, Alessandro Addis DVM, Alessandro Candreva MD, Fabian Nietlispach MD, PhD, Thea Fleischmann DVM, Maximilian Y. Emmert MD, PhD, Francesco Maisano MD. 


\section{Abstract}

Aims: To report preclinical safety and feasibility of a new transcatheter direct mitral annuloplasty intervention in an acute animal model

Methods and Results: Twenty healthy pigs underwent Cardioband (ValtechCardio, Or Yehuda, Israel) transcatheter implantation under intracardiac echocardiographic and fluoroscopic guidance. Through a neo-inferior vena cava approach, transseptal access was arranged. The device was delivered in the left atrium using a multi-steerable catheter and fixated to the mitral annulus with multiple helix anchors. Following device cinching, reduction of annular size was evaluated.

In all animals the device could be successfully implanted and displayed $100 \%$ function, with the average procedure-duration and fluoroscopy times being $78 \pm 23$ minutes and $27 \pm 9$ minutes, respectively. In total of 246 anchors (average 12.3 per device) were delivered and optimal anchor placement was achieved in 95.1\%, while inadequate anchor position (4\%) and injury of the coronary sinus or atrium $(0.8 \%)$ occurred in the rest.

Following maximal cinching, diastolic transmitral flow velocity and coaptation lengths were markedly increased $(p<0.001)$, whereas septo-lateral and intercommissural distances were significantly decreased $(p<0.001)$, when compared to pre-contraction baseline, demonstrating efficient annular reduction by the device.

Conclusion: Transcatheter direct annuloplasty with a surgical-like adjustable device is feasible in the porcine animal model. The humanized model has been instrumental to demonstrate feasibility and to establish the procedural steps. 


\section{Introduction}

Transcatheter mitral valve interventions are a valuable alternative to surgery for high risk and inoperable patients with mitral regurgitation (MR) $(1,2)$. Currently MitraClip (Abbott Vascular, Santa Rosa, CA, USA) is the most commonly performed transcatheter mitral repair procedure (1). Although excellent clinical outcomes have been associated with MitraClip therapy, complete MR abolition is obtainable only in a minority of patients. The absence of concomitant annuloplasty has been advocated as a potential explanation (3).

Annuloplasty is a surgical standard procedure performed either as a stand-alone therapy (mostly in case of functional MR), or as an adjunct to leaflet repair in patients with degenerative MR (4). Surgical mitral annuloplasty has been associated with improved early outcomes and longer repair durability in patients with degenerative MR (5). Lack of annuloplasty is an independent factor for recurrent MR, particularly in patients with more advanced mitral valve disease and annular dilatation (6). A reliable transcatheter annuloplasty could provide a desirable adjunct to percutaneous leaflet repair.. Further, transcatheter annuloplasty could also be used as a stand-alone procedure in selected patients with functional mitral regurgitation. Herein we report the preclinical acute outcomes with a transcatheter direct annuloplasty device Cardioband (ValtechCardio, Or Yehuda Israel) designed to implant a "surgical-like" annuloplasty ring with a transeptal approach on the beating heart under fluoroscopic and echocardiographic guidance (7).

\section{Methods}

\section{The animal model}

The present series is a subgroup of animal from a larger series previously reported (8). The peculiarity of this subgroup is that all the animals underwent complete transcatheter implant of the Cardioband system with subsequent full cinching of the device after the implantation. In particular, study population is composed of 20 consecutive healthy white female adult pigs (104 $\pm 9 \mathrm{Kg}$ ). All the procedures were performed under intracardiac echocardiography (ICE) and fluoroscopic guidance, in two institutions equipped with hybrid operation room. The animal model followed standardized protocols in both institutions.

The animal studies were conducted in compliance with Italian Ministry of Health national law (116/92), European Union guideline (86/609/EEC) and Swiss Federal animal protection law and ordinance (license ZH 138/2010).

After loss of postural reflexes following premedication with ketamine $(20 \mathrm{mg} / \mathrm{kg})$, azaperone $(1.5 \mathrm{mg} / \mathrm{kg})$ and atropine $(0.75 \mathrm{mg})$, the anesthesia was deepened by a bolus 
injection of propofol (1-2 mg/kg BW) and the animals were intubated. Anesthesia was then maintained with $2-3 \%$ isoflurane and propofol $(2-5 \mathrm{mg} / \mathrm{kg} / \mathrm{h})$. Amiodarone $(2-3$ $\mathrm{mg} / \mathrm{kg}$ bolus iv) was administered to stabilize the heart rhythm. Pain management included fentanyl constant-rate-infusion $(0.02 \mathrm{mg} / \mathrm{kg} / \mathrm{h})$ for the duration of the procedure.

Under general anesthesia, vital parameters and EKG monitoring were continuously monitored and recorded. A $6 \mathrm{~F}$ and $10 \mathrm{~F}$ sheaths were placed in the femoral artery and vein, respectively, for blood pressure monitoring, post-procedural coronary angiogram and intra-cardiac echocardiography.

In order to mimic an human position implantation in this porcine model, a neoinferior vena cava was surgically implanted, as previously described (8). Briefly, after additional local anesthesia (intercostal block) a right thoracotomy was performed and the pericardial sac was incised, exposing the right and left atrium and the inferior vena cava. A $10 \mathrm{~mm}$ Dacron tube graft was anastomosed to the right atrium. The graft was oriented with a $45^{\circ}$ angle to the midline of the animal, to reproduce a "human-like" angulation. A large bore sheath with a hemostatic valve was then fixed at the opposite end of the tube graft to serve as an access point for the further interventional steps. Transseptal access was gained through the neo inferior vena cava approach.

For the introduction of ICE probe (ViewFlexTMXtra 9Fr, St. Jude Medical Company, Irvine, USA), a 10Fr introducer sheath was positioned in the left ventricle through the apex through a surgical sub-xyphoid incision. The apical probe was used to achieve long axis images of the mitral valve. A second ICE probe was introduced from the left femoral vein and positioned in the right atrium to guide transseptal puncture and to provide short-axis views of the annulus. Heparin was administered at $250 \mathrm{IU} / \mathrm{kg}$ and repeated if activated clotting time was shorter than $300 \mathrm{sec}$ until the completion of the experiment.

At the end of the procedure after a left coronary angiogram was performed to rule out coronary damage, the animals were euthanized by overdose of Na-pentobarbital and the hearts were explanted for subsequent analysis.

\section{The Cardioband system}

The CardioBand is a variable length tubular Dacron band delivered over the posterior circumference of the annulus and fixated with multiple helical stainless steel anchors (Figure 1).

The Cardioband Delivery System (CDS) consists of the Implant Delivery System (IDS) and the 24F Transseptal Steerable Sheath (TSS). The IDS is comprised of a steerable Guide Catheter (GC) and an Implant Catheter (IC) with the Cardioband implant mounted on its distal portion. A set of helicoidal anchors is used to fixate the implant to the native annulus (one anchor every $8 \mathrm{~mm}$ of mitral annular circumference). Each anchor is repositionable and retrievable, until release from the torque transmission cable. 


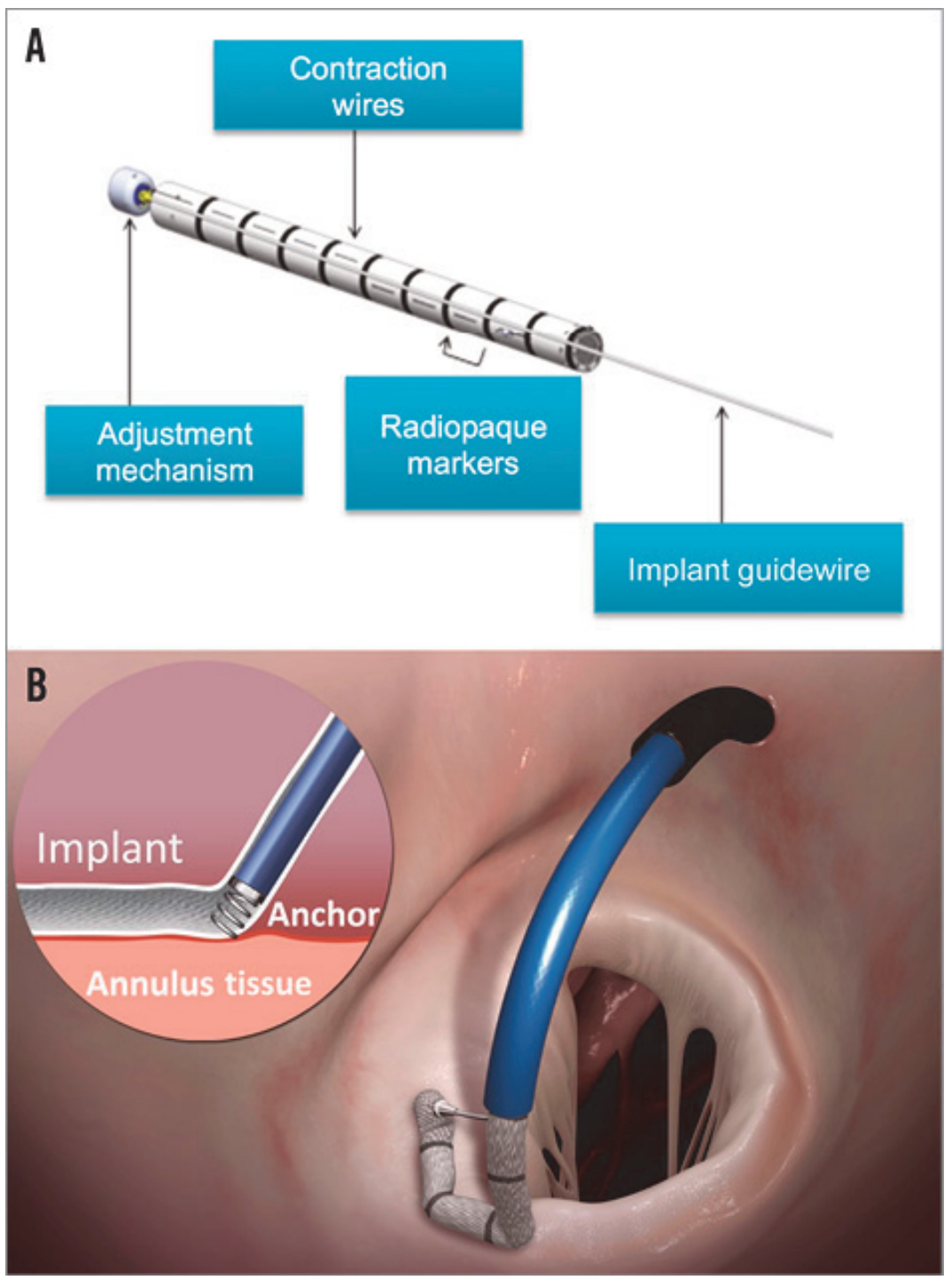

Figure 1. The Cardioband device. A) The Cardioband implant, which is a variable length tubular Dacron band. Several radiopaque markers (one every $8 \mathrm{~mm}$ ) allow its visualisation under fluoroscopy. The implant contraction wire inside the Dacron band allows the cinching. B) The implant is delivered over the posterior circumference of the mitral annulus, on the atrial side, and fixed with multiple helical anchors.

The anchors are delivered from inside the Cardioband to abolish the risk of anchor embolization and to simplify the delivery. After the placement of all the anchors, the IDS is removed and cinching is performed by using a Size Adjustment Tool (SAT) that is inserted and engaged to the adjustment mechanism of the implant. The spool is rotated to reduce the Cardioband length. Once the required implant size is reached, the SAT is disengaged, the tension on the contraction wires is locked and the implant guide-wire is removed. 


\section{The implant technique}

\section{Device implant}

Using the neo-inferior vena cava graft as access, a standard transseptal system with a Brockenbrough curved needle was used to cross the interatrial septum under ICE guidance. Following heparin administration, a 0.035" Amplatz super-stiff wire (Boston Scientific, Natick, Massachusetts, USA) was then advanced in the left atrium. The TSS was then advanced over the wire until it reached the middle of the left atrium. Then it was deflected to approximately $90^{\circ}$ and turned towards the mitral valve. The IDS was then advanced until the tip of the delivery system was in reach of the anterolateral commissural area, on the atrial side. An 0.0018" wire emerging $4 \mathrm{~mm}$ from the side of the implant, was used to guide the device towards the anterolateral commissure. Echocardiography was used as follows: short axis projections were used to identify the deliverysystem location around the annulus, while long-axis projections were used to visualize the relative position of the device to the annulus, to follow anchors deployment and to prevent damage to adjacent structures (e.g. leaflets, circumflex artery, atrial wall, coronary sinus). The first anchor was then implanted in correspondence of the anterolateral commissural annulus by gentle rotation knob in the delivery system under echocardiographic and fluoroscopic guidance (Figure 2A). Before anchor release a pull test was done to assure anchor fixation. If correctly implanted, then the anchor would be released. The tip of the implant was then positioned posterior and medial to the first anchor, along the mitral annulus and a second anchor was implanted (Figure 2B). These maneuvers were performed repeatedly until the posteromedial commissure was reached and the last anchor delivered (Figure 2C): After implanting all the anchors the implant would be released from the IDS and the catheter removed, while keeping the TSS in place. Only a wire remained connected to the implant cinching mechanism. Over this wire, the cinching tool, (SAT) was advanced and connected to enable the postimplant cinching.

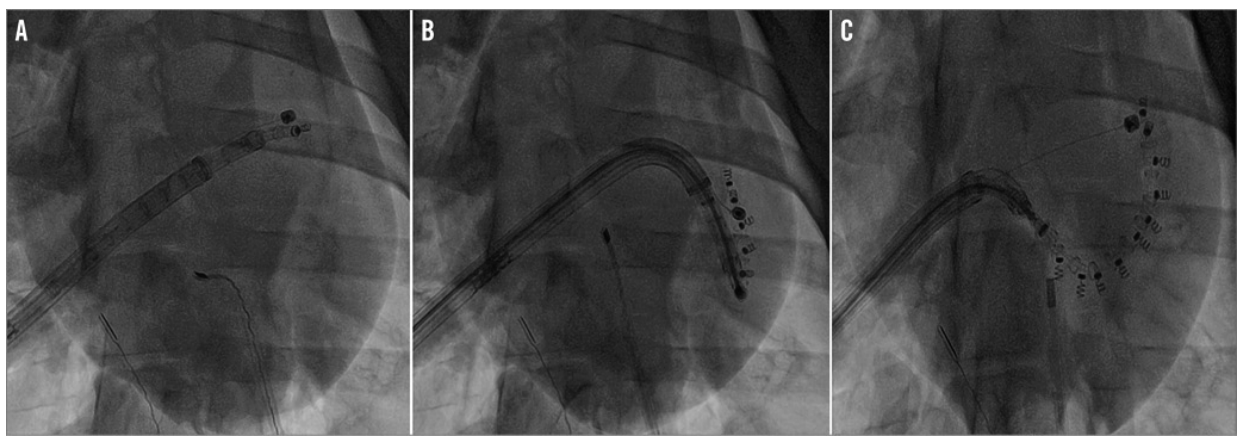

Figure 2. Fluoroscopic procedural steps of the Cardioband implantation. After crossing the interatrial septum, the TSS was advanced to the middle of the left atrium and steered towards the mitral valve. The IDS was then 
progressed until the tip of the delivery system was at the level of the anterolateral commissural area. A wire emerging $4 \mathrm{~mm}$ from the side of the implant served to guide the device towards the anterolateral commissure and to provide stability for the first anchor implantation (A). By gentle manoeuvring of the TSS and the IDS under fluoroscopic and echocardiography guidance, the implant delivery system was moved along the mitral annulus and subsequent anchors were placed (B) at $8 \mathrm{~mm}$ intervals in order to attach the annuloplasty implant to the tissue, until the posteromedial commissure was reached (C).

\section{Annular cinching}

Cinching was performed in all animals under ICE guidance. Since the animals had normal mitral valve function, the efficacy of cinching was tested by determining the achievable amount of annular reduction and the creation of a diastolic gradient. For this reason the Cardioband was cinched until maximal contraction was achieved. Echocardiographic analysis of mitral valve parameters such as diastolic septo-lateral and intercommissural distance, leaflet coaptation length, annulus surface area as well as maximal pressure gradient and blood velocity over the valve were performed at this point. Using the SAT, the Cardioband was returned to baseline dimensions to allow post-mortem examination of the location of the anchors. The SAT was then disconnected and retrieved.

\section{Fluoroscopic imaging}

Due to the different orientation of the heart relative to the chest cavity in the animal model, a slightly caudal antero-posterior projection is equivalent to the left anterior oblique projection in humans. Lateral projections in the animal are equivalent to right anterior oblique projections in humans.

\section{Data collection and analysis}

Data on procedural time, anchor implantation time, total fluoroscopy time and implantation success was collected. Procedural time was determined as time elapsed from transseptal puncture to the deployment of the last anchor. Anchor implantation time was defined as the duration between implantation of the first and the last anchor. Total fluoroscopy time was defined as the time (minutes) under effective fluoroscopy for each implant. Successful implantation was defined as a full deployment (from commissure to commissure) of the Cardioband device in the posterior annulus was achieved, and commissure-device gap (distance between the commissure and the first anchor) was less than $1 \mathrm{~cm}$.

Procedural adverse events were recorded during the implantation. Upon explant, gross pathological examination was performed and relevant observations were docu- 
mented, including distance of implant from annulus and lesions of surrounding structures.

\section{Results}

Twenty healthy female adult pigs were successfully implanted with CardioBand system (Table 1).

Table 1. Basic characteristics.

\begin{tabular}{|c|c|c|}
\hline \multicolumn{2}{|l|}{ Number } & 20 \\
\hline \multicolumn{2}{|l|}{ Female gender } & $20 / 20$ \\
\hline \multicolumn{2}{|l|}{ Weight (kg) } & $104 \pm 9$ \\
\hline \multicolumn{2}{|c|}{ Temperature baseline $\left({ }^{\circ} \mathrm{C}\right)$} & $36.8 \pm 0.9$ \\
\hline \multicolumn{2}{|c|}{ HR baseline (bpm) } & $79 \pm 16$ \\
\hline \multirow[t]{2}{*}{ Post-procedural } & Temperature $\left({ }^{\circ} \mathrm{C}\right)$ & $36.1 \pm 0.9$ \\
\hline & HR (bpm) & $88 \pm 23$ \\
\hline
\end{tabular}

The transseptal access was achieved, and the delivery system was advanced in the left atrium in all animals without complications. The device was successfully implanted in all animals, with a mean procedure time of $78 \pm 23$ minutes and a mean total fluoroscopy time of $27 \pm 9$ minutes. Total of 246 anchors were implanted, with a successful-anchorplacement rate of $95.1 \%$. Implantation time from first to last anchor was $52 \pm 19$ minutes. On average $6 \pm 2$ minutes per anchor.

Complete pre- and post-cinching echo quantitative assessment was available for 12 animals. Following Cardioband cinching a marked $(p<0.001)$ decrease in septo-lateral ($8.2 \pm 6.4 \mathrm{~mm})$ and intercomissural distance $(-9.6 \pm 3.5 \mathrm{~mm})$ was observed. Moreover, significant $(p<0.001)$ increase in coaptation length $(3.8 \pm 1.6 \mathrm{~mm})$ and pressure gradient $(2.4 \pm 1.9 \mathrm{mmHg}$ ) over the mitral valve were recorded (Figure 3).

Procedural adverse events and observations at post-mortem examination are listed in (Table 2). 

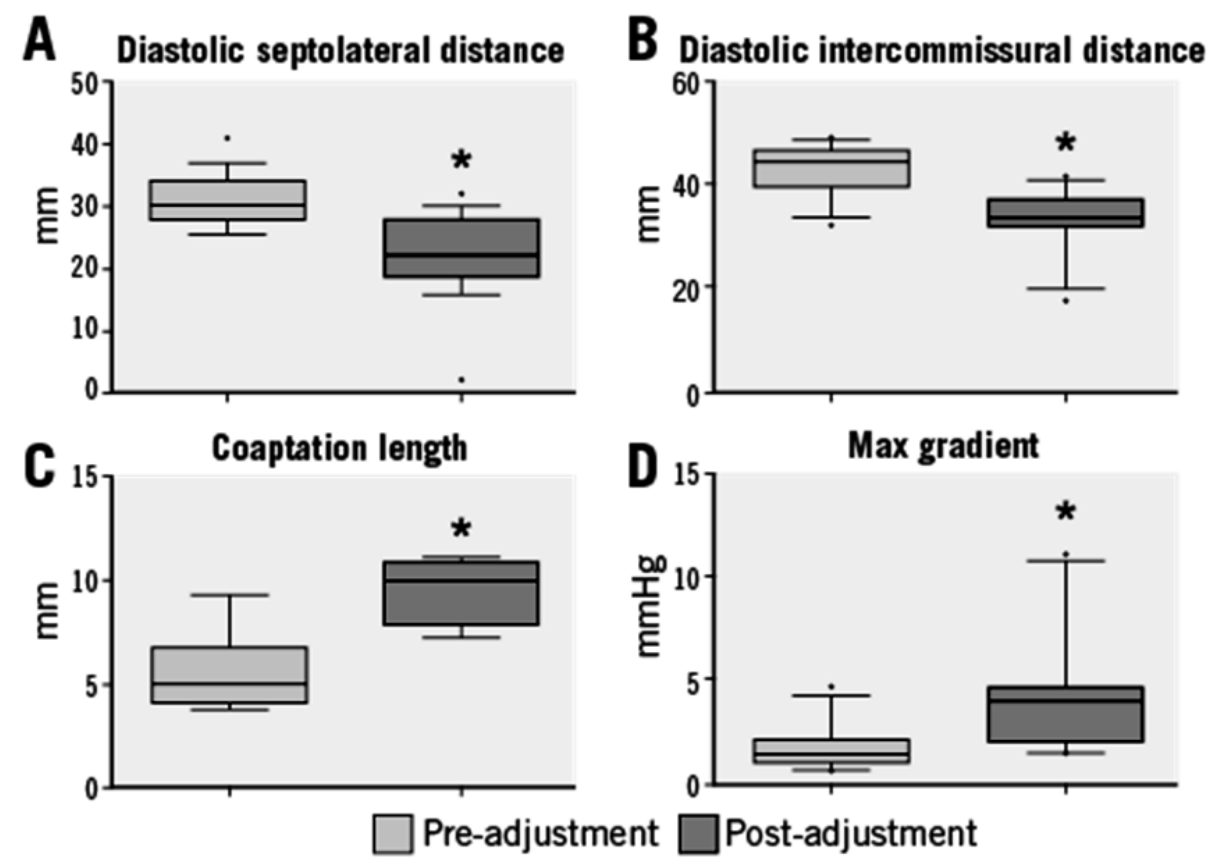

Figure 3. Box-plot presentation of relevant mitral valve parameters measured by intracardiac echocardiography (ICE) after the implantation of the Cardioband as well as after reduction of the annular size by device contraction (cinching) (data available for 12/20 animals). In particular, panels A and B show the reduction of septolateral and intercommissural distance of the mitral annulus, respectively. Panel $\mathrm{C}$ shows the variation in coaptation length and panel $D$ the increase of peak transmitral gradient. Each box represents $10-90$ percentile range with "•" being the outliers. Statistically significant $(p<0.001)$ results were marked with an asterisk $(*)$. 
Table 2. Periprocedural results and post-mortem examination data.

\begin{tabular}{|l|c|}
\hline Periprocedural results & $n=20$ implants \\
\hline Successful implantations & $20 / 20(100 \%)$ \\
\hline Pericardial effusion & $0 / 20(0 \%)$ \\
\hline Air embolism & $0 / 20(0 \%)$ \\
\hline Loss of transseptal access & $1 / 20(5 \%)$ \\
\hline Coronary vessel haemorrhage or occlusion & $0 / 20(0 \%)$ \\
\hline Damage to atrial wall & $1 / 20(5 \%)$ \\
\hline Leaflet damage & $0 / 20(0 \%)$ \\
\hline Post-mortem examination data & $n=246$ anchors \\
\hline Successful implantations & $234 / 246(95.1 \%)$ \\
\hline Anchor detachment & $0 / 246(0 \%)$ \\
\hline Anchor punctured coronary artery & $0 / 246(0 \%)$ \\
\hline Anchor punctured coronary sinus & $1 / 246(0.4 \%)$ \\
\hline Anchor punctured atrium & $1 / 246(0.4 \%)$ \\
\hline Anchor-point haematoma & $2 / 246(0.8 \%)$ \\
\hline Anchor positioned <1 mm from leaflet & $4 / 246(1.6 \%)$ \\
\hline Anchor positioned $>5$ mm from leaflet & $1 / 246(0.4 \%)$ \\
\hline $\begin{array}{l}\text { Suboptimal anchor positioning } \\
\text { (i.e., orientation, kinking) }\end{array}$ & $3 / 246(1.2 \%)$ \\
\hline
\end{tabular}

\section{Discussion}

By using multimodality imaging guidance in an animal model specifically designed to test "human grade" devices with an endovascular approach, percutaneous transcatheter mitral annuloplasty with CardioBand was successfully completed in all animals. Echocardiographic quantification showed that device cinching significantly reduced mitral annulus diameter and increased coaptation length and maximal pressure gradient over the mitral valve in the 12 animals assessed.

MitraClip in particular has been successfully used to reduce MR in diverse pathology settings (9). Although early outcomes are promising, lack of annuloplasty could explain some early failures and durability issues (10).

Different annuloplasty ring devices are commonly used in surgical practice (complete or incomplete, rigid, semi-rigid or flexible), and there is no consensus for the best technique for surgical annuloplasty: surgeon preference and experience are the main determinant in the choice of the device. Cardioband system is the first device devel- 
oped to strictly reproduce surgical mitral valve annuloplasty by fixating a flexible incomplete Dacron band to the annulus using multiple helix anchors, on a beating heart. As the anchors, like surgical sutures, are placed $8 \mathrm{~mm}$ apart, total number of anchors, and procedural duration for that matter, are strongly dependent on the size of the annulus.

The animal model chosen to prove the Cardioband concept was the healthy adult swine: since annuloplasty is an established technique for mitral repair, the animal model was mainly designed to demonstrate feasibility of a transcatheter, transeptal implant of a surgical-like annuloplasty device in the mitral annulus, under echocardiographic and fluoroscopic guidance (Figure 4). Of note, the Cardioband size can be decreased and increased as long as the SAT is connected.

Transcatheter mitral valve therapies require precise imaging for guidance. While fluoroscopy remains mandatory to monitor device manipulation, echocardiography is necessary to identify the left heart structures. Currently, live 3D echocardiography is the gold-standard imaging modality for mitral interventions including the MitraClip therapy $(11,12)$. This remains a challenge in the large porcine model, as TEE imaging of the mitral valve could be obscured by an interposed lung lobe.

In contrast to previously described difficulties (13), transfemoral and trans-apical ICE for long- and short-axis views of the mitral valve, were successfully used to guide the procedure in this study (Figure 5). Device and all relevant cardiac structures were clearly visible in both, fluoroscopic and ICE imaging, resulting in high marks in visibility (Figure 2). 

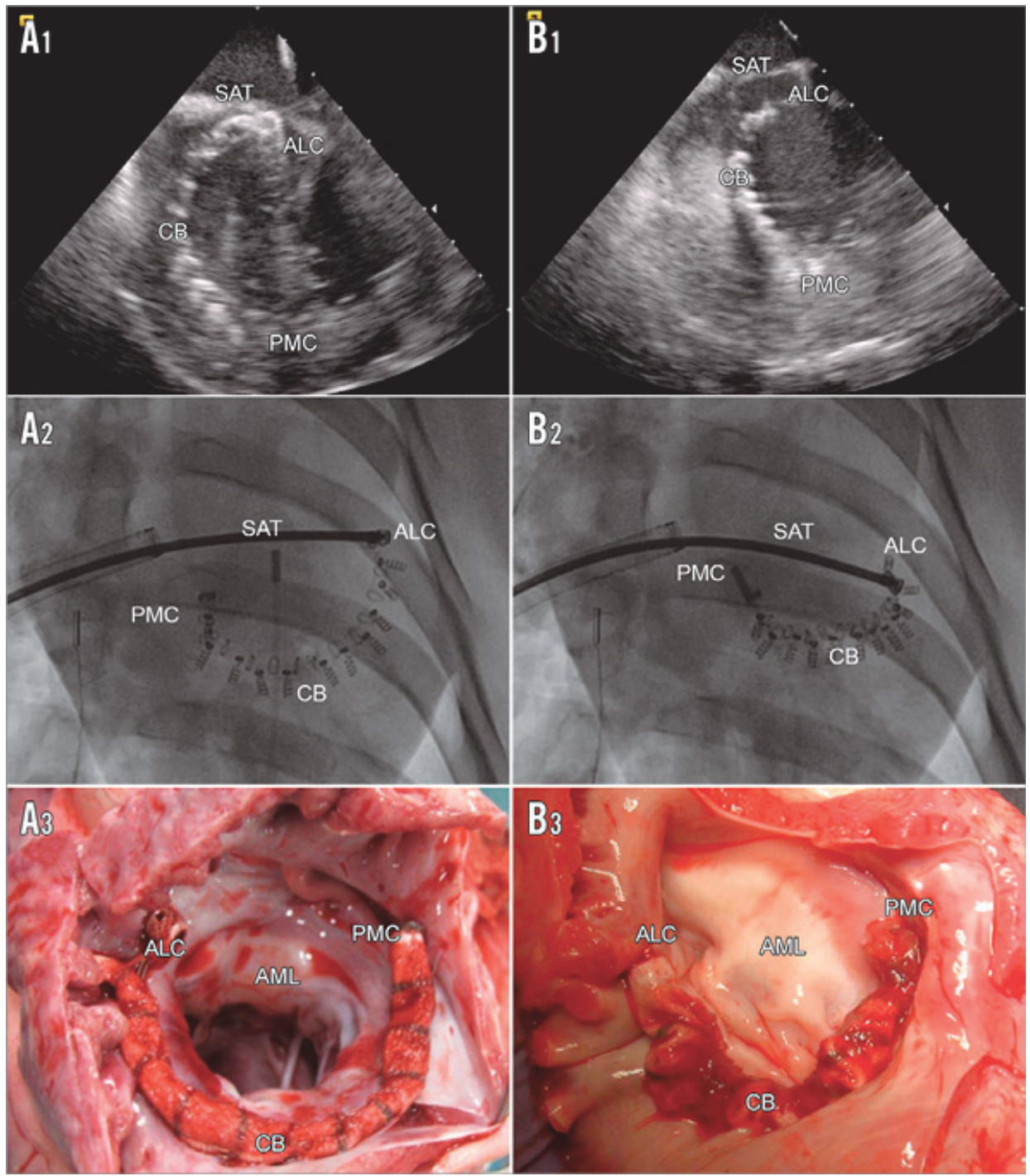

Figure 4. ICE short-axis, fluoroscopic and native post-mortem, representative images of the fully implanted uncinched (A1 to A3) and cinched (B1 to B3) Cardioband system. ALC: anterolateral commissure; AML: anterior mitral leaflet; CB: Cardioband; PMC: posteromedial commissure; SAT: size adjustment tool. 


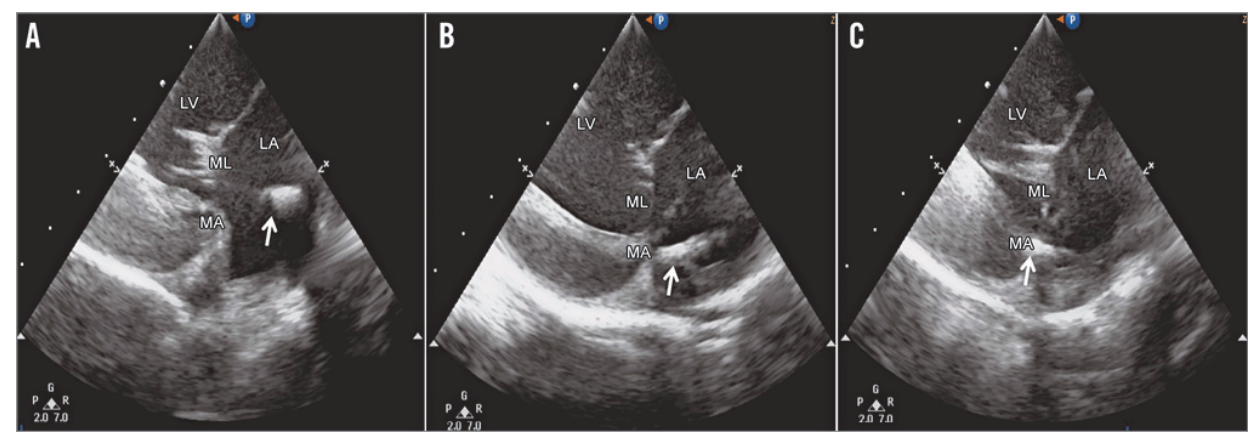

Figure 5. Intracardiac echoradiography of the Cardioband implantation procedure. Intracardiac echoradiography guidance of the Cardioband implantation procedure in a large animal model is essential in order to achieve optimal positioning. The delivery system was first oriented towards the leaflets (A) and, after correction, properly positioned on the mitral annulus (B), where the anchor was deployed in the tissue (C). White arrow indicates the tip of the delivery system (A \& B) and the anchor implanted in the MA in C. LA: left atrium; LV: left ventricle; MA: mitral annulus; ML: mitral leaflet.

In conclusions, the Cardioband system is the first transcatheter device developed to strictly reproduce surgical annuloplasty. This study demonstrated that transseptal beating-heart implantation of an adjustable annuloplasty device is safe and feasible in the animal model. The animal model has been instrumental to develop the procedural steps and to prepare the implanting physicians to the first-in-man trial.

\section{Limitations}

Due to limitation of the healthy animal model, therapeutic efficacy of the Cardioband could not be demonstrated in this study. Although complete annuloplasty is considered the gold standard for stand alone annuloplasty in functional MR, a posterior band configuration of the device was preferred for safety reasons, since the risk of aortic valve injury was felt as a potential issue when designing the transcatheter approach. Moreover, the main determinant for repair durability after annuloplasty in functional MR is the achievement of good leaflet coaptation rather than the type of ring used $(14,15)$. Reduction of SL and IC length as well as increase in maximal pressure gradient and leaflet coaptation length after cinching of the annuloplasty band, suggest that the Cardioband induces changes in annular geometry, which are similar to a surgical implant.

Another limitation is that complete pre- and post- echocardiographic quantification was available only for 12 animals. 


\section{References}

1. Maisano F, Franzen O, Baldus S, Schafer U, Hausleiter J, Butter C, Ussia GP, Sievert H, Richardt G, Widder JD, Moccetti T, Schillinger W. Percutaneous mitral valve interventions in the real world: early and 1-year results from the ACCESS-EU, a prospective, multicenter, nonrandomized post-approval study of the MitraClip therapy in Europe. Journal of the American College of Cardiology 2013;62(12):1052-61.

2. Siminiak T, Wu JC, Haude M, Hoppe UC, Sadowski J, Lipiecki J, Fajadet J, Shah AM, Feldman T, Kaye DM, Goldberg SL, Levy WC, Solomon SD, Reuter DG. Treatment of functional mitral regurgitation by percutaneous annuloplasty: results of the TITAN Trial. European journal of heart failure 2012;14(8):931-8.

3. Alfieri O, Maisano F, De Bonis M, Stefano PL, Torracca L, Oppizzi M, La Canna G. The double-orifice technique in mitral valve repair: a simple solution for complex problems. J Thorac Cardiovasc Surg 2001;122(4):674-81.

4. Gillinov AM, Cosgrove DM. Mitral valve repair for degenerative disease. J Heart Valve Dis 2002;11 Suppl 1:S15-20.

5. Gillinov AM, Tantiwongkosri K, Blackstone EH, Houghtaling PL, Nowicki ER, Sabik JF, 3rd, Johnston DR, Svensson LG, Mihaljevic T. Is prosthetic anuloplasty necessary for durable mitral valve repair? The Annals of thoracic surgery 2009;88(1):76-82.

6. Flameng $W$, Herijgers $P$, Bogaerts $K$. Recurrence of mitral valve regurgitation after mitral valve repair in degenerative valve disease. Circulation 2003;107(12):1609-13.

7. Maisano F, Vanermen H, Seeburger J, Mack M, Falk V, Denti P, Taramasso M, Alfieri O. Direct access transcatheter mitral annuloplasty with a sutureless and adjustable device: preclinical experience. Eur J Cardiothorac Surg 2012.

8. Maisano F, Reser D, Pavicevic J, Guidotti A, Denti P, Taramasso M, Addis A, Cesarovic N, Emmert MY, Nietlispach F, Swain J, Falk V, Leon M. A translational "humanised" porcine model for transcatheter mitral valve interventions: the neo inferior vena cava approach. Eurolntervention : journal of EuroPCR in collaboration with the Working Group on Interventional Cardiology of the European Society of Cardiology 2015.

9. Maisano F, Franzen O, Baldus S, Schafer U, Hausleiter J, Butter C, Ussia GP, Sievert H, Richardt G, Widder JD, Moccetti T, Schillinger W. Percutaneous Mitral Valve Interventions in the Real World: Early and One Year Results From the ACCESS-EU, a Prospective, Multicenter, Non-Randomized Post-Approval Study of the MitraClip(R) Therapy in Europe. J Am Coll Cardiol 2013.

10. Mauri L, Foster E, Glower DD, Apruzzese P, Massaro JM, Herrmann HC, Hermiller J, Gray W, Wang A, Pedersen WR, Bajwa T, Lasala J, Low R, Grayburn P, Feldman T, Investigators El. 4-year results of a randomized controlled trial of percutaneous repair versus surgery for mitral regurgitation. Journal of the American College of Cardiology 2013;62(4):317-28.

11. Swaans MJ, Post MC, ten Berg JM. Transapical repair of mitral valve paravalvular leakage using 3-D transesophageal guidance. Catheterization and cardiovascular interventions : official journal of the Society for Cardiac Angiography \& Interventions 2011;77(1):121-3.

12. Swaans MJ, Van den Branden BJ, Van der Heyden JA, Post MC, Rensing BJ, Eefting FD, Plokker HW, Jaarsma W. Three-dimensional transoesophageal echocardiography in a patient undergoing percutaneous mitral valve repair using the edge-to-edge clip technique. European journal of echocardiography : the journal of the Working Group on Echocardiography of the European Society of Cardiology 2009;10(8):982-3.

13. Maisano F, Vanermen H, Seeburger J, Mack M, Falk V, Denti P, Taramasso M, Alfieri O. Direct access transcatheter mitral annuloplasty with a sutureless and adjustable device: preclinical experience. European journal of cardio-thoracic surgery : official journal of the European Association for Cardio-thoracic Surgery 2012;42(3):524-9.

14. Mihaljevic T, Lam BK, Rajeswaran J, Takagaki M, Lauer MS, Gillinov AM, Blackstone EH, Lytle BW. Impact of mitral valve annuloplasty combined with revascularization in patients with functional ischemic mitral regurgitation. Journal of the American College of Cardiology 2007;49(22):2191-201. 
15. Wu AH, Aaronson KD, Bolling SF, Pagani FD, Welch K, Koelling TM. Impact of mitral valve annuloplasty on mortality risk in patients with mitral regurgitation and left ventricular systolic dysfunction. Journal of the American College of Cardiology 2005;45(3):381-7. 



\section{Chapter}

\section{Cardioband, a transcatheter surgical-like direct mitral valve annuloplasty system: early results of the feasibility trial}

Francesco Maisano MD, Maurizio Taramasso MD, Georg Nickenig MD, Christoph Hammerstingl MD, Alec Vahanian MD, David Messika-Zeitoun MD, Stephan Baldus MD, Michael Huntgeburth MD, Ottavio Alfieri MD, Antonio Colombo MD, Giovanni La Canna,

Eustachio Agricola MD, Michel Zuber MD, Felix C. Tanner MD, Yan Topilsky MD, Felix Kreidel MD, Karl-Heinz Kuck MD 


\section{Abstract}

Background. The Cardioband system is a direct annuloplasty adjustable device that is implanted in the beating heart on the posterior annulus under fluoroscopic and transesophageal echocardiographic (TEE) guidance. We report the early (1 month) outcomes of the first-in-man pre-CE-mark feasibility and safety trial.

Methods and results. The study enrolled high-risk adult individuals at 5 institutions in Europe with symptomatic secondary mitral regurgitation (MR) despite optimal medical therapy. The primary efficacy endpoints included technical success rate of implantation, feasibility of the Cardioband adjustment (technical performance) and ability to reduce the annular septolateral dimension and MR grade at hospital discharge and at 30 days. Study group included 31 consecutively enrolled high-risk patients with moderate-tosevere or severe secondary MR with at least one month of follow-up (mean age $71.8 \pm$ 6.9 years). All patients received the full implant of a Cardioband. Adjustment of the Cardioband resulted in a significant reduction in the septolateral dimension in all but 2 patients (septolateral dimension from $36.8 \pm 4.8 \mathrm{~mm}$ to $29 \pm 5.5 \mathrm{~mm}$ after the procedure, $p$ <0.01). Following Cardioband adjustment (29/31 patients) MR was none or trace in $6(21 \%)$, mild in $21(72 \%)$ and moderate in $2(7 \%)$. No patient had severe MR after adjustment. Procedural mortality was zero and in-hospital mortality was $6.5 \%$ (2/31 patients, not procedure or device -related). At 30 days 22/25 patients (88\%) had $M R \leq 2+$.

Conclusions: This study demonstrates the feasibility and safety of percutaneous direct mitral annuloplasty with the Cardioband device in high-risk patients with MR. 


\section{Introduction}

Transcatheter mitral valve interventions are progressively being introduced into clinical practice targeting a population of patients with mitral regurgitation (MR) deemed inoperable or at an unacceptable surgical risk (1). While MitraClip (Abbott Vascular, Santa Rosa, CA, USA) therapy is widely performed, there are presently no direct percutaneous annuloplasty devices available for clinical use. Annuloplasty in an open-chest surgical approach is the most commonly performed repair treatment for MR. Annuloplasty is added to leaflet repair in degenerative MR to improve coaptation and prolong durability, and it is often used as a stand-alone procedure to improve coaptation in secondary $M R(M R)$, also referred to as functional MR (FMR). Secondary MR is caused by sustained previous damage to the left ventricle (LV) due to a myocardial infarction or dilated cardiomyopathy, resulting in annular dilatation and lateral displacement of the papillary muscles.

The Cardioband system is a percutaneous surgical-like direct annuloplasty device that is implanted in the beating heart on the posterior annulus under fluoroscopic and transesophageal echocardiographic (TEE) guidance. Following the implantation, it is contracted to remodel the annulus and improve MR. We report the early (1 month) outcomes of the first-in-man pre-CE-mark feasibility and safety trial. The study outcomes represent the early experience of 5 European sites.

\section{Methods}

\section{Trial design, inclusion criteria and patient selection}

The study was a non-blinded, non-randomized, single arm, multicenter, prospective study enrolling patients at 5 institutions in Europe. The study enrolled high-risk adult individuals with symptomatic MR despite optimal medical therapy including cardiac resynchronization therapy (CRT) where indicated. Patients with a left ventricular (LV) ejection fraction less than or equal to $25 \%$ and a LV end-diastolic diameter greater or equal to $70 \mathrm{~mm}$ were excluded. Other main exclusion criteria included: organic lesions of the mitral valve, calcification of the annulus, acute endocarditis, coronary artery disease requiring revascularization, dialysis, significant concomitant valve disease, life expectancy less than 12 months, and recent cerebral event.

The anatomical feasibility of Cardioband implantation was assessed prior-procedure by Echocardiography and cardiac computed tomography (CT). CT scanning was used to size the mitral annulus, and to plan the procedure (location of transseptal puncture, mitigating the risk of injury to the left circumflex coronary artery, and planning of fluoroscopic views). 
The implant size was chosen according to the length of the posterior annulus (from left trigone to right trigone) at maximal diastolic opening of the valve.

The primary efficacy endpoints included:

a. Technical success rate of Cardioband implantation, defined as the ability to advance the implant, load anchors, anchor the implant to the tissue, and retract the Implant Delivery System;

b. Technical feasibility of Cardioband adjustment, defined as the ability to connect the adjustment tool, reduce the implant dimension, and retract the adjustment tool with the guide wire;

c. Cardioband ability to reduce the annular septolateral dimension and MR as measured by TEE post-procedure, and transthoracic echocardiography (TTE) at hospital discharge and at the post-operative 30-day visit.

The standardization of echocardiographic images was achieved by using a pre-specified protocol that addressed the issues of echocardiographic acquisition. MR was assessed by an independent Core Laboratory. MR severity is determined by a combination of qualitative and quantitative methods as per the Echocardiography society guidelines for MR analysis in MR patients (2). Analysis of echocardiography data was performed both by the investigational site as well as in a standardized mode by an independent core laboratory (Paul Grayburn, MD, Baylor Health, TX, USA).

The overall rate of major serious adverse events (MSAEs) and serious adverse device effects (SADEs) until hospital discharge and at 30 days post implantation was the primary safety endpoint. Both the MSAEs and the SADEs were collected and independently adjudicated by a Clinical Event Committee. MSAEs include: death, myocardial infarction, cardiac tamponade, device-related cardiac surgery, and stroke.

The clinical investigation was performed in conformity with the ethical principles set forth by the Declaration of Helsinki, Good Clinical Practice (GCP) principles, and in accordance with ISO 14155:2011. The study has been registered at ClinicalTrials.gov as NCT01841554.

\section{The Cardioband Adjustable Annuloplasty System}

The Cardioband Adjustable Annuloplasty System includes the implant and three main accessories:

a. The implant is a polyester sleeve with radiopaque markers spaced $8 \mathrm{~mm}$ apart (Figure $1 \mathrm{~A}$ and $\mathrm{B}$ ). The sleeve mounted on the delivery system and the anchor depoloyed from the internal part. A contraction wire in the Cardioband is connected to an adjusting spool. Activating the spool enables shorten the implant. The implant size is adjusted to the patient's needs under TEE guidance and the size can be completely reversed. The implant is available in six lengths (Table 1). 
Table 1. Cardioband implant size

\begin{tabular}{ll}
\hline Implant size & No. of subjects (\%) $\mathrm{N}=31$ \\
\hline B $(81-88 \mathrm{~mm})$ & $1(3 \%)$ \\
C $(89-96 \mathrm{~mm})$ & $5(16 \%)$ \\
D $(97-104 \mathrm{~mm})$ & $13(42 \%)$ \\
E $(105-112 \mathrm{~mm})$ & $7(23 \%)$ \\
F $(113-120 \mathrm{~mm})$ & $5(16 \%)$ \\
\hline
\end{tabular}

b. TF Delivery system: The Cardioband Delivery System (CDS) consists of the Implant Delivery System (IDS) and the 25F Transseptal Steerable Sheath (TSS). The IDS is comprised of a steerable Guide Catheter (GC) and an Implant Catheter (IC) with the Cardioband implant mounted on its distal end (Figure 1C).

A

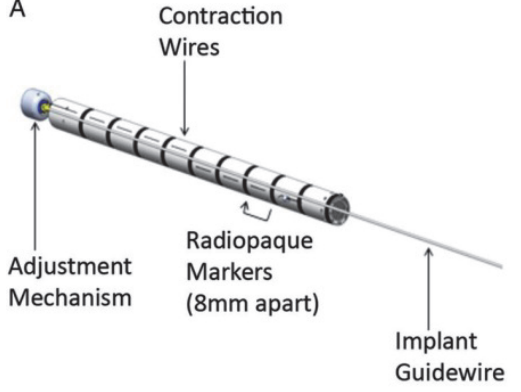

B

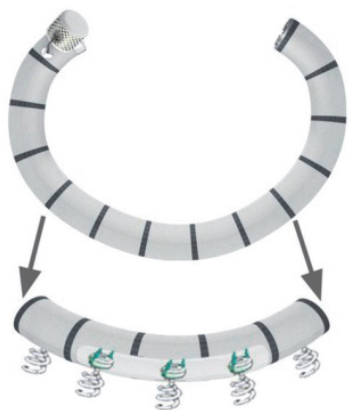

Implant

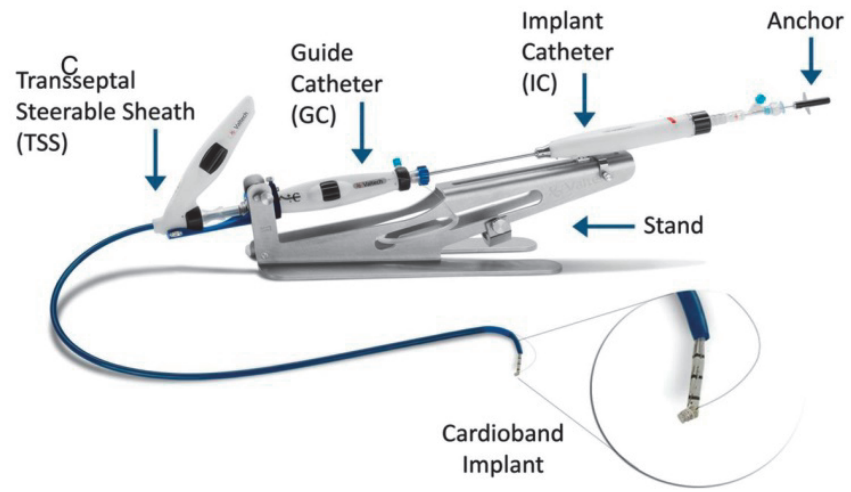

Figure 1. Cardioband implant before implantation (A) and after implantation (B). The implant is a polyester sleeve with radiopaque markers spaced $8 \mathrm{~mm}$ apart. (C) The Cardioband delivery system, assembled in the implantation mode. The Cardioband delivery system consists of an implant delivery system and a $25 \mathrm{~F}$ transseptal steerable sheath. The implant delivery system comprises a steerable guide catheter and an implant catheter with the Cardioband implant mounted on its distal end.

c. Implantable metal anchors and anchor delivery shafts: Implantable stainless steel, $6 \mathrm{~mm}$ long anchors, are used to fasten the Cardioband implant to the annulus (Figure 
2). Between 12 and 17 anchors are implanted using a delivery shaft. The anchors are fully repositionable and retrievable until deployed.

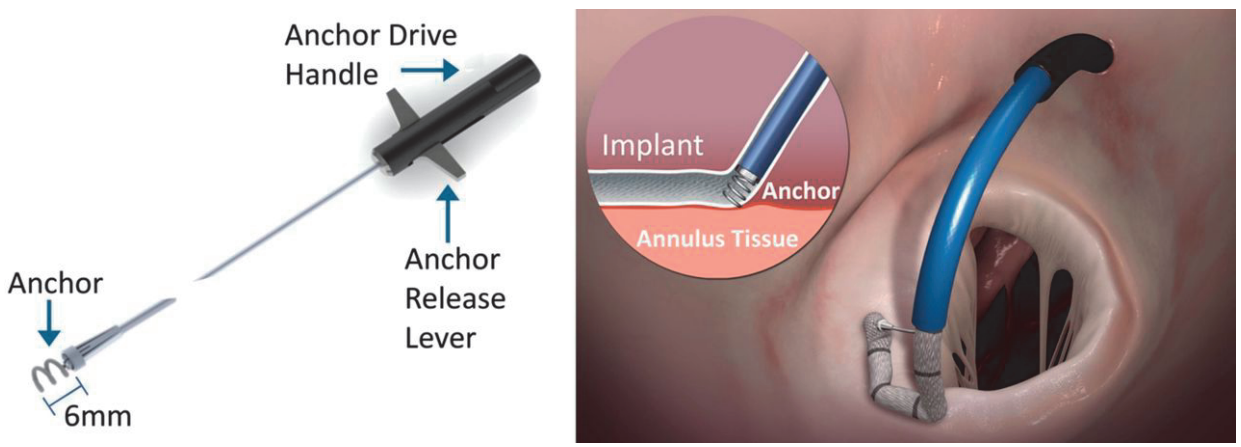

Figure 2. Anchor delivery system and implantable metal anchor (left panel). Anchor deployment through implant and tissue (right panel). The anchor is delivered and implanted using the anchor delivery drive inside the implant catheter through the Cardioband implant fabric and into the annulus tissue under echocardiographic and standardized fluoroscopic guidance.

d. Size adjustment tool (SAT): The SAT distal tip is connected over the implant wire and is used to control the implant adjustment spool and the implant size.

\section{The procedure}

The procedure is performed under general anesthesia with 3D-TEE guidance. Femoral vein and arterial access is obtained. Following echo-guided transseptal puncture, systemic heparinization is performed to achieve an activated clotting time between 250 and $300 \mathrm{sec}$. The TSS is advanced over a super-stiff guide wire into the left atrium. The IDS is then advanced through the TSS. The delivery system is steered, until the tip of the IC is placed over the anterior commissure. Verification of the first anchoring location is obtained with TEE. The anchor should be placed close to the leaflet hinge, as anterior as possible in the annulus, close to the anterior commissure. Following confirmation of the location with 3D-TEE, coronary angiography is performed to rule out the risk of circumflex damage. The first anchor is delivered and implanted using the anchor delivery drive inside the IC through the Cardioband implant fabric and into the annulus tissue. The anchor is released after proper anchoring is checked with push-and-pull testing under echocardiographic and standardized fluoroscopic guidance. The Cardioband implant is deployed until the radiopaque marker of the IC channel reaches the next marker on the implant. The IC tip is then navigated, by actuating the TSS and GC steering knobs, to the next anchoring point along the posterior annulus using echocardiographic guidance. These actions are repeated until the implant catheter tip reaches the last anchoring site on the posterior commissure. 
The last anchor is then deployed and the implant disconnected from the Implant Delivery System (IDS), which is subsequently removed. The SAT is then inserted through the TSS, over the implant guide wire, until its distal end reaches the adjustment spool of the implant. After SAT connection, the implant is contracted by clockwise rotation of the adjustment roller (Figure 3). Adequate reduction of MR severity is assessed by TEE under beating heart conditions. When the appropriate implant size has been reached, the SAT is detached from the adjustment spool leaving the implant with the desired degree of contraction.

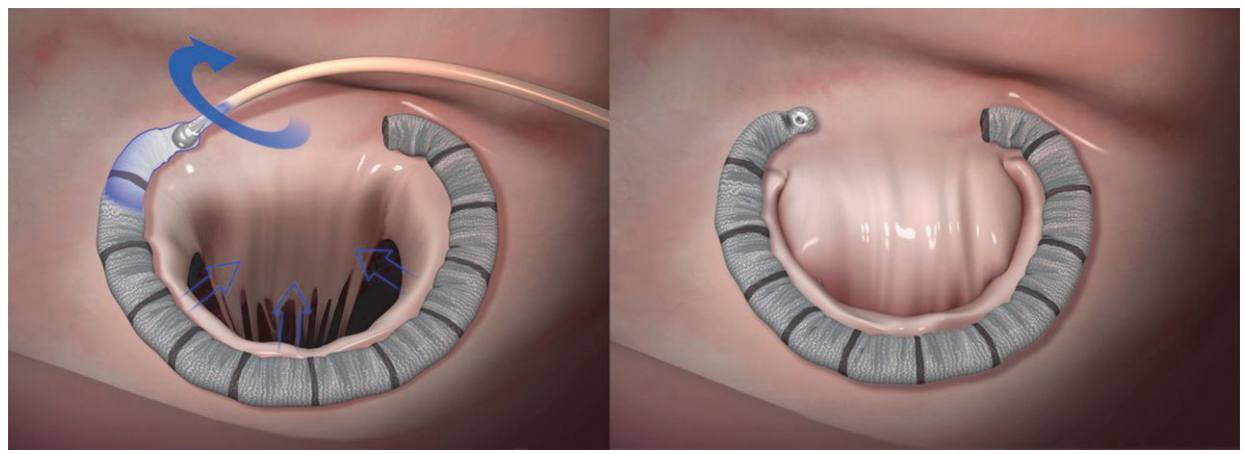

Figure 3. Cardioband adjustment. The size adjustment tool distal tip is connected over the implant wire and is used to control the implant adjustment spool. Activating the spool shortens the implant. The implant size is adjusted to the patient's needs under transoesophageal echocardiographic guidance.

\section{Statistics}

Statistical analysis was conducted using JMP 8.0 software (SAS Institute Inc., Cary, NC, USA). Continuous variables are presented as mean \pm SD or as median (IQR, Q1-Q3) and categorical variables are expressed as percentages. Univariable comparisons (differences between pre- and post- values) were performed with the Student's paired t-test for continuous normally distributed data, which was tested by the Shapiro-Wilk normality test. A p-value $<0.05$ was considered statistically significant; reported p-values are two-sided. The two-sided 95\% confidence interval (Cl) of clinical prevalence was calculated using the Clopper-Pearson method.

\section{Results}

\section{Patients}

In January 2015, 31 consecutively enrolled patients with secondary (functional) MR had reached at least one month of follow-up. The majority of patients (19/31 [61\%]) had restricted leaflet motion (Carpentier classification type $\mathrm{IIb}$ ), while the remaining had 
predominantly annular dilatation (Type I MR). Etiology of secondary MR was ischemic in $60 \%$ of the patients. Mean age of the patients was $71.8 \pm 6.9$ years, 26 pts $(84 \%)$ were male. All patients were symptomatic for congestive heart failure after optimization of medical therapy and CRT where indicated; 30/31 pts were in NYHA functional class IIIIV.

Coronary artery disease was the identifiable cause of heart failure in 18 pts (58\%), and 10 pts (32\%) had a history of myocardial infarction. Fourteen patients (45\%) had previously undergone open-heart surgery at least once. Most common comorbidities included moderate to severe renal imperment (92\%), Atrial fibrillation (77\%) diabetes (45\%), poor mobility $(23 \%)$, chronic pulmonary disease $(23 \%)$, prior stroke $(12 \%)$, extracardiac arteriopathy (10\%), and neurological dysfunction (3\%).

According to the core-lab adjudication at the time of preprocedural screening, MR was moderate to severe in all patients, with no patient showing organic leaflet motion abnormalities, as per protocol. Average LV ejection fraction, LV end-diastolic volume and LV end-systolic volume were $34 \pm 11 \%, 188 \pm 51 \mathrm{ml}$ and $127 \pm 49 \mathrm{ml}$, respectively. Moderate to severe pulmonary hypertension was present in 22 pts (71\%). Concomitant moderate to severe tricuspid regurgitation was present in 14 pts (45\%).

\section{Procedural outcomes}

\section{Technical implantation success rate}

All patients in whom the procedure was initiated received the full implant of a Cardioband. However, the technical success rate of implantation was (93.6\%; Cl: 78.6-99.2\%) because in one case 2 anchors were not implanted and the implant did not reach the posterior commissure, due to technical difficulties in the early phase of the experience. In another case the implant size could not be reduced due to technical failure. According to the preprocedural CT scan, most patients (13/31 [42\%]) had a posterior annular size between $97 \mathrm{~mm}$ and $104 \mathrm{~mm}$.

The total procedure duration was 3:06 \pm 0:46 hours, while the average implantation time $(2: 45 \pm 0: 44)$ tended to become shorter with growing operator experience (Figure 4). 


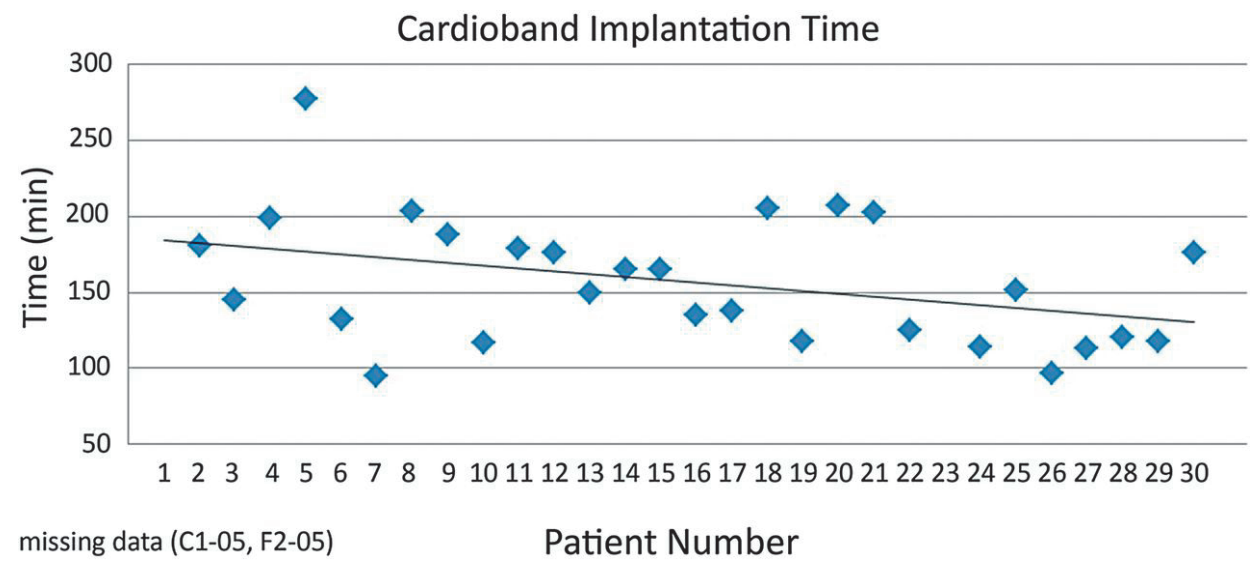

Figure 4. Duration of Cardioband implantation over time for the first 30 patients. The average implantation time $(2: 45 \pm 0: 44)$ tended to become shorter with growing operator experience.

\section{Technical adjustment success rate}

The technical performance of Cardioband adjustment was fully successful in 29 of 31 subjects (93.6\%; Cl: 78.6-99.2\%). Connecting the adjustment tool was fully successful in $31 / 31$ subjects $(100 \%)$, reducing the septolateral dimension was fully successful in $30 / 31$ subjects $(96.8 \%)$, and retracting the adjustment tool with the guide wire was fully successful in 29/31 subjects (93.6\%). Failures were due to device malfunction and procedural errors which occurred early in the series and which have been identified and solved.

Adjustment of the Cardioband device resulted in a significant reduction in the septolateral dimension in all study patients but two. The average septolateral dimension was $36.8 \pm 4.8 \mathrm{~mm}$ before the procedure and $29.0 \pm 5.5 \mathrm{~mm}$ after the procedure, resulting in a significant overall reduction of $21.1 \%$ ( $p$ value $<0.0001$ ). (Figure 5 ) 


\section{S-L Dimension ( $\mathrm{N}=29)$}

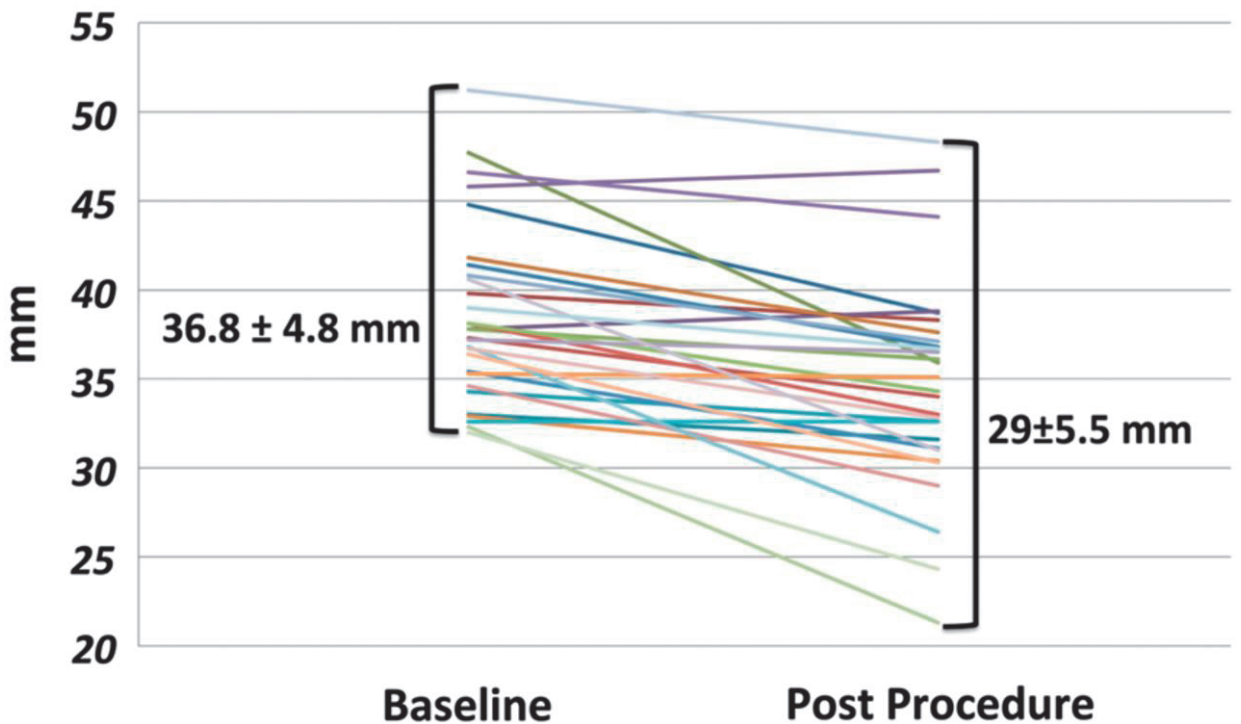

Figure 5. Septolateral dimension (in $\mathrm{mm}$ ) at baseline and post Cardioband procedure for the first 31 patients.

Intraprocedural $M R$ reduction

Intraoperative MR (TEE) following Cardioband adjustment (available in 29 patients) was none or trace in 6 (21\%), mild in 21 (72\%) and moderate in 2 (7\%). No patient had severe MR after Cardioband adjustment. At 30 days (core lab adjudication data available for 27 pts), MR was uncertain in $2(7 \%)$, none or trace $(<1+)$ in $1(4 \%)$, mild $(1+)$ in 17 (63\%), moderate $(2+)$ in $4(15 \%)$, and severe $(3+/ 4+)$ in $3(11 \%)$. Thus, $22(88.0 \%$; $\mathrm{Cl}$ : 68.8-97.5\%) of 25 patients had $M R \leq 2+$ at 30 days (Figure 6). Effective Regurgitant Orifice Area decreased from $0.28 \pm 0.11 \mathrm{~cm} 2$ at baseline to $0.17 \pm 0.13 \mathrm{~cm} 2$ at 30 days $(p=0.04)$. 


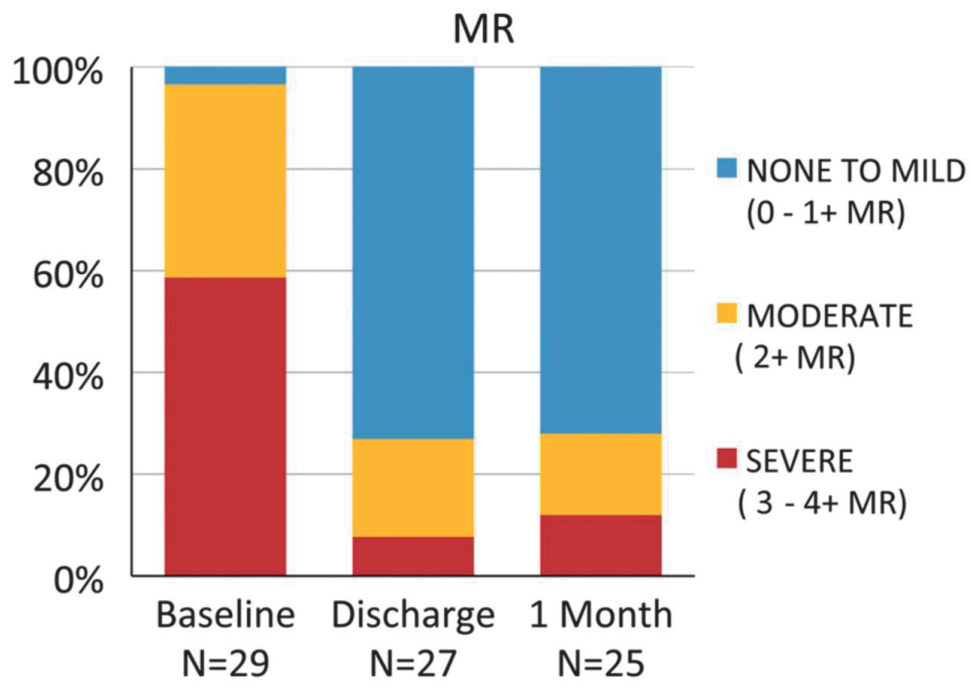

Figure 6. Mitral regurgitation reduction by transoesophageal echocardiography at baseline $(N=29)$ discharge $(\mathrm{N}=27)$ and 1-month follow-up ( $\mathrm{N}=25)$ for the first 31 patients (core-lab assessment). Twenty-seven patients were analysed at discharge; two patients died prior to discharge and the echo results were uncertain by corelab for two patients. Twenty-five of the 31 patients were analysed at 1-month follow-up two died prior to discharge, one withdrew prior to 1-month follow-up, the echo results were uncertain for two patients. One patient had mild MR measured by transoesophageal echocardiography at baseline, but had moderate mitral regurgitation as determined by transoesophageal echocardiography and was therefore included in the study.

\section{Safety}

Procedural mortality was zero, in-hospital mortality was 6.5\% (2/31 patients; $\mathrm{Cl}$ : 0.79 $21.4 \%)$ one patient died as a result of hemorrhagic stroke and another patient died of multi-organ failure 30 days after elective open heart surgery. The first event was a complication of a triple anticoagulant therapy that was indicated because of a recently implanted stent and atrial fibrillation. This therapy was the same as before the Cardioband procedure and therefore it was concluded that this event was unrelated to the device or procedure. The second fatal event was due to an elective surgical mitral valve replacement and tricuspid annuloplasty procedure following unsatisfactory MR reduction due to inability to adjust the annular dimension (device malfunction). This event was not related to the device or procedure, since the decision to perform the mitral valve surgery was unrelated to the Cardioband implantation and the subsequent device malfunction. Overall, 16 serious adverse events (SAEs) were reported in 9 patients until 30 days post implantation. All SAEs were expected. The 16 SAE's were as follows: 2 fatal events ( 1 of which hemorrhagic stroke), 2 MR recurrence (related to device, partial anchor detachment at early phases), 2 renal insufficiency (possibly related to procedure), 2 pericardial effusion (possibly related to procedure), 1 open heart surgery, 1 left femoral pseudo aneurysm (related to procedure), 1 bleeding complication (related to 
procedure), 1 dyspnea, 1 upper limb hemiparesis, 1 gastrointestinal bleeding, 1 prolonged hospitalization for diabetes management, 1 hospitalization to treat a home accident.

\section{Discussion}

The initial experience with the Cardioband system shows that transfemoral implantation of a surgical-like direct annuloplasty device is feasible, safe and effective. Cardioband device closely reproduces surgical annuloplasty with sustained and effective septolateral reduction of the annulus and MR reduction in all patients.

\section{Annuloplasty to treat $M R$}

Isolated transcatheter direct annuloplasty may play a major role in the treatment of patients with MR deemed inoperable or at high surgical risk. Patients with LV dysfunction and significant MR have a poor prognosis and increasing severity of MR is associated with worse outcome (3). Although a survival benefit has not yet been clearly demonstrated, surgical repair of severe FMR has been associated with improvement of symptoms and quality of life and with reverse LV remodelling $(4,5)$. Surgical correction of MR is mainly performed by way of an undersized annuloplasty $(6,7)$ : by reducing the septolateral dimension of the mitral annulus, undersized annuloplasty forces leaflets coaptation and thereby reduces MR. However, perioperative mortality after mitral surgery for $M R$ is not negligible, ranging from 8.8 to $21 \%$ in different series $(5,8-10)$, and the number of patients with severe MR who are not referred for surgery is increasing (11).

\section{Percutaneous annuloplasty}

The less invasive, percutaneous implantation of a "surgical-like" annuloplasty device offers the opportunity of safer treatment as compared to conventional open-heart surgery. It may also have a potential role in an earlier indication for treatment to improve the chance of prognostic benefit (12). Multiple transcatheter technologies and various approaches are presently under clinical study or in development (1). To date, Cardioband is the only device that closely reproduces surgical annuloplasty with a transcatheter approach. After demonstrating the proof of concept and feasibility in a chronic animal model (13), the Cardioband device was initially implanted in humans under direct vision through right mini thoracotomy (14). Initial experience in 5 patients with degenerative MR who underwent minimally invasive surgical mitral valve repair showed the feasibility and durability out to 2 years of implantation of the sutureless Cardioband system. This preliminary experience also showed the efficacy of Cardioband adjustability to decrease the septolateral dimension and increase leaflet coaptation. 
Following this initial clinical experience, the first-in-man fully percutaneous transfemoral implantation was successfully performed in 2013 (15).

\section{Feasibility of Cardioband implantation}

The Cardioband device was successfully implanted in all enrolled patients with no intraprocedural mortality. In the EVEREST I trial, MitraClip was successfully implanted in 24/27 patients (89\%) (16). In the TITAN trial, the procedural success rate of coronary sinus annuloplasty with the Carillon device was only 68\% (36/53 patients) in the intention-to-treat series (17), mainly due to anatomical reasons. Even if the patients enrolled in this study were carefully selected, the $100 \%$ implantation feasibility of the Cardioband suggests that this device has the potential of wide clinical application in the real world. Compared to MitraClip therapy, Cardioband closely reproduce surgical standard therapy for FMR, and leaves the door open to potential further transcatheter treatments including mitral replacement.

The learning curve is one of the most important determinants of procedure duration, as previously demonstrated with the MitraClip (18). Improvement in procedural imaging guidance is expected to shorten the learning period and, thus, procedure duration.

\section{Patient selection, procedural planning and imaging guidance}

The use of CT angiography to plan the procedure was previously validated in an animal study (19). Pre-procedural CT angiography supports patient selection (next to TEE) and procedural planning, allows the operator to rule out annular calcifications (which represent the most important anatomical contraindication to annuloplasty implantation), size the length of the posterior mitral annulus, plan the correct location for transseptal puncture, and assess the distance between the annulus and the left circumflex coronary artery to estimate the risk of injury. Moreover, CT angiography predicted the optimal fluoroscopic planes to implant the anchors during the procedure.

As for all types of transcatheter mitral valve therapy, advanced integrated imaging played a fundamental role also in procedural guidance (3D and 2D TEE live guidance and fluoroscopy) in all steps of the procedure, from transseptal puncture to anchor implantation to final adjustment.

\section{Safety}

The safety profile of the Cardioband system is on the order of magnitude of that observed with the MitraClip in real-world clinical use. Intraprocedural mortality was $0 \%$, while $2 / 31$ patients (6.5\%) died at 30 days/prior to discharge, both not device-related; 30-day mortality in the ACCESS-EU and EVEREST II high-risk registries was $3.4 \%$ and 
$4.8 \%$, respectively 20,21 . The safety of the procedure is also supported by the very low incidence of procedural and device-related major events (only 2 events). The high safety profile of the procedure is particularly relevant if compared to transcatheter mitral valve replacement, which, although clinical evidence is still very limited, seems to be associated with relatively higher morbidity and mortality in high-risk patients1.

\section{Efficacy}

The preliminary results obtained with the Cardioband system are comparable with those reported from the EVEREST I study (16) even accounting for a per-protocol analysis. Among the patients who were discharged with at least 1 successfully implanted clip (24 out of 27 patients), only $64 \%$ of the patients had $M R \leq 2+$ at 30 days (compared to more than $80 \%$ obtained with the Cardioband device). In the 2 cases with residual significant MR intraprocedurally, this was related to impossibility to contract the Cardioband after the implantation, because of a technical device failure. This device-related failure was solved with an iteration of the device after the first 10 patients and final contraction was successfully obtained in all subsequent cases.

Apart from acute MR reduction, the most significant result in terms of efficacy observed in this study is the reduction of the septolateral mitral annular dimension observed after the final adjustment (Figure 7). The majority of surgeons prefer to perform undersized annuloplasty with a complete rigid ring to address MR. For many years, both partial and complete rings have been used in patients with MR. The use of a complete ring has recently been associated with increased freedom from recurrent significant MR at follow-up (22). However, surgical experience suggested that the main determinant for repair durability after undersized annuloplasty in MR is the achievement of good leaflet coaptation rather than the type of ring: a coaptation length of at least $8 \mathrm{~mm}$ should be obtained to ensure a durable repair $(9,10)$. Coaptation length is strictly related to the reduction in septolateral dimension. After the final adjustment we were able to obtain a more than $21 \%$ reduction in septolateral dimension, which is comparable with that obtained after surgical undersized annuloplasty with a complete ring (22\% with Edwards Physio II ring and 25\% with the IMR ETlogix ring) (23). Compared to conventional surgical rings, the possibility of beating-heart adjustment of the Cardioband may allow optimizing the reduction in septolateral diameter and the final coaptation length. 


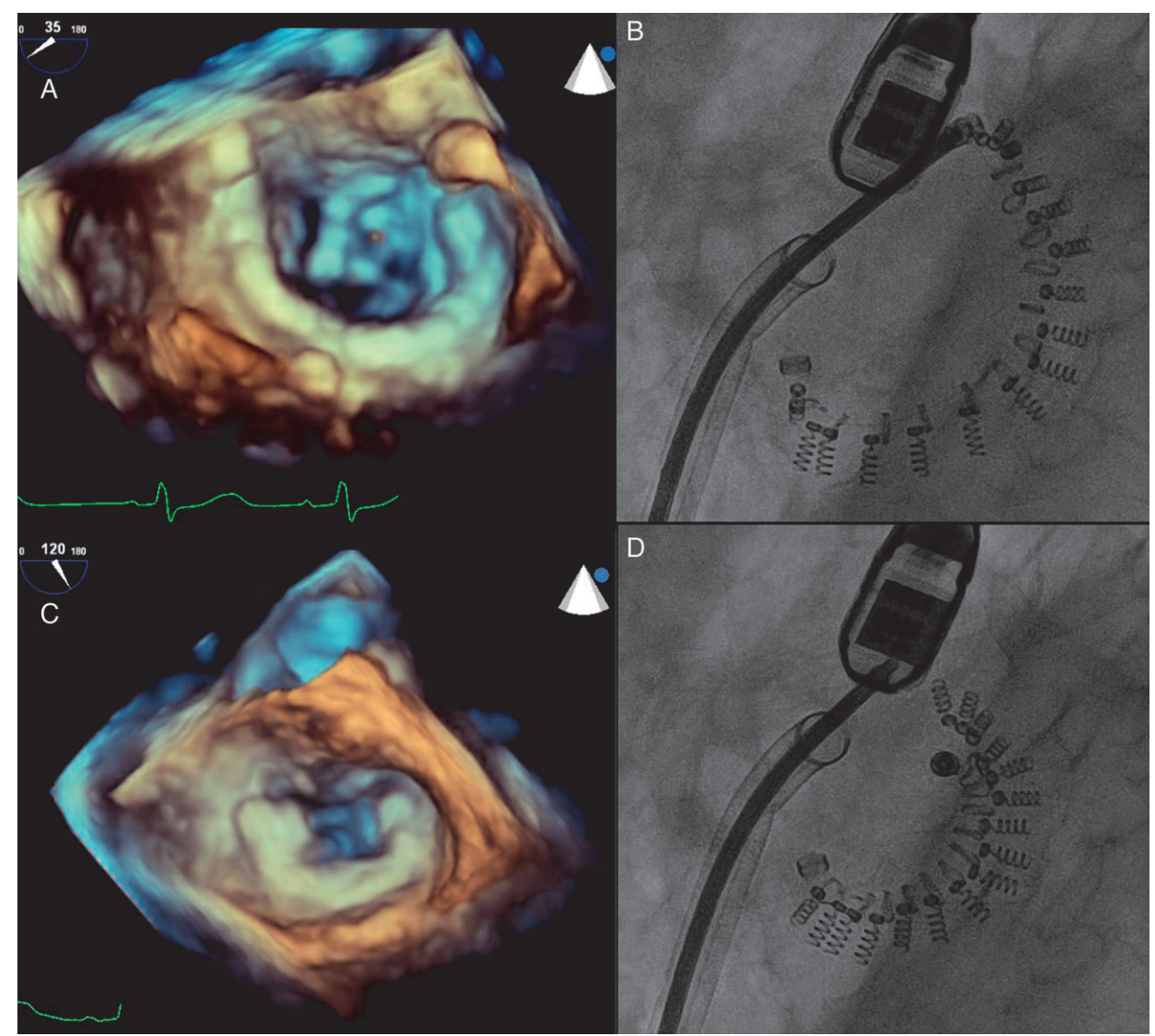

Figure 7. Three-dimensional echocardiography surgical view and fluoroscopic view of the Cardioband before ( $A$ and $B$, respectively) and after final adjustment (Panels $C$ and $D$ ).

\section{Clinical role of transcatheter mitral valve annuloplasty}

The introduction of a reliable annuloplasty device does not prevent the eligibility of other transcatheter interventions in the future. About $20 \%$ of patients still have residual MR after MitraClip, and only a minority of patients undergoing MitraClip treatment has less than 2+ MR after the procedure $(21,24,25)$. Considering that surgical experience has shown that long-term results of edge-to-edge mitral valve repair in the absence of annuloplasty are suboptimal $(26,27)$, the absence of mitral valve annuloplasty is a concern regarding the durability of MitraClip treatment. Moreover, some patients screened for MitraClip have been denied therapy due to anatomical ineligibility due to annular dilatation, suggesting that there is a clinical need for an adjunctive transcatheter mitral repair approach (28). Although the Cardioband device is currently primarily intended for use in the treatment of MR, the combination of devices may become an alternative for patients with diverse aetiologies and more complex anatomies. 
Compared to MitraClip, the Cardioband is a pure anatomical implant. The device is implanted directly on the atrial side of the posterior mitral annulus using a standardized technique. This feature, together with the high safety profile and the preserved option for future transcatheter MV replacement, make the Cardioband an ideal device for early indication in the field of catheter-based mitral treatment.

\section{Conclusion}

This study demonstrates the feasibility and safety of percutaneous direct mitral annuloplasty with the Cardioband device in high-risk patients with MR. Acute efficacy is comparable to that observed with transcatheter edge-to-edge mitral valve repair. Further investigation is needed to assess durability and long-term outcome.

This technology, based on a solid surgical background, is a promising tool to improve the results of transcatheter mitral valve interventions. It has the potential to expand the overall number of patients who could benefit from a transcatheter mitral intervention and to improve the efficacy and the durability of the currently available techniques, by the combination of annular and leaflet repair in selected patients. 


\section{References}

1. Maisano F, Alfieri O, Banai S, Buchbinder M, Colombo A, Falk V, Feldman T, Franzen O, Herrmann H, Kar S, Kuck KH, Lutter G, Mack M, Nickenig G, Piazza N, Reisman M, Ruiz CE, Schofer J, Sondergaard L, Stone GW, Taramasso M, Thomas M, Vahanian A, Webb J, Windecker S, Leon MB. The future of transcatheter mitral valve interventions: competitive or complementary role of repair vs. replacement? European heart journal 2015.

2. Lancellotti P, Tribouilloy C, Hagendorff A, Popescu BA, Edvardsen T, Pierard LA, Badano L, Zamorano JL. Recommendations for the echocardiographic assessment of native valvular regurgitation: an executive summary from the European Association of Cardiovascular Imaging. European heart journal cardiovascular Imaging 2013;14(7):611-44.

3. Grigioni F, Enriquez-Sarano M, Zehr KJ, Bailey KR, Tajik AJ. Ischemic mitral regurgitation: long-term outcome and prognostic implications with quantitative Doppler assessment. Circulation 2001;103(13):1759-64.

4. Acker MA, Bolling S, Shemin R, Kirklin J, Oh JK, Mann DL, Jessup M, Sabbah HN, Starling RC, Kubo SH. Mitral valve surgery in heart failure: insights from the Acorn Clinical Trial. The Journal of thoracic and cardiovascular surgery 2006;132(3):568-77, 577.e1-4.

5. De Bonis M, Taramasso M, Grimaldi A, Maisano F, Calabrese MC, Verzini A, Ferrara D, Alfieri O. The GeoForm annuloplasty ring for the surgical treatment of functional mitral regurgitation in advanced dilated cardiomyopathy. European journal of cardio-thoracic surgery : official journal of the European Association for Cardio-thoracic Surgery 2011;40(2):488-95.

6. Bolling SF, Deeb GM, Brunsting LA, Bach DS. Early outcome of mitral valve reconstruction in patients with end-stage cardiomyopathy. The Journal of thoracic and cardiovascular surgery 1995;109(4):676-82; discussion 682-3.

7. Silberman S, Klutstein MW, Sabag T, Oren A, Fink D, Merin O, Bitran D. Repair of ischemic mitral regurgitation: comparison between flexible and rigid annuloplasty rings. The Annals of thoracic surgery 2009;87(6):1721-6; discussion 1726-7.

8. Bax JJ, Braun J, Somer ST, Klautz R, Holman ER, Versteegh MI, Boersma E, Schalij MJ, van der Wall EE, Dion RA. Restrictive annuloplasty and coronary revascularization in ischemic mitral regurgitation results in reverse left ventricular remodeling. Circulation 2004;110(11 Suppl 1):li103-8.

9. Mihaljevic T, Lam BK, Rajeswaran J, Takagaki M, Lauer MS, Gillinov AM, Blackstone EH, Lytle BW. Impact of mitral valve annuloplasty combined with revascularization in patients with functional ischemic mitral regurgitation. Journal of the American College of Cardiology 2007;49(22):2191-201.

10. Wu AH, Aaronson KD, Bolling SF, Pagani FD, Welch K, Koelling TM. Impact of mitral valve annuloplasty on mortality risk in patients with mitral regurgitation and left ventricular systolic dysfunction. Journal of the American College of Cardiology 2005;45(3):381-7.

11. Mirabel M, lung B, Baron G, Messika-Zeitoun D, Detaint D, Vanoverschelde JL, Butchart EG, Ravaud P, Vahanian $A$. What are the characteristics of patients with severe, symptomatic, mitral regurgitation who are denied surgery? European heart journal 2007;28(11):1358-65.

12. Beeri R, Yosefy C, Guerrero JL, Abedat S, Handschumacher MD, Stroud RE, Sullivan S, Chaput M, Gilon D, Vlahakes GJ, Spinale FG, Hajjar RJ, Levine RA. Early repair of moderate ischemic mitral regurgitation reverses left ventricular remodeling: a functional and molecular study. Circulation 2007;116(11 Suppl):I288-93.

13. Maisano F, Vanermen H, Seeburger J, Mack M, Falk V, Denti P, Taramasso M, Alfieri O. Direct access transcatheter mitral annuloplasty with a sutureless and adjustable device: preclinical experience. European journal of cardio-thoracic surgery : official journal of the European Association for Cardio-thoracic Surgery 2012;42(3):524-9.

14. Alfieri O TM, Denti P, Cioni M, Blasio A, Buzzatti N, La Canna G, Maisano F. INITIAL CLINICAL EXPERIENCE WITH THE CARDIOBAND SYSTEM: DIRECT ACCESS MITRAL ANNULOPLASTY WITH A SUTURELESS AND ADJUSTABLE DEVICE. EACTS Annual Meeting 2012, Barcelona 2012. 
15. Maisano F, La Canna G, Latib A, Denti P, Taramasso M, Kuck KH, Colombo A, Alfieri O, Guidotti A, Messika-Zeitoun D, Vahanian A. First-in-man transseptal implantation of a "surgical-like" mitral valve annuloplasty device for functional mitral regurgitation. JACC Cardiovascular interventions 2014;7(11):1326-8.

16. Feldman T, Wasserman HS, Herrmann HC, Gray W, Block PC, Whitlow P, St Goar F, Rodriguez L, Silvestry F, Schwartz A, Sanborn TA, Condado JA, Foster E. Percutaneous mitral valve repair using the edge-toedge technique: six-month results of the EVEREST Phase I Clinical Trial. I Am Coll Cardiol 2005;46(11):2134-40.

17. Siminiak T, Wu JC, Haude M, Hoppe UC, Sadowski J, Lipiecki J, Fajadet J, Shah AM, Feldman T, Kaye DM, Goldberg SL, Levy WC, Solomon SD, Reuter DG. Treatment of functional mitral regurgitation by percutaneous annuloplasty: results of the TITAN Trial. European journal of heart failure 2012;14(8):931-8.

18. Ledwoch J, Franke J, Baldus S, Schillinger W, Bekeredjian R, Boekstegers P, Hink U, Kuck KH, Ouarrak T, Mollmann H, Nickenig G, Senges J, Franzen O, Sievert H. Impact of the learning curve on outcome after transcatheter mitral valve repair: results from the German Mitral Valve Registry. Clinical research in cardiology : official journal of the German Cardiac Society 2014;103(11):930-7.

19. Sundermann SH, Gordic S, Manka R, Cesarovic N, Falk V, Maisano F, Alkadhi H. Computed tomography for planning and postoperative imaging of transvenous mitral annuloplasty: first experience in an animal model. The international journal of cardiovascular imaging 2015;31(1):135-42.

20. Glower DD, Kar S, Trento A, Lim DS, Bajwa T, Quesada R, Whitlow PL, Rinaldi MJ, Grayburn P, Mack MJ, Mauri L, McCarthy PM, Feldman T. Percutaneous mitral valve repair for mitral regurgitation in high-risk patients: results of the EVEREST II study. J Am Coll Cardiol 2014;64(2):172-81.

21. Maisano F, Franzen O, Baldus S, Schafer U, Hausleiter J, Butter C, Ussia GP, Sievert H, Richardt G, Widder JD, Moccetti T, Schillinger W. Percutaneous mitral valve interventions in the real world: early and 1-year results from the ACCESS-EU, a prospective, multicenter, nonrandomized post-approval study of the MitraClip therapy in Europe. Journal of the American College of Cardiology 2013;62(12):1052-61.

22. Kwon MH, Lee LS, Cevasco M, Couper GS, Shekar PS, Cohn LH, Chen FY. Recurrence of mitral regurgitation after partial versus complete mitral valve ring annuloplasty for functional mitral regurgitation. J Thorac Cardiovasc Surg 2013;146(3):616-22.

23. Wong VM, Wenk JF, Zhang Z, Cheng G, Acevedo-Bolton G, Burger M, Saloner DA, Wallace AW, Guccione $J M$, Ratcliffe MB, Ge L. The effect of mitral annuloplasty shape in ischemic mitral regurgitation: a finite element simulation. The Annals of thoracic surgery 2012;93(3):776-82.

24. Schillinger W, Hunlich M, Baldus S, Ouarrak T, Boekstegers P, Hink U, Butter C, Bekeredjian R, Plicht B, Sievert H, Schofer J, Senges J, Meinertz T, Hasenfuss G. Acute outcomes after MitraClip therapy in highly aged patients: results from the German TRAnscatheter Mitral valve Interventions (TRAMI) Registry. EuroIntervention 2013;9(1):84-90.

25. Taramasso M, Maisano F, Latib A, Denti P, Buzzatti N, Cioni M, La Canna G, Colombo A, Alfieri O. Clinical outcomes of MitraClip for the treatment of functional mitral regurgitation. Eurolntervention 2014;10(6):746-52.

26. Maisano F, Caldarola A, Blasio A, De Bonis M, La Canna G, Alfieri O. Midterm results of edge-to-edge mitral valve repair without annuloplasty. J Thorac Cardiovasc Surg 2003;126(6):1987-97.

27. De Bonis M, Lapenna E, Maisano F, Barili F, La Canna G, Buzzatti N, Pappalardo F, Calabrese M, Nisi T, Alfieri O. Long-term results ( $</=18$ years) of the edge-to-edge mitral valve repair without annuloplasty in degenerative mitral regurgitation: implications for the percutaneous approach. Circulation 2014;130(11 Suppl 1):S19-24.

28. Grayburn PA, Roberts BJ, Aston S, Anwar A, Hebeler RF, Jr., Brown DL, Mack MJ. Mechanism and severity of mitral regurgitation by transesophageal echocardiography in patients referred for percutaneous valve repair. Am J Cardiol 2011;108(6):882-7. 


\section{Chapter}

\section{Transcatheter mitral valve interventions: Pathophysiological considerations in choosing reconstruction versus transcatheter valve implantation}




\begin{abstract}
Over the last years, several surgical procedures have inspired percutaneous devices to treat mitral regurgitation (MR) in high-risk or inoperable patients, including valve repair and valve replacement technologies.

As the field of transcatheter mitral valve intervention is rapidly developing, the interventional community is wondering whether valve implantation should become the leading percutaneous mitral valve therapy, and whether the introduction of reliable replacement technology will reduce the clinical value of repair approaches.

Since clinical experience with transcatheter mitral valve implantation (TMVI) is really preliminary and all the patients treated with this approach are so far really sick candidates with prohibitive risk, it is really difficult to properly define which patients could benefit the more from TMVI versus transcatheter mitral valve repair (TMVR). The specific aim of this report is to state few important clinical and pathophysiological considerations in order to clarify when and why a repair strategy should be preferred over replacement.
\end{abstract}




\section{Introduction}

Over the last years, several surgical procedures have inspired percutaneous devices to treat mitral regurgitation (MR) in high-risk or inoperable patients, including valve repair and valve replacement technologies.

Today, transcatheter repair with the MitraClip system (Abbott Vascular Inc, Menlo Park, CA, USA) is the most advanced technology available for clinical use, with proven safety, efficacy and durability in different clinical settings [1-3]. Beyond MitraClip system, different technologies with diversified approaches are under development to improve the transcatheter mitral valve repair (TMVR) therapeutic spectrum, ranging from leaflet and annular repair to left ventricular remodelling.

Feasibility of transcatheter mitral valve implantation (TMVI) has been initially showed in patients with previous open-heart surgery and a degenerated bioprosthesis or with recurrent MR following surgical annuloplasty (valve-in-valve and valve-in-ring procedures) $[4,5]$ or in case of calcified mitral valve $[6,7]$.

TMVI in native valve anatomy has been recently reported in high-risk patients [8], mainly with functional aetiology, with different devices, which are under preliminary clinical evaluation (Table 1).

Table 1. Transcatheter mitral valve prostheses implanted in humans with preliminary reported outcomes.

\begin{tabular}{|l|l|l|l|l|}
\hline \multicolumn{2}{|c|}{ CardiAQ } & & \\
\end{tabular}

As the field of transcatheter mitral valve intervention is rapidly developing, the interventional community is wondering whether valve implantation should become the leading percutaneous mitral valve therapy, and whether the introduction of reliable replacement technology will reduce the clinical value of repair approaches.

Since clinical experience with TMVI is really preliminary and all the patients treated with this approach are so far really sick candidates with prohibitive risk, it is really diffi- 
cult to properly define which patients could benefit the more from TMVI versus TMVR. The several technical challenges and unsolved issues that specifically refer to both TMVI and TMVR are not the subject of this manuscript and therefore they will not be here discussed. The specific aim of this report is to state few important clinical and pathophysiological considerations in order to clarify when and why a repair strategy should be preferred over replacement, strongly believing that in the next future TMVI and TMVR will play a complementary rather than competitive role in the routine clinical practice.

\section{Valve repair is more respectful of the physiology}

The mitral valve is an integrated part of the left ventricle (LV). In order to point out the complexity of the interaction between the valve components and the LV, this anatomical structure is usually defined as "mitral complex", which is composed by the leaflets, the annulus, the chordae, the papillary muscles, and it is in continuity with the atrial wall and the aortic valve.

From an anatomical standpoint, the mitral valve plays a fundamental role in the demarcation of the inflow-outflow ventricular tracts. This anatomical peculiarity has important hemodynamic implications, since it directs the blood flow through the heart chambers. Imaging studies $[9,10]$ showed that in the LV during diastole the free edge of the anterior mitral leaflet direct the blood flow towards the lateral LV wall. Part of the blood volume is thus redirected towards the outflow tract, according to a vortex-like pattern. Loss of the vortex-like circulation is observed in patients with LV dysfunction and heart failure. This non-physiological flow results in increased LV stress and less efficient work and may contribute to the ongoing maladaptive remodelling process, which is observed in heart failure[11, 12]. Since the physiological vortex-like circulation is preserved only after mitral repair, while this pattern is compromised after mitral replacement [13], it is arguable that a better preservation of the physiology and of hemodynamic associated with repair could provide improved clinical outcomes compared to valve replacement.

\section{Preservation of the mitral-LV structural contiguity}

Mitral valve replacement is associated with a discontinuation of the structural contiguity of mitral apparatus and LV, which results in LV maladaptive remodelling and worse performance, since it affects the reciprocal mitral-LV "crosstalk". Moreover, the fixation of a prosthetic valve to the mitral annulus, which is normally a dynamic threedimensional structure in direct contiguity to the basal portion of the LV, makes the annulus a static structure. This may be an issue mainly in heart failure patients with 
reduced $E F$, since it leads to a reduction of the systolic contribution of the basal portion to the ejection.

\section{Valve replacement is associated with prosthetic-related events}

Life expectancy of a patient implanted with a prosthetic valve is reduced, mainly due to thromboembolic and haemorrhagic events and to the risk of prosthetic-related endocarditis [14]. Thromboembolic complications are the most important cause of morbidity and mortality in patients with a prosthetic heart valve, with an estimated incidence of clinical events ranging from $0.6 \%$ to $2.3 \%$ per patient-year $[15,16]$. The risk of thromboembolic complications is similar for patients with mechanical valves on warfarin therapy and bioprosthetic valves without warfarin therapy. Moreover, obstruction of a prosthetic valve may be caused by thrombus formation, pannus ingrowth, or their combination. The incidence of obstructive valve thrombosis varies between $0.3 \%$ and $1.3 \%$ per patient-year in patients with mechanical valves $[16,17]$. Haemorrhagic complications are another major concern related to long-term anticoagulation, with an annual risk of $\approx 1 \%$ per patient-year $[15,16,18]$.

The incidence of prosthetic valve endocarditis is $\approx 0.5 \%$ per patient-year, even with appropriate antibiotic prophylaxis. Prosthetic valve endocarditis is an extremely serious condition with high mortality rates (30\% to $50 \%)[15,19]$.

\section{Durability: a limitation of repair and replacement}

Durability of a tissue valve in mitral position is a major concern in surgery. Due to the high-pressure gradient between left atrium and LV, durability of biological prosthesis in mitral position is largely suboptimal, especially in patients younger than 65 years. On average, the degeneration process of a biological prosthesis starts 5 years after operation in mitral position [16]. So far, durability of a transcatheter mitral prosthesis has represented a minor concern, since patients treated are mainly high-risk, elderly or inoperable patients. However, if transcatheter procedures aim to expand indications to a lower risk and younger population, durability of the device should be considered a priority.

Durability is off course a major issue also for mitral repair. Acute successful reduction of MR is fundamental to provide durable results in TMVR. Four-years results of the EVEREST II trial [20] showed that, when acute procedural result is optimal, transcatheter mitral repair is durable. However, in case of MR persistence or recurrence after mitral repair, outcomes are poor [20-24] This suggests that patients eligible for reparative procedures should be treated only in high-volume high-experienced centres. 


\section{TMVI and valve thrombosis: need for anticoagulation}

Valve thrombosis represents a major issue in this preliminary phase of the development of TMVI. The Fortis Edwards Clinical Trial recently stopped patients' enrolment to further investigate this safety issue, since evidence of valve thrombosis has been observed in some of the patients implanted.

All the patients who undergo TMVI would probably require long-term anticoagulation. Although at the moment no long-term data are available, it is likely that duration of anticoagulation will be long-life.

\section{Lessons learned from surgery: the complementary role of repair and replacement in degenerative and functional MR}

Although transcathteter interventions may act differently, surgical background can be source of inspiration for the future. In patients with degenerative MR (DMR), effective and timely correction of MR has a highly beneficial impact on the prognosis and can even be associated with a life expectancy and a quality of life similar to those of the age-matched general population $[25,26]$. The positive prognostic benefit of early intervention in young patients with DMR is lost when a prosthesis is implanted, due to the prosthesis related morbidity and mortality [14].

The benefits of surgical repair over replacement in patients with functional MR (FMR) are less clear compared to DMR patients. Currently, the majority of the patients who undergo transcatheter mitral procedure are high-risk patients with FMR. In surgical practice, mitral repair is more often performed in patients with earlier diagnosis (smaller ventricle, less advanced anatomical and functional deterioration). In these cases, the chance of successful and durable repair is higher, and prosthesis related complications are avoided.

Traditionally, mitral valve replacement has been associated with higher risk of early mortality due to less efficient preservation of left ventricular function. Unfortunately there is lack of properly designed studies to fully support the choice between repair and replacement in surgical candidates. Acker et al. [27] in a large multicentre randomized trial compared mitral repair and mitral replacement in 251 patients with severe ischemic FMR. The authors did not observe any significant difference in LV reverse remodeling or survival at 12 months, despite a higher recurrence of MR in repair group. The conclusion was that replacement provided a more durable correction of $M R$, but this was not associated with difference in clinical outcome. In heart failure patients with FMR, repair can be beneficial even at the cost of a higher recurrence rate, due to a superior safety profile. 


\section{Safety should be the first indicator of success for transcatheter mitral intervention: towards a prognostic approach}

Early timing is crucial to achieve a substantial prognostic benefit: restore expectancy of life in DMR patients and obtain reverse remodelling in FMR patients [21, 25]. When patients are treated in a too advanced clinical status, outcomes become poor and any intervention is unable to influence the prognosis modifying the natural history of the disease. The impact of any mitral intervention is much more efficient when executed early in the clinical course of the disease. Several issues raise concerns on the role of TMVI in patients in their early stage of the disease. Only a very safe procedure can justify a transcatheter therapy as a first-line option. If we consider safety and early indication, repair should be preferred to TMVI due to the lack of the consequences of a prosthesis (including anticoagulant therapy, risk of structural valve deterioration and risk of infection).

\section{Conclusions}

From a pathophysiological and clinical standpoint, durability, safety and distortion of the physiology remain major concerns regarding TMVI as compared to TMVR. Impact on physiology is minimal and safety profile is higher. Therefore, TMVR may in the future aspire to a prognostic approach and to early indication in lower risk patients.

TMVI will be a complementary therapeutic option for a great number of patients, especially in an advanced phase of the disease, with both DMR and FMR, who are not amenable for valve repair. Transcatheter mitral repair should remain in our opinion the first-line therapy whenever feasible and should be mainly performed in highexperienced centres. Careful patient selection will be extremely important to define the complementary clinical role of TMVI and TMVR. 


\section{References}

1. Lim, D.S., et al., Improved Functional Status and Quality of Life in Prohibitive Surgical Risk Patients With Degenerative Mitral Regurgitation Following Transcatheter Mitral Valve Repair with the MitraClip(R) System. J Am Coll Cardiol, 2013.

2. Maisano, F., et al., Percutaneous mitral valve interventions in the real world: early and 1-year results from the ACCESS-EU, a prospective, multicenter, nonrandomized post-approval study of the MitraClip therapy in Europe. J Am Coll Cardiol, 2013. 62(12): p. 1052-61.

3. Taramasso, M., et al., Clinical outcomes of MitraClip for the treatment of functional mitral regurgitation. Eurolntervention, 2014. 10(6): p. 746-52.

4. Descoutures, F., et al., Transcatheter valve-in-ring implantation after failure of surgical mitral repair. Eur J Cardiothorac Surg, 2013. 44(1): p. e8-e15.

5. Cheung, A. and A. Al-Lawati, Transcatheter mitral valve-in-valve implantation: current experience and review of literature. Curr Opin Cardiol, 2013. 28(2): p. 181-6.

6. Fassa, A.A., et al., Transseptal transcatheter mitral valve implantation for severely calcified mitral stenosis. JACC Cardiovasc Interv, 2014. 7(6): p. 696-7.

7. Hasan, R., et al., First in human transapical implantation of an inverted transcatheter aortic valve prosthesis to treat native mitral valve stenosis. Circulation, 2013. 128(6): p. e74-6.

8. Cheung, A., et al., Short-term results of transapical transcatheter mitral valve implantation for mitral regurgitation. J Am Coll Cardiol, 2014. 64(17): p. 1814-9.

9. Kilner, P.J., et al., Asymmetric redirection of flow through the heart. Nature, 2000. 404(6779): p. 759-61.

10. Debonnaire, P., et al., Contemporary imaging of normal mitral valve anatomy and function. Curr Opin Cardiol, 2012. 27(5): p. 455-64.

11. Hsiao, A., et al., Inlet and outlet valve flow and regurgitant volume may be directly and reliably quantified with accelerated, volumetric phase-contrast MRI. J Magn Reson Imaging, 2014.

12. Pedrizzetti, G., F. Domenichini, and G. Tonti, On the left ventricular vortex reversal after mitral valve replacement. Ann Biomed Eng, 2010. 38(3): p. 769-73.

13. Faludi, R., et al., Left ventricular flow patterns in healthy subjects and patients with prosthetic mitral valves: an in vivo study using echocardiographic particle image velocimetry. J Thorac Cardiovasc Surg, 2010. 139(6): p. 1501-10.

14. Puvimanasinghe, J.P., et al., Prognosis after aortic valve replacement with a bioprosthesis: predictions based on meta-analysis and microsimulation. Circulation, 2001. 103(11): p. 1535-41.

15. Vesey, J.M. and C.M. Otto, Complications of prosthetic heart valves. Curr Cardiol Rep, 2004. 6(2): p. 10611.

16. Hammermeister, K., et al., Outcomes 15 years after valve replacement with a mechanical versus a bioprosthetic valve: final report of the Veterans Affairs randomized trial. J Am Coll Cardiol, 2000. 36(4): p. 1152-8.

17. Roudaut, R., K. Serri, and S. Lafitte, Thrombosis of prosthetic heart valves: diagnosis and therapeutic considerations. Heart, 2007. 93(1): p. 137-42.

18. Pibarot, P. and J.G. Dumesnil, Prosthetic heart valves: selection of the optimal prosthesis and long-term management. Circulation, 2009. 119(7): p. 1034-48.

19. Butchart, E.G., et al., Recommendations for the management of patients after heart valve surgery. Eur Heart J, 2005. 26(22): p. 2463-71.

20. Mauri, L., et al., 4-year results of a randomized controlled trial of percutaneous repair versus surgery for mitral regurgitation. J Am Coll Cardiol, 2013. 62(4): p. 317-28.

21. De Bonis, M., et al., Recurrence of mitral regurgitation parallels the absence of left ventricular reverse remodeling after mitral repair in advanced dilated cardiomyopathy. Ann Thorac Surg, 2008. 85(3): p. 932-9. 
22. Crabtree, T.D., et al., Recurrent mitral regurgitation and risk factors for early and late mortality after mitral valve repair for functional ischemic mitral regurgitation. Ann Thorac Surg, 2008. 85(5): p. 1537-42; discussion 1542-3.

23. Grayburn, P.A., et al., Relationship between the magnitude of reduction in mitral regurgitation severity and left ventricular and left atrial reverse remodeling after MitraClip therapy. Circulation, 2013. 128(15): p. 1667-74.

24. Paranskaya, L., et al., Residual mitral valve regurgitation after percutaneous mitral valve repair with the MitraClip(R) system is a risk factor for adverse one-year outcome. Catheter Cardiovasc Interv, 2013. 81(4): p. 609-17.

25. Detaint, D., et al., Surgical correction of mitral regurgitation in the elderly: outcomes and recent improvements. Circulation, 2006. 114(4): p. 265-72.

26. Ling, L.H., et al., Early surgery in patients with mitral regurgitation due to flail leaflets: a long-term outcome study. Circulation, 1997. 96(6): p. 1819-25.

27. Acker, M.A., et al., Mitral-valve repair versus replacement for severe ischemic mitral regurgitation. $N$ Engl J Med, 2014. 370(1): p. 23-32. 



\section{Chapter}

\section{Conventional surgery and transcatheter closure via surgical transapical approach for paravalvular leak repair in high-risk patients: results from a single center experience}

Maurizio Taramasso MD, Francesco Maisano MD, Azeem Latib MD, Paolo Denti MD, Andrea Guidotti, Alessandro Sticchi MD, Vasilis Panoulas MD, Gennaro Giustino MD, Alberto Pozzoli MD, Nicola Buzzatti MD, Linda Cota MD, Michele De Bonis MD, Matteo Montorfano MD, Alessandro Castiglioni MD, Andrea Blasio MD, Giovanni La Canna MD, Antonio Colombo MD, Ottavio Alfieri MD 


\begin{abstract}
OBJECTIVES: Paravalvular leaks (PVL) occur in up to $17 \%$ of all surgically implanted prosthetic valves. Reoperation is associated with high morbidity and mortality. Transcatheter closure via surgical transapical approach (TAp) is an emerging alternative for selected high-risk patients with PVL. The aim of this study is to compare the in-hospital outcomes of patients who underwent surgery and TA-closure for PVL in our singlecenter experience.
\end{abstract}

METHODS: From October 2000 and June 2013, 139 patients with PVL were treated in our Institution. All the TA procedures were performed under general anesthesia in a hybrid operative room: in all but 1 case an Amplatzer Vascular Plug III device was utilized.

RESULTS: 139 patients with PVL were treated: 122 patients (87.3\%) underwent surgical treatment (68\% mitral-PVL; 32\% aortic-PVL) and 17 patients $(12.2 \%)$ underwent transcatheter closure via a surgical TAp approach (all the pts had mitral PVL; 1 case had combined mitral and aortic PVLs); in $35 \%$ of surgical patients and in $47 \%$ of TAp patients, multiple PVLs were present.

Mean age was $62.5 \pm 11$ years; Logistic EuroScore was $15.4 \pm 3$. Most of the patients were in NYHA functional class III-IV (57\%). Symptomatic hemolysis was present in 35\% of the patients, and it was particularly frequent in the TAp (70\%). Many patients had more than 1 previous cardiac operation (46\% overall and $82 \%$ of TAp patients were at their second of reoperation). Acute procedural success was $98 \%$. In-hospital mortality was 9.3\%; no in-hospital deaths occurred in patients treated through TAp approach). All the patients had less than moderate residual valve regurgitation after the procedure. Surgical treatment was identified as a risk factor for in-hospital death at univariate analysis (OR 8, Cl 95\% 1.8-13; p=0.05). Overall actuarial survival at follow-up was $39.8 \pm 7 \%$ at 12 years and it was reduced in patients who had more than 1 cardiac reoperation ( $42 \pm 8 \%$ Vs $63 \pm 6 \%$ at 9 years; $p=0.009$ ).

CONCLUSIONS: Transcatheter closure via a surgical TAp approach appears to be a safe and effective therapeutic option in selected high-risk patients with PVL and is associated with a lower hospital mortality than surgical treatment, in spite of higher predicted risk. Long-term survival remains suboptimal in these challenging patients. 


\section{Introduction}

Paravalvular leak (PVL) is a common complication after surgical valve replacement, with reported incidences at follow-up of $2 \%$ to $10 \%$ for prosthetic valves in the aortic position and $7 \%$ to $17 \%$ in the mitral position (1-3). Although most PVLs remain clinically silent, $1-3 \%$ of patients require reoperations because of heart failure, hemolysis or a combination of both (4-6). Surgical closure of PVL remains the most common therapy for these defects; however, re-do surgery is often associated with high morbidity and mortality rates as well as a high risk of recurrence $(1,7)$. Furthermore, mortality increases progressively with the number of reoperations (up 37\% after the third reoperation) (7). Therefore, percutaneous closure of PVL has been proposed as an attractive and less invasive alternative to surgical closure and has been found to alleviate the consequences and symptoms of PVLs in high-risk patients (8).

Percutaneous PVL closure can be performed antegradely or retrogradely. In the past, most of the procedures were performed through venous or arterial transfemoral access. However, both of these approaches may be extremely complex and technically demanding. A very simple alternative access for transcatheter PVL closure is the transapical approach (TAP), which may be performed with a small surgical incision with limited exposure of the left ventricle, allowing a more direct access to the therapeutic target (9). The aim of this study is to report the in-hospital outcomes of patients who underwent surgery and TAp-closure for PVLs in our single-center experience.

\section{Methods}

We retrospectively analyzed the clinical and echocardiographic data of a cohort of consecutive patients who underwent surgical PVL closure without associated procedure between October 2000 and June 2013 and all the patients who underwent transcatheter PVL closure through a surgical TA approach between January 2012 and June 2013. Clinical, doppler echocardiographic, operative, and outcome data were collected prospectively. All the patients underwent preoperative coronary angiography and transesophageal Doppler echocardiography (TEE). Periprosthetic paravalvular leak was defined as a regurgitant jet, demonstrated by TEE, originating between the outer margin of the prosthetic sewing ring and the native tissues around the valve. The severity of the PVL was defined as mild $(1+/ 4+)$, moderate $(2+/ 4+)$, moderate-to-severe $(3+/ 4+)$ and severe $(4+/ 4+)$ using an integrative approach, as recommended by the current guidelines (10). All the patients included in the study had preoperative moderate-tosevere ( $23 \%$ of the cases) or severe (77\% of the cases) PVL.

All the patients who underwent TAp closure underwent preoperative 3D TEE and angio-CT scan for a better definition of the leak anatomy. Patients were considered for surgical or transcatheter PVL closure if the following criteria were met: severe symp- 
toms of dyspnea (NYHA class III-IV or class II with significant lifestyle or occupational impairment) or clinically significant hemolytic anemia, moderately severe or severe paravalvular prosthetic regurgitation, absence of active endocarditis. Symptomatic hemolysis was defined as hemolytic anemia (hemoglobin $\leq 10 \mathrm{~g} / \mathrm{dl}$, lactate dehydrogenase $\geq 600 \mathrm{mg} / \mathrm{dl}$, haptoglobin $\leq 10 \mathrm{mg} / \mathrm{dl}$ ) requiring $>2 \mathrm{U}$ of blood transfusions and/or erythropoietin injections within 90 days to maintain hemoglobin $\geq 10 \mathrm{~g} / \mathrm{dl}$, without any other source of blood loss (11). Patients with associated prosthetic dysfunction and patients with active acute endocarditis were excluded from this study. The individual selection of treatment (surgery vs. transcatheter) was based on a multimodality decision making process including evaluation of surgical risk by Logistic EuroSCORE (http://www.euroscore.org/) as well as adjunctive risk evaluation such as the presence of advanced liver cirrhosis, severe neurological impairment and frailty.

Acute procedural success was defined as significant reduction in paravalvular regurgitation to mild or less residual regurgitation, in absence of the need for emergency surgery in patients undergoing TA approach or procedural death.

The study protocol was performed in accordance with the institutional ethics committee, and all patients gave informed written consent for the procedures. The need for consent to participate in this research study was waived in view of its observational, retrospective and anonymous nature.

\section{Surgical treatment}

The majority of the patients underwent surgery through a midline sternotomy and moderate hypothermic cardiopulmonary bypass. A minority of the patients with isolated mitral PVL underwent mitral surgery on beating heart via a right thoracotomy (7 patients). In case of mitral PVL, the mitral prosthesis was approached through a conventional left atriotomy; in case of aortic PVL, the aortic prosthesis was approached through transversal aortotomy. After the inspection of the prosthesis and the identification of the PVL, repair was performed with interrupted Tycron 2-0 sutures with pledgets (median 3 sutures). If repair was judged unfeasible by the surgeon, replacement of the prosthesis was performed. The use of interrupted over running suture for valve replacement depended on surgeons preferences.

\section{Transcatheter closure through surgical Transapical Access}

All procedures were performed under general anesthesia either in a hybrid operating theatre or catheterization laboratory with fluoroscopic and Real-time 3D TEE guidance. Unfractioned heparin was administered in all patients aiming for an activated clotting time $(A C T)>250$ seconds. A left anterolateral mini thoracotomy was performed to expose the left ventricular apex. A purse-string suture was placed on the apex, it was then punctured under direct visualization, and a short 6F sheath was inserted into the left 
ventricle. A 0.035" Terumo straight-tip wire, directed by the sheath or a multipurpose diagnostic catheter was then used to cross the defect into the left atrium in all the mitral procedures. In the single aortic procedure, the leak was crossed retrograde by the wire from the aortic side through femoral artery access and then the wire was recaptured from the apical access. The 6Fr sheath was then advanced across the defect. At this stage, two 0.035" J-tip guidewires were advanced through the sheath, the sheath was removed and a 6Fr sheath was advanced over each guidewire, thus allowing deployment of at least 2 occluder devices if needed. In cases where multiple devices were required, these were either deployed simultaneously or sequentially. The occluder device used in our study was the Amplatzer Vascular Plug $Ш$ in all but 1 cases, in which an Amplatzer Vascular Plug II was used (AGA Medical Corp., Plymouth, Minnesota).

\section{Statistical Analysis}

Statistical analysis has been conducted using the JMP 8.0 software (SAS Institute Inc, NC, USA). Continuous variables are presented as mean \pm SD and categorical variables are expressed as percentages. Univariable comparisons have been performed with Student's unpaired t-test for continuous normally distributed data, which has been tested by the Shapiro-Wilk normality test; Mann-Whitney rank sum test was used for comparisons of non parametric continuous data and the chi-square test for categorical data. Univariate analysis for predictors of in-hospital death was performed with nominal logistic regression. Long-term survival was presented using the Kaplan-Meier method; comparisons were performed with Log-Rank test.

\section{Results}

\section{Patient characteristics}

A total of 139 patients with PVL were treated: 122 patients (87.3\%) underwent surgical treatment (68\% mitral-PVL; 32\% aortic-PVL) and 17 patients $(12.2 \%)$ underwent transcatheter closure via a surgical TAp approach (all the pts had mitral PVL; 1 case had combined mitral and aortic PVLs); in $35 \%$ of surgical patients and in $47 \%$ of TAp patients, multiple PVLs were present.

Mean age of the overall study population was $62.5 \pm 11$ years. Predicted surgical risk with Logistic EuroScore was 15.4 \pm 3 . Most of the patients were in NYHA functional class III-IV (57\%). Symptomatic hemolysis was present in $35 \%$ of the patients, and it was particularly frequent in the TAp (70\%). Many patients had more than 1 previous cardiac operation ( $46 \%$ overall and $82 \%$ of TAp patients were at their second of more reoperation). 
Demographic and clinical features of all the patients and of the patients of TAp subgroup are detailed in Table 1.

Table 1. Preoperative clinical features of overall study population and of TAp subgroup

\begin{tabular}{lll}
\hline & $\begin{array}{l}\text { Overall } \\
(\mathrm{n}=139)\end{array}$ & $\begin{array}{l}\text { TAp subgroup } \\
(\mathrm{n}=17)\end{array}$ \\
\hline Age (years) & $62.5 \pm 11$ & $67.6 \pm 9$ \\
Female gender $(\mathrm{n}, \%)$ & $48(34)$ & $8(49.9)$ \\
Log EuroScore (\%) & $15.4 \pm 3$ & $18.7 \pm 8$ \\
Log EuroScore $>25 \%(\mathrm{n}, \%)$ & $27(19)$ & $4(23)$ \\
Number of previous cardiac surgeries (mean \pm SD) & $1.7 \pm 1$ & $2.4 \pm 0.8$ \\
More than 1 reoperation (n, \%) & $64(46)$ & $14(82)$ \\
Peripheral artery disease (n, \%) & $12(9)$ & $1(5)$ \\
Previous endocarditis ( $\mathrm{n}, \%)$ & $40(29)$ & $7(41)$ \\
Atrial fibrillation (n, \%) & $83(60)$ & $10(59)$ \\
Chronic Renal Failure (n, \%) & $22(16)$ & $4(23)$ \\
COPD (n, \%) & $19(14)$ & $5(30)$ \\
Symptomatic hemolysis (n, \%) & $49(35)$ & $12(70)$ \\
Diabetes (n, \%) & $20(14)$ & $2(12)$ \\
NYHA functional class III-IV (n, \%) & $80(57)$ & $10(59)$ \\
LV Ejection fraction (mean $\pm S D)$ & $58.9 \pm 5$ & $56.7 \pm 7$ \\
\hline
\end{tabular}

$\mathrm{TAp}=$ Transapical; $\mathrm{COPD}=$ Chronic Obstructive Pulmonary Disease; NYHA= New York Heart Association; LV= left ventricle; SD=standard deviation.

${ }^{\dagger}$ Student's unpaired t-test for continuous data; chi-square test for categorical data.

\section{Procedural and in-hospital outcomes}

Acute procedural success was 98\% (136/139 patients: 2 patients treated with conventional surgery with residual severe PVL required redo-surgery before discharge; 1 patient treated with TAp approach had device embolization and required emergent conversion to conventional open heart surgery). A mean of $2.3 \pm 0.8$ plugs were implanted in TAp group (min 1 plug; max 4 plugs). The surgical procedures included the reattachment of the prosthesis with interrupted 2-0 Tycron sutures with pledgets in 79 patients (65\%) and replacement of the prosthesis in 43 patients (35\%).

In-hospital mortality was $9.3 \%$ (13/139 patients, all treated with conventional surgery: 7 patients died from acute cardiogenic shock, 4 patients died from multi-organ failure secondary to sepsis, 1 patient died from perioperative acute myocardial infarction, 1 patients died from bleeding complications and haemorrhagic shock). No inhospital deaths occurred in patients treated through TAp approach.

Overall, postoperative median mean length-of-stay (LOS) was 7 days (IQR 5;13); in patient treated with TAp approach median LOS was 8 days (IQR 4;12). 

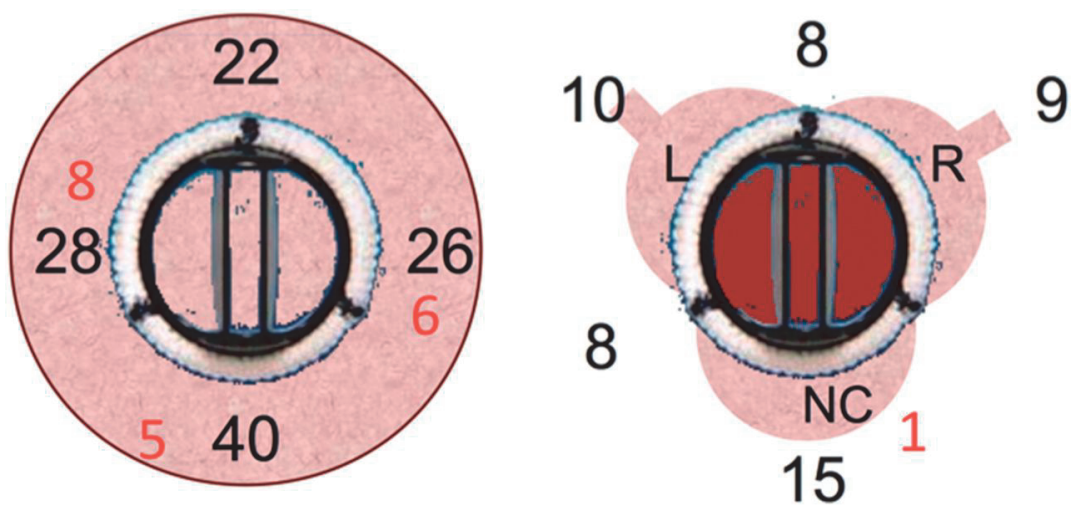

Figure 1: Locations of perivalvular leaks in mitral and aortic position; $35 \%$ of surgical patients and $47 \%$ of transapical patients had multiple leaks (black: surgical group; red: transapical group).

No differences in peri-procedural outcomes were observed according to type of prosthesis (biological Vs mechanical) ( $p=0.5$ ) or according to leak location (mitral Vs aortic; $\mathrm{p}=0.1$ ).

Post-procedural echocardiography showed a residual significant PVL in 2 patients of surgical group, who required redo surgery within the same admission. All the patients treated through TAp approach had less than moderate residual PVL. Table 2 summarizes the peri-procedural results. Table 3 shows the univariate analysis of risk factors for in-hospital death.

Surgical treatment was identified as the only predictor of in-hospital death at nominal logistic analysis (OR 8; $\mathrm{p}=0.05 ; \mathrm{Cl} 95 \% 1.8-13$ ). No independent predictors of inhospital death were identified at multivariable analysis.

Table 2. Perioperative results of overall study population and of TAp subgroup

\begin{tabular}{lll}
\hline & $\begin{array}{l}\text { Overall } \\
(\mathrm{n}=139)\end{array}$ & $\begin{array}{l}\text { TAp subgroup } \\
(\mathrm{n}=17)\end{array}$ \\
\hline In-hospital mortality $(\mathrm{n}, \%)$ & $13(9.3)$ & 0 \\
Acute procedural success $(\mathrm{n}, \%)$ & $136(98)$ & $16(94)$ \\
Severe Acute Kidney Injury (n, \%) & $5(4)$ & $1(5)$ \\
LCOS (n, \%) & $6(5)$ & 0 \\
Major Infection/Sepsis (n, \%) & $6(5)$ & 0 \\
Major stroke (n, \%) & $1(0.7)$ & 0 \\
AMI (n, \%) & $1(0.7)$ & 0 \\
Residual significant PVL at discharge $(n, \%)$ & $2(1)$ & 0 \\
\hline
\end{tabular}

$\mathrm{AMI}=$ Acute Myocardial Infarction; LCOS= low cardiac output syndrome; PVL= perivalvular leak; SD= standard deviation

${ }^{\dagger}$ Chi-square test 
Table 3. Univariate analysis of risk factors for in-hospital death.

\begin{tabular}{|c|c|c|c|}
\hline & $\begin{array}{l}\text { In-hospital deaths } \\
(n=13)\end{array}$ & $\begin{array}{l}\text { In-hospital survivors } \\
(\mathrm{n}=126)\end{array}$ & $p$-value ${ }^{\dagger}$ \\
\hline Surgical treatment (n, \%) & $13(100)$ & $109(86)$ & 0.05 \\
\hline Age (years, mean $\pm S D$ ) & $62 \pm 11$ & $64 \pm 12$ & 0.5 \\
\hline Atrial fibrillation (n, \%) & $6(47)$ & $77(63)$ & 0.2 \\
\hline Coronary artery disease (n, \%) & $2(15)$ & $24(19)$ & 0.7 \\
\hline Diabetes (n, \%) & $2(15)$ & $18(14)$ & 0.8 \\
\hline $\operatorname{COPD}(n, \%)$ & $1(8)$ & $18(14)$ & 0.4 \\
\hline Chronic renal failure (n, \%) & $4(30)$ & $18(14)$ & 0.1 \\
\hline Hemolysis (n, \%) & $3(23)$ & $46(36)$ & 0.5 \\
\hline NYHA class III-IV (n, \%) & $6(46)$ & $74(58)$ & 0.6 \\
\hline Pulmonary hypertension ( $\mathrm{n}, \%$ ) & $5(38)$ & $68(53)$ & 0.3 \\
\hline More than 1 REDO (n, \%) & $7(53)$ & $54(42)$ & 0.5 \\
\hline Logistic EuroScore (\%, mean \pm SD) & $15 \pm 3$ & $15 \pm 1$ & 0.8 \\
\hline
\end{tabular}

$\mathrm{SD}=$ standard deviation; $\mathrm{COPD}=$ Chronic Obstructive Pulmonary Disease; NYHA= New York Heart Association; REDO $=$ cardiac reoperation

+ Student's unpaired t-test for continuous data; chi-square test for categorical data.

\section{Long-term results}

Overall, actuarial survival at follow-up was $39.8 \pm 7 \%$ at 12 years. Long-term actuarial survival was significantly lower in patients who had more than 1 cardiac reoperation at the time of index procedure $(42 \pm 8 \%$ Vs $63 \pm 6 \%$ at 9 years; $p=0.009)$.

Median follow-up of the TAp subgroup was 20.8 months (IQR 9;23 months). Major adverse events included: 1 patient died from heart failure 22 months after the index procedure because of heart failure and severe hemolysis due to recurrent MR; 1 patient had recurrent MR with heart failure symptoms and re-hospitalization, in absence of hemolysis. No other major events were observed.

\section{Discussion}

Of all implanted surgical prosthetic heart valves, 5 to $17 \%$ will eventually develop PVL and about 5\% of total PVLs require reoperation (1), usually because of severe heart failure symptoms and/or persisting hemolysis requiring blood transfusions. Historically reoperation was the standard treatment $(3,5-6)$ and it was associated with improved survival and symptoms compared to conservative management in symptomatic patients with PVL (3). However, redo surgery is associated with high morbidity and mortality. Different series report in-hospital mortality between 6 and 22\% after surgical reoperation for PVL and increased risk was observed in patients severely symptomatic (NYHA 
class III-IV and severe haemolysis) (3,5). Multiple reinterventions and associated copathologies may further increase operative risk. Since first reported by Hourihan et al. (12), percutaneous PVL closure was proposed as an attractive less invasive alternative to surgical closure and was found to alleviate the consequences and symptoms of PVLS in high-risk patients.

Percutaneous PVL repair can be performed antegradely or retrogradely and via venous, arterial or transapical access (13). Access site selection depends on the location of the prosthesis, the location of the defect in relation to the valve, the presence of mechanical valves, operator's experience and preference and anatomical peculiarities of the individual patient; closure of aortic PVL is mostly performed retrograde from the femoral artery, while closure of mitral PVL is more challenging than aortic and is mostly performed using a femoral transvenous-transeptal approach.

An alternative access described for mitral PVL repair is the transapical approach. Transapical route has been shown to be a simple and safe approach for both aortic and mitral transcatheter valve implantation (14-15). This approach allows the most direct engagement of PVL irrespective of defect location (especially for mitral PVL), but very few data are reported today in the literature and precise clinical results of this approach compared to conventional route are currently unknown.

Technical success rates of transcatheter PVL closure vary from 60 to $90 \%$ according to published data, which included both aortic and mitral PLVs (11,16-18). The largest series of transcatheter PVL closure via the transfemoral approach (115 patients including 78\% mitral PVLs) by Sorajja et al. (11) reported a technical success rate for device deployment (defined as no or only mild residual leak in the absence of prosthetic obstruction or any major adverse events) in mitral PVLs of 76\%. Cortes et al. (17), in a series of 27 transcatheter mitral PLV closures via the transfemoral route reported successfully implantation in $63 \%$ of patients, with a $50 \%$ reduction in mitral regurgitation. In another large series consisting of 43 patients by Ruiz et al. (18), where the transapical approach was used for the majority of mitral PVLs, technical success rate for device deployment in mitral PVLs was 89\%, although the precise percentage of TAp cases was not reported.

Technical complexity of transfemoral PVL closure remains an issue: the use of TAp approach may allow safe, direct and simple access and exit to PVL and would reduce the need for more complex transvenous-transseptal approach for mitral PVL repair, possibly improving acute procedural success.

Jelnin et al. (9) showed that the transapical access, thanks to the more direct approach to the target, led to a significant decrease in the procedural and fluoroscopy times for closure of mitral PVLs compared to conventional procedures, with low complication rate.

Smolka et al. (19) reported a small series of 7 patients with mitral PVLs who underwent transapical closure with the Amplatzer Vascular Plug III device: excellent sealing of mitral PVL was obtained in 6/7 cases. This resulted in HF symptom reduction and de- 
creased NT-proBNP plasma concentration. No procedure-related complications were observed, suggesting that transapical access could be an efficient and safe alternative for transvascular approach for mitral transcatheter PVL closure.

The safety and efficacy of TAp PVL repair has never been compared to surgical reoperation in a randomized trial.

In the present study, the single-centre experience with the surgical and percutaneous TAp treatment of PVL in selected high-risk patients was reported. Notably, the two categories were different and patients undergoing surgical closure were in slight better condition. The patients treated with the TAp approach were at very high risk for surgery. This paper shows that even high-risk patients for surgery can be treated with excellent peri-procedural results, because the in-hospital mortality was $0 \%$ in TAp patients. The program of hybrid TAp PVL closure is functional for a global reduction of procedural-related mortality and morbidity in these complex and high-risk patients. On the contrary to the past, the current implementation with a less invasive treatment is extremely appealing, allowing for a better patient selection and a tailored strategy that could decrease the risk profile of surgical patients. Therefore, the addition of a hybrid programme to a surgical programme could help to relieve the undertreatment of patients with PVLS.

Safety. The results of the present study showed the safety of TAp approach for PVL closure, even in the presence of an extremely high surgical risk (about 19\% of Logistic EuroScore). Patients who underwent TAp closure had a higher risk profile, mainly due to a higher prevalence of COPD and to more previous cardiac operations: it has been showed that mortality increases progressively with the number of reoperations: $13 \%$ after the first, $15 \%$ after the second, and 37\% after the third (7). In the present study, about $80 \%$ of the patients of the TAp group had more than 1 previous cardiac operation, compared to about $40 \%$ of the patients of surgical group.

In spite of a much worse risk profile at baseline, no in-hospital deaths were observed in TAp group.

These results suggest that in high-risk patients with suitable anatomy who are not amenable for surgery, a less-invasive approach should be considered, in order to improve clinical outcomes. On the other hand, in-hospital mortality in the surgical group was acceptable and congruent with other surgical series $(3,5,7)$ confirming that appropriate patient selection is the key to achieving good results also in high-risk setting.

Efficacy. Regarding efficacy, acute procedural success was achieved in $98 \%$ of surgical patients and in $94 \%$ of TAp patients. Re-leak after surgical closure of the primary PVL remains an issue (incidence of recurrent significant PVL up to $22 \%$, with a linearized rate of recurrence of $1 \%$ patient-year) (3).

In our experience, all the patients in which the devices were successfully deployed (all but 1) had a significant reduction in PVL grade; in all these cases residual PVL grade was less than moderate at discharge. These results favourably compare with the acute procedural success reported in the literature with different and technically more de- 
manding approaches $(11,16-18)$, suggesting that the TAp approach may be a very simple and effective therapeutic option in this context. The main advantage of the TAp approach for mitral PVL closure is the proximity of the access to the therapeutic target: this element allows easy implantation of multiple plugs when required, aiming in the majority of the cases the complete obliteration of the PVL (using on average more than 2 plugs per patients, in our series procedural success was 94\%). However, precise evaluation of the anatomy is crucial in order to obtain the complete elimination of the regurgitant jet, which is not always feasible. There are leaks with a multichannel and tortuous course, in which complete obliteration of the cavity may be technically extremely challenging. Preoperative imaging with angio-CT scan and 3D TEE plays a fundamental role in the patient selection and in the planning of the procedure; also the use of 3D TEE live guidance during the procedure plays an important role to further improve the success rate.

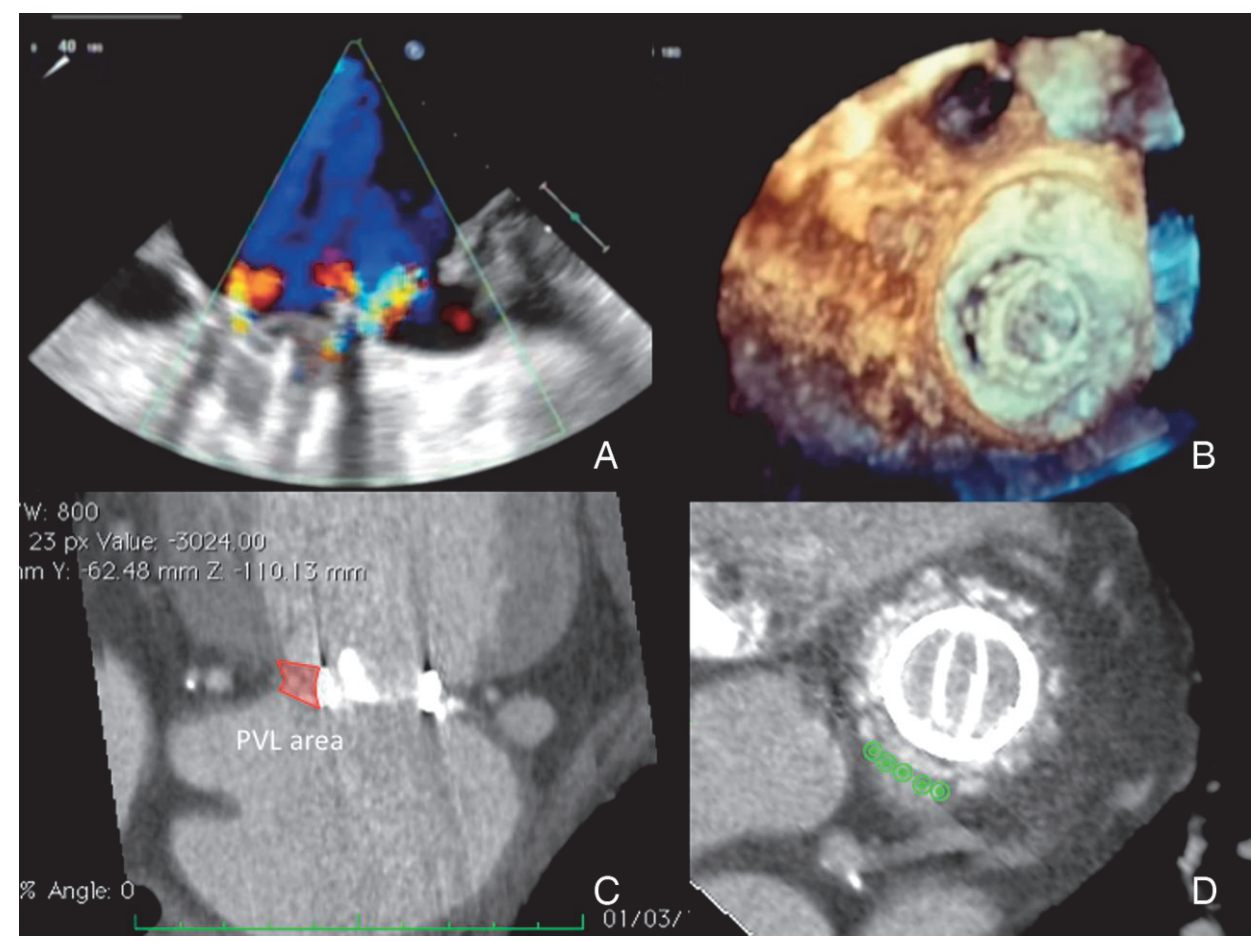

Figure 2: Pre-operative imaging of a wide crescent-shape mitral paravalvular leak in the anterolateral position. (A) and (B) Two-dimensional and 3D echocardiographic imaging. (C) The longitudinal section of the anatomic course of the leak at angio-CT scan (red area); this view is important to determine the tortuosity of the leak channel, which can make the procedure technically demanding. (D)The precise extension of the leak on the annular plane (green spots); this view is useful to predict the eventual need for multiple plugs. 
Follow-up data confirmed that clinical outcomes in this challenging population are still suboptimal. Although a satisfactory outcome was observed in TAp patients, longer follow-up data would be needed for this subgroup.

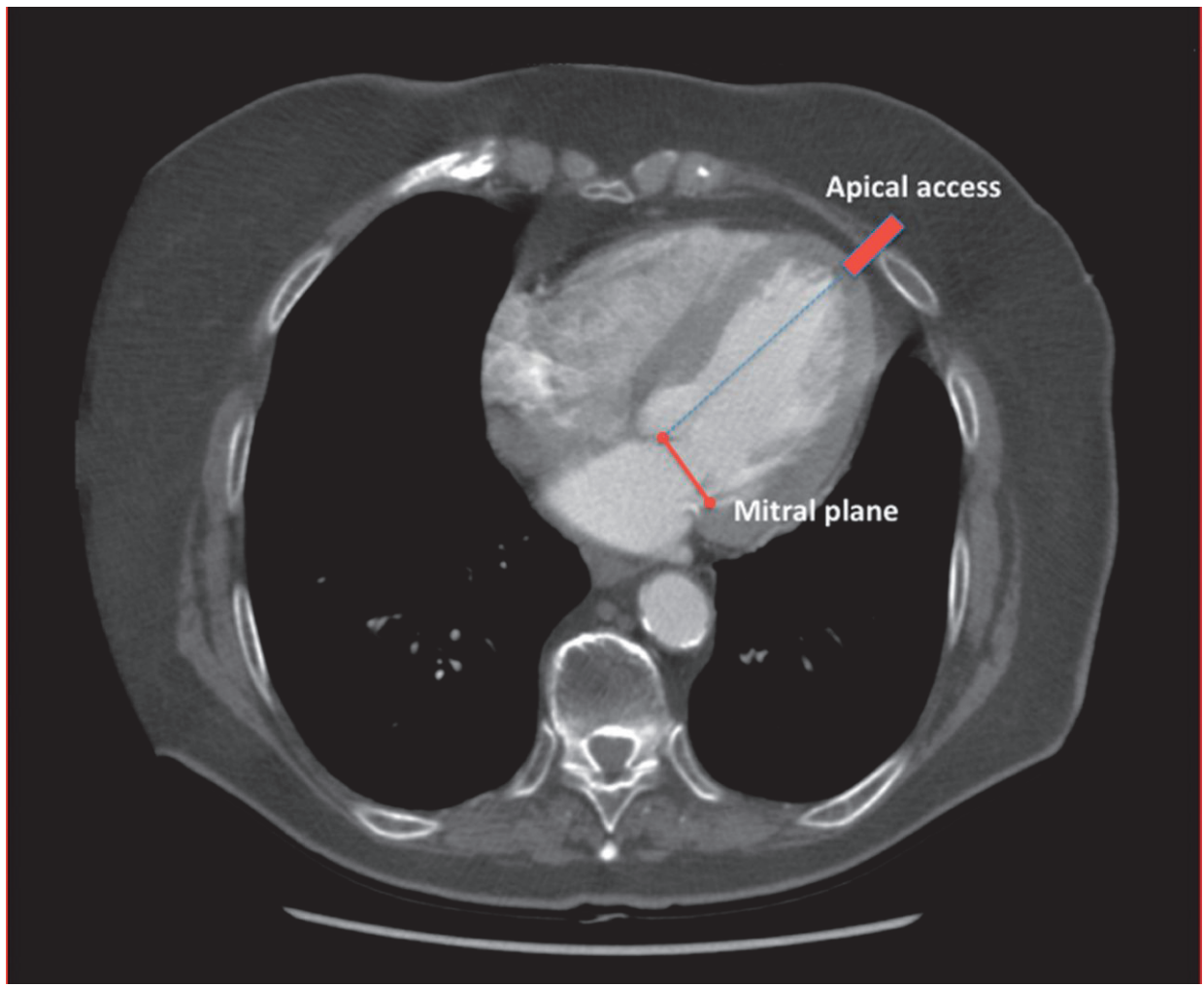

Figure 3: Axial CT-scan section showing the proximity of the apical access to the therapeutic target.

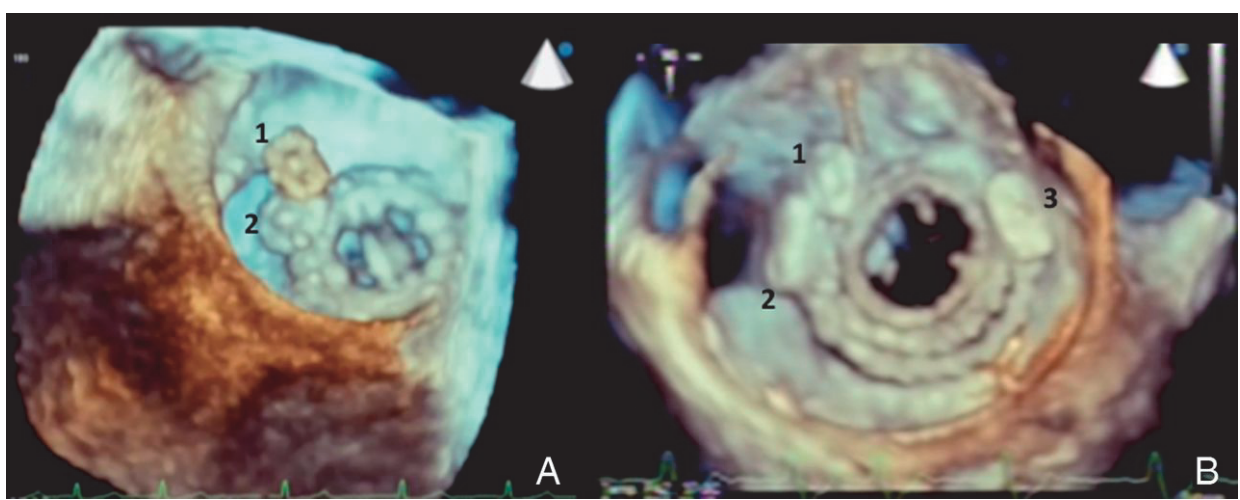

Figure 4: Two cases of post-procedural 3D echocardiography showing multiple plugs implantation [two in (A) for a single large leak; three in (B) for two separate leaks in different positions], with optimal procedural result. 


\section{Conclusions}

According to the satisfactory results reported in this study, transcatheter TAp closure should be always considered in patients with unacceptable or high surgical risk. Considering the excellent success rate in terms of safety and efficacy in this very high-risk population, TAp approach could be considered as a first line therapy alternatively to surgical treatment also in selected intermediate risk patients with mitral PVL. Long-term outcomes in these challenging patients are suboptimal and are available only for conventional surgical treatment.

In the next years, the use of dedicated percutaneous apical closure devices will allow safe access and exit for a fully percutaneous apical approach to PVL and will reduce the need for the more complex transvenous-transseptal approach for mitral PVL repair.

\section{Limitations of the study}

This study was an observational, retrospective single center study; therefore the size was too small to make strong conclusions. The groups were not randomized into the different treatment arms, and results include the initial learning curve. Moreover, the two groups of this study are not numerically homogeneous. In particular, the number of patients of TAp group is very small compared to the surgical group. Randomized selected groups would be required in a prospective study in order to compare the different treatments and to eliminate selection bias and to make direct comparisons of the results. 


\section{References}

1. Hammermeister K, Sethi GK, Henderson WG, Grover FL, Oprian C, Rahimtoola SH. Outcomes 15 years after valve replacement with a mechanical versus a bioprosthetic valve: final report of the Veterans Affairs randomized trial. J Am Coll Cardiol 2000;36:1152-8.

2. Ionescu A, Fraser AG, Butchart EG. Prevalence and clinical significance of incidental paraprosthetic valvar regurgitation: a prospective study using transoesophageal chocardiography. Heart 2003;89:1316 -21.

3. Genoni $M$, Franzen $D$, Vogt $P$, et al. Paravalvular leakage after mitral valve replacement: improved longterm survival with aggressive surgery? Eur J Cardiothorac Surg 2000;17:14 -9.

4. Bloch G, Vouhe PR, Menu P, et al. Long-term evaluation of bioprosthetic valves: 615 consecutive cases. Eur Heart J 1984;5 Suppl D:73-80.

5. Jindani A, Neville EM, Venn G, Williams BT. Paraprosthetic leak: a complication of cardiac valve replacement. J Cardiovasc Surg (Torino) 1991;32:503-8.

6. Miller DL, Morris JJ, Schaff HV, Mullany CJ, Nishimura RA, Orszulak TA. Reoperation for aortic valve periprosthetic leakage: identification of patients at risk and results of operation. J Heart Valve Dis 1995;4:160-5.

7. Echevarria JR, Bernal JM, Rabasa JM, Morales D, Revilla Y, Revuelta JM. Reoperation for bioprosthetic valve dysfunction. A decade of clinical experience. Eur J Cardiothorac Surg. 1991;5:523-6.

8. Garcia-Borbolla Fernandez R, Sancho Jaldon M, Calle Perez G, et al. Percutaneous treatment of mitral valve periprosthetic leakage. An alternative to high-risk surgery? Rev Esp Cardiol 2009;62:438-41.

9. Jelnin $V$, Dudiy $Y$, Einhorn BN, et al. Clinical experience with percutaneous left ventricular transapical access for interventions in structural heart defects a safe access and secure exit. JACC Cardiovasc Interv. 2011;4:868-74.

10. Lancellotti P, Tribouilloy C, Hagendorff A, et al. Recommendations for the echocardiographic assessment of native valvular regurgitation: an executive summary from the European Association of Cardiovascular Imaging. Eur Heart J Cardiovasc Imaging. 2013;14:611-44.

11. Sorajja P, Cabalka AK, Hagler DJ, Rihal CS. Percutaneous repair of paravalvular prosthetic regurgitation: acute and 30-day outcomes in 115 patients. Circ Cardiovasc Interv. 2011;4:314-21.

12. Hourihan M, Perry SB, Mandell VS, et al. Transcatheter umbrella closure of valvular and paravalvular leaks. J Am Coll Cardiol. 1992;20:1371-7.

13. Binder RK, Webb JG. Percutaneous mitral and aortic paravalvular leak repair: indications, current application, and future directions. Curr Cardiol Rep. 2013;15:342.

14. Walther T, Thielmann M, Kempfert J, et al. One-year multicentre outcomes of transapical aortic valve implantation using the SAPIEN XT ${ }^{\mathrm{TM}}$ valve: the PREVAIL transapical study. Eur J Cardiothorac Surg. 2013;43:986-92.

15. Cheung A, Webb JG, Barbanti M, et al. 5-year experience with transcatheter transapical mitral valve-invalve implantation for bioprosthetic valve dysfunction. J Am Coll Cardiol. 2013;61:1759-66.

16. Hein R, Wunderlich N, Robertson G, Wilson N, Sievert H. Catheter closure of paravalvular leak. Eurolntervention 2006;2:318-25.

17. Cortes M, Garcia E, Garcia-Fernandez MA, Gomez JJ, Perez-David E, Fernandez-Aviles F. Usefulness of transesophageal echocardiography in percutaneous transcatheter repairs of paravalvular mitral regurgitation. The American journal of cardiology 2008;101:382-6.

18. Ruiz CE, Jelnin V, Kronzon I et al. Clinical outcomes in patients undergoing percutaneous closure of periprosthetic paravalvular leaks. Journal of the American College of Cardiology 2011;58:2210-7.

19. Smolka G, Pysz P, Jasinski M, et al. Transapical closure of mitral paravalvular leaks with use of amplatzer vascular plug III. J Invasive Cardiol. 2013;25:497-501. 
Chapter

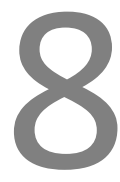

Discussion 



\subsection{Current issues: wrap-up}

My research tried to focus on some current issues in interventional mitral valve procedures.

In the last year, I have concentrated my personal research on the definition of the optimal candidate or optimal approach for some existing procedures in order to reduce invasiveness and improve outcomes (as for the MitraClip and for the paravalvular leak occlusion), as well as on the preclinical development of new approaches (as the Cardioband) and the subsequent introduction in the clinical practice. Based on these experiences, I have also tried to speculate how the next future of transcatheter mitral valve intervention can be with the introduction of the replacement technologies.

\subsubsection{The clinical role of MitraClip}

At the moment, the mitral intervention with the widest clinical use is the MitraClip System. MitraClip can be used to treat both DMR and FMR and, according to the last European and American Guidelines for the management of heart valve disease, can be considered in high risk or inoperable patients with severe symptomatic MR.

However, there is a huge lack of evidence in this field in order to define the optimal candidate for this therapy, which patients could benefit more from a less invasive treatment and which is the correct timing to achieve clinical benefit. Therefore, MitraClip has been considered by many physicians a palliative therapy for end-stage patients with no alternative option.

Today, the learning curve of the MitraClip therapy is completed and in experienced hands optimal results can be achieved. In order to obtain also optimal clinical results, there is a need for a precise definition of the clinical and anatomical characteristics of the ideal candidate for this procedure.

In the "Heart Team" era, evidences are required in order to define reproducible and algorithms to guide the appropriate decision making process in every single patient to define which therapy is more appropriate for which patient.

\section{MitraClip in degenerative mitral regurgitation}

Degenerative $\mathrm{MR}$ is particularly frequent in the elderly. Advanced age is a common contraindication for cardiac surgery, particularly in high-risk patients with comorbidities, such as pulmonary and renal impairment, associated coronary artery disease, and neurological disorders. In elderly patients with DMR who are not eligible for conventional surgery, percutaneous valve repair is emerging as a viable alternative therapeutic option (18), because these interventions are associated with reduced perioperative mortality, clinical improvement, and faster recovery than is possible with surgical procedures. However, given that surgery remains the gold-standard treatment and should 
still be considered an option regardless of a patient's age, transcatheter mitral valve repair should be performed only in candidates who will gain the most benefit from it. The balance between the risks and benefits, and the value versus the futility of procedures to treat degenerative mitral regurgitation in elderly patients should be assessed by a specialized multidisciplinary care team.

Currently, most patients undergoing the MitraClip procedure are nonsurgical highrisk candidates.

According to the ESC 2012 Guidelines (23), the percutaneous edge-to-edge procedure may be considered in patients with symptomatic severe DMR who fulfil the echocardiographic criteria of eligibility, are judged inoperable or at high surgical risk by a "Heart Team," and have a life expectancy greater than 1 year (class IIb, level of evidence C).

The High Risk Study (HRS), an arm of the EVEREST II trial, enrolled symptomatic patients with moderate to severe or severe MR for whom surgical perioperative risk of mortality was estimated to be higher than 12\%, using either the Society of Thoracic Surgeons (STS) calculator or surgeon co-investigator estimated mortality risk of at least $12 \%$ based on prespecified criteria. A degenerative aetiology was present in 105 patients. Thirty-day mortality was $6.7 \%$. At 1-year, $85 \%$ of the DMR patients had sustained a reduction in MR; $87 \%$ of the patients improved to a NYHA functional class I/II at 1year. The annual rate of hospitalization for heart failure was significantly reduced compared to baseline after MitraClip implantation (17).

In the ACCESS-EU study, out of 567 patients undergoing the MitraClip procedure, 117 patients (20\%) had a DMR aetiology25. The majority of ACCESS-EU Phase I DMR patients presented multiple co-morbidities at baseline. About $90 \%$ of patients achieved an $\mathrm{MR}$ reduction to grade $\leq 2+$ at discharge. Thirty-day mortality was $6.0 \%$. Overall rate of freedom from MR > grade $2+$ was $75 \%$ at 12 months. Meaningful clinical improvements were observed: $80.8 \%$ of the patients were in NYHA functional class I-II at 1-year follow-up. Both Minnesota Living with Heart Failure questionnaire (MLHFQ) scores and 6MWT distance improved significantly at 12 months compared with baseline. Overall mortality at 1 year was $17 \%$.

The results of the ACCESS-EU DMR study showed that MitraClip therapy might serve as a complementary non-surgical therapeutic option for DMR patients who are considered at high risk or ineligible for surgery, providing significant reductions in MR and improvements in clinical outcomes at 12 months in selected high-risk patients with DMR.

Compared to registries, very good clinical outcomes in the setting of DMR elderly patients were reported in our study, showed in Chapter 2 (27). Forty-eight high-risk consecutive patients with severe DMR underwent MitraClip implantation (mean age 78.5 years; $57 \%$ of the patients were older than 80 years). Mean STS score was $12 \%$ and $71 \%$ of patients were in New York Heart Association class III or IV. The device was successfully implanted in 47 of 48 patients (98\%). In-hospital mortality was very low (2\%), with very low rate of complications and short length of stay. Pre-discharge echocardiog- 
raphy showed a mitral regurgitation reduction to grade $2+$ or less in 43 of 47 patients (91.5\%). Actuarial survival was $89 \%$ and $70.2 \%$ at 1 and 2 years, respectively $(82 \%$ in patients aged $<80$ years and $95 \%$ in patients older than 80 years at 1 year). Freedom from mitral regurgitation $3+$ or greater was $80 \%$ at 1 year and $76.6 \%$ at 2 years. At 1 year, $93 \%$ of survivors were in NYHA class I-II (100\% of patients aged $<80$ years and $88 \%$ of patients aged $\geq 80$ years). Significant quality of life and functional status improvements were documented at follow-up.

The results showed in Chapter 2, alongside the multicentre trials mentioned above, lends further support to transcatheter mitral valve repair as a valuable alternative to surgery in elderly patients with DMR. At present, no data are available to indicate whether the outcomes obtained with transcatheter mitral valve repair in patients with DMR could be improved by ensuring that all such patients are treated in high-volume centres. However, in our opinion, the favourable results reported in our single-centre study suggest that centres with substantial expertise in the treatment (both surgical and percutaneous) of complex presentations of DMR might lead to improved outcomes. The outcomes reported by large multicentre registries could, therefore, have been affected by the initial learning curve, which is more pronounced in low-volume centres.

As we reported, the low rate of postprocedural complications after MitraClip, due to the absence of the surgical trauma, did not prolong recovery time and did not have a significant impact on the quality of life in elderly and high-risk population. Patients who have received the MitraClip demonstrated improved physical and mental quality of life scores.

In this scenario, transcatheter edge-to-edge treatment of DMR could play a relevant clinical role in the near future. Several reports suggest that the reduction in invasiveness of the transcatheter edge-to-edge is associated to low procedural risk and to significant clinical benefit, and this can be beneficial in the subset of very old and high-risk populations. This is particularly true in patients with associated cardiac conditions (i.e., associated coronary artery disease or atrial fibrillation), because transcatheter interventions offer the unique opportunity of staging interventions to mitigate risk. For all these reasons the MitraClip procedure is now approved by the Federal Drug Administration in patients with DMR considered at very high risk for surgical treatment.

The upcoming randomized HIRIDE trial, which will compare MitraClip and surgery in patients with severe DMR at intermediate and high surgical risk, will provide evidences to fill the lack of knowledge in this field, in order to define the best treatment option in this group of patients.

\section{MitraClip and functional mitral regurgitation}

The use of transcatheter edge-to-edge to treat isolated FMR has exactly the same level of evidence and class of indication as the surgical treatment, reflecting a similar lack of evidence to support a more aggressive treatment strategy. In 2012, MitraClip was recommended by both the ESC Heart Failure and ESC/EACTS guidelines on valvular heart disease 
$(23,41)$ for patients with symptomatic severe secondary MR despite optimal medical therapy (including CRT if indicated), with anatomical suitability, who are judged inoperable or at high surgical risk by a team of cardiologists and cardiac surgeons, and with a life expectancy greater than 1 year (recommendation class IIb, level of evidence C).

Several clinical experiences with satisfactory acute and mid-term results in FMR are now reported in the literature $(17,37-39)$.

The High-Risk Registry of the EVEREST II study was the first to suggest a potential prognostic benefit in high-risk patients treated with the MitraClip in patients with FMR (17). Patients treated with the MitraClip had a better survival rate at 1 year compared to a matched group managed with optimal medical treatment alone. In addition, the registry demonstrated a significant reduction in heart failure hospitalization by a factor of approximately $50 \%$ as compared to the year before implantation, improvement in clinical symptoms, and significant LV reverse remodeling over 12 months in patients submitted to MitraClip therapy.

Satisfactory clinical results have been reported in different registries (42-45), even in critically ill patients (NYHA IV) (38), leading to symptomatic improvement in over twothirds of these patients.

However, there is still lack of evidence to support the ideal therapeutic strategy for individual patient with FMR and to predict the clinical outcome after the treatment. Three randomized trial comparing MitraClip therapy versus optimal medical treatment alone in patients with FMR are now ongoing (RESHAPE II and MITRA-FR in Europe; COAPT in United States).

Although surgical repair of severe FMR has been associated with improvement of symptoms and quality of life, the prognostic impact of surgical correction of the condition is debatable. Perioperative mortality is not negligible, ranging from $8.8 \%$ to $21 \%$ in different series, and residual or recurrent mitral regurgitation after surgery still occurs in a considerable number of patients (20\% after three to five years) $(7-10,31,33,35,36)$.

Today, there is an ongoing randomized trial in Europe comparing MitraClip and surgery in FMR patients (the MATTERHORN trial).

In a previous study we retrospectively described the clinical characteristics and outcomes of two groups of patients undergoing correction of FMR with surgical undersized annuloplasty versus MitraClip therapy. In the surgical group, in-hospital mortality was $6.6 \%$ and one-year freedom from mitral regurgitation of $\geq 3+$ was $94 \%$ with $89 \%$ of patients surviving. In the MitraClip group, in-hospital mortality was $0 \%$ and one-year freedom from mitral regurgitation of $\geq 3+$ was $79 \%$ with $88 \%$ of patients surviving. Although rates of recurrent mitral regurgitation were higher with MitraClip, the device proved to be a safe therapeutic option in selected high-risk patients with functional mitral regurgitation and it was associated with lower hospital mortality, in spite of worse preoperative conditions.

Now that it has proven safety, MitraClip is considered as an alternative option for patients with FMR at high surgical risk. Some issues regarding efficacy and long-term 
durability have to be addressed in order to reduce the threshold of risk and expand Mitraclip therapy to lower risk population. Final results of the EVEREST II trial showed that when acute optimal results are achieved with MitraClip, durability up to five years is usually guaranteed (17). MitraClip therapy is not so far a palliative therapy, when properly performed. This implies correct patient selection and timing, advanced procedural imaging and optimal procedural performance. The results reported in Chapter 3 clearly demonstrated the pre-procedural level of pro-BNP are independently related to outcomes (39).

In the next years, MitraClip is probably becoming a first-line option in patients with isolated FMR. Surgery will still be considered in intermediate risk patients, particularly when associate conditions (such as atrial fibrillation and coronary artery disease) are present. However, we need to treat patients at an earlier stage, if we look for a significant prognostic benefit and in this context a heart team approach will be mandatory.

\subsubsection{Percutaneous direct annuloplasty with the Cardioband: from the pre-clincal experiences to the first-in-man trial}

The research in the field of transcatheter mitral annuloplasty reported in Chapters 4 and 5 represents a paradigmatic example of the process of development of a therapy from the pre-clinical to the clinical scenario. The animal experience describerd in Chapter 4 proved safety and feasibility of this approach and, most importantly, allowed us to standardize the different procedural steps. In particular, the development of the "neocava" animal model was mandatory in this regard.

Preliminary results of the first in man trial described in Chapter 5 showed safety of the Cardioband device in high risk patients with FMR. Efficacy at 30 days is comparable to those observed today with the MitraClip in the same clinical context, and favourable compares to MitraClip if we compare the Cardioband results to the first results reported with MitraClip in the real initial phase of its clinical application.

The precise clinical role of transcatheter mitral annuloplasty is still not yet well established, since it is a new therapeutic approach and clinical results are still limited. However, based on the preliminary results and on the lessons learned from surgery, it is possible to try to define which the clinical role of this therapy will be.

- In DMR patients, annuloplasty may represent as an adjunctive therapy in combination with leaflets repair, to achieve better acute results and improve repair durability.

- In FMR patients, annuloplasty might represent a stand-alone procedure, in patients with favourable anatomy. Patients with predominant annular dilatation and limited valve tethering could be the ideal candidates for annuloplasty, while in presence of predominant leaflets tethering, MitraClip could still represent the most appropriate therapy. 
Combination of different technologies may represent an ideal option in selected FMR patients with particularly advanced tethering and LV remodelling, as it has been showed in surgical experience.

The main advantage of direct annuloplasty with the Cardioband device is that the impact of this therapy on the physiology is minimal and safety profile is high. The combination of these two features may potentially support an "early indication" strategy. When patients are treated in a too advanced clinical status, outcomes become poor and transcatheter mitral procedures are unable to modify the clinical course of the disease and to influence the prognosis. The impact of the intervention will be much more efficient when executed early in the clinical course of the disease. Only a very safe procedure can justify a transcatheter "early indication" approach. In fact, when considering an early indication, beyond efficacy, safety plays a dominant role. Transcatheter direct annuloplasty may represent the ideal procedure that could be used a safe first-line therapy in FMR patients. Considering an early indication approach, if comparable efficacy will be proven, direct annuloplasty may present some advantages compared to MitraClip: possibility of valve-in-ring implantation and does not preclude the option of surgery.

\subsubsection{Transcatheter mitral repair and replacement: complementary rather than competitive}

In Chapter 6 we tried to define which the future role of transcathter mitral valve repair and replacement will be. At the moment, given the rapid evolution in device development, the future role of TMVRep and TMVI must be considered only speculative. In general terms, as discussed in Chapter 6, TMVI is likely to be technically simpler and more reproducible in terms of MR reduction. However, durability, safety and disruption of adjacent cardiac structures remain important concerns. Transcatheter mitral valve repair is more complex and likely carries a steeper learning curve, and individual device may be applicable only in selected patients with less predictable MR reduction. Of note, the safety profile of TMVRep is generally excellent, and durability is likely to be robust in most patients when acute procedural success is achieved and the impact of TMVRep on physiology is minimal. Therefore, in our opinion, TMVRep may in the future aspire to an early treatment option, aiming at a prognostic approach.

In low-risk DMR patients, surgical repair will remain the standard of care for many years, with TMVRep and TMVI playing a role in high- risk or inoperable patients, who are not amenable for minimally invasive surgical mitral valve repair or eventually for TMVRep.

In patients with severe FMR, the role of surgery is less well-established in patients who are not candidates for CABG, and most patients are treated medically. Transcatheter mitral valve repair may be a safe, palliative approach for such patients, and several large-scale randomized ongoing trials investigate the effectiveness of the MitraClip in 
this scenario. Transcatheter mitral valve implantation may potentially be a therapeutic option for patients with more advanced disease and severe anatomical and functional abnormalities, who are not eligible for valve repair.

Careful patient selection will play a fundamental role to define which patient could benefit the most from each therapy, and pre-procedural imaging will play a leading role to guide the complex process of patient selection. Some procedures may become complementary, while other procedures may preclude others (i.e. following TMVI there are no options for further repair, and a transcatheter edge-to-edge repair may preclude future TMVI).

The development of TMVRep techniques has already taken 15 years, and transcatheter valve implantation technology will likely require more time until the devices and implant procedure are optimized. In the meantime, there will be room for both surgery and current TMVRep devices.

In the future, focus should be placed in designing and testing new devices, improving imaging guidance, and then carefully evaluate the risks and benefits of each promising approach in individual patients in varying clinical settings, ultimately relying on randomized trial evidence to guide clinical decision-making.

\subsubsection{Transcatheter occlusion should become the first-line treatment for perivalvular leak}

Reduction of invasiveness and of procedural risks represents a constant element of our own research. The study showed in Chapter 7 was the first comparing the outcomes of transapical transcatheter approach to treat mitral PVL to the surgical treatment, which still represent the gold standard therapy in many cases. The safety profile of the transcatheter closure through the transapical access ( $0 \%$ mortality compared to almost $10 \%$ mortality observed with surgery), together with its technical simplicity, makes clear in our opinion that the percutaneous approach should be considered as a first line therapy alternatively to surgical treatment in all the patients with mitral PVL. Although longterm follow-up of this approach are still lacking, our group demonstrated that long term results of surgical treatment are suboptimal, and this observation may justify the use of the transapical transcatheter approach even in younger patients. Compared to a fully percutantous transseptal approach, the transapical route has the advantage to be technically easy, since wiring the leak is facilitated by the retrograde direction of the regurgitant blood and by the coaxiality ensured by the transapical puncture. The advantage is particularly evident in medial defects, which can be sometimes impossible to cross with an antegrade approach.

On the other hand, transapical approach is more invasive and requires general anesthesia. Therefore, in experienced centres transseptal antegrade approach is usually attempted first. 

Chapter

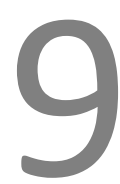

Summary 



\section{Introduction}

The clinical impact of heart valve disease are constantly growing in the last years. Advancements in valve surgery and, more recently, in transcatheter valve interventions, are rapidly shifting therapeutic management by enabling less invasive options for patients. Over the past few years, new transcatheter techniques have been developed to treat mitral MR with less invasive approaches. Different types of transcatheter procedures are becoming available. Currently, the device with the widest clinical use is the MitraClip System, which can be used to treat both degenerative mitral regurgitation (DMR) and functional mitral regurgitation (FMR). Beyond the MitraClip device, additional repair and replacement technologies are being developed to expand the transcatheter mitral intervention armamentarium.

\section{Main Results}

In the first chapter, the epidemiology and clinical background of the clinical need to develop less invasive treatment for mitral valve disease is discussed. The device that at the moment has the largest clinical diffusion (the MitraClip system) is introduced, describing its favourable results in high-risk patients with both degenerative and functional mitral regurgitation.

The Cardioband is another percutanoeus device recently introduced in the clinical practice and it is introduced as well in Chapter 1 . At the end of the chapter, current challenges in the field of mitral valve interventions are discussed.

In Chapter 2, the role of MitraClip therapy in high-risk patients with DMR is discussed.

In a single large volume centre experience, 48 high-risk consecutive patients with severe DMR underwent MitraClip implantation. Procedural success was obtained in $98 \%$, with an in-hospital mortality of $2 \%$. Pre-discharge echocardiography showed an MR reduction to grade $\leq 2+$ in $91.5 \%$. This study showed that MitraClip therapy is a valuable alternative to surgery in high-risk and elderly patients with DMR, with significant clinical benefits also in octogenarians.

In Chapter 3, the issue of MitraClip therapy in heart failure patients with severe FMR is discussed. Whether MitraClip could confer to patients with FMR a survival benefit in adjunction to optimal medical therapy is not yet supported by randomized data.

More than 100 consecutive patients with FMR underwent MitraClip implantation. Procedural success was $99 \%$ and 30 -day mortality was $1.8 \%$. At discharge, $87 \%$ patients had $\mathrm{MR} \leq 2+$. At 12 months, EF improved from $28 \pm 11$ to $35 \pm 10 \%$. At one-year follow-up, $86 \%$ of patients were in NYHA Class I-II. Preoperative pro-BNP level $\geq 1,600 \mathrm{pg} / \mathrm{ml}$ was identified as an independent risk factor of mortality at follow-up. 
In Chapter 4, safety and feasibility of a new direct mitral annuloplasty treatment has been successfully assessed in large animal model. The study demonstrated for the first time that transcatheter direct annuloplasty with a surgical-like adjustable device was feasible. The most valuable aspect of this preclinical study was that it has been fundamental to establish and standardize the procedural steps before moving to the first-inman clinical study.

In Chapter 5, the results of the first-in-man Cardioband study are reported. The firstin-man study enrolled 31 high-risk heart failure patients with symptomatic functional MR from 5 different institutions in Europe. All patients received the full implant of a Cardioband. Procedural mortality was zero and in-hospital mortality was 6.5\%. At 30 days $88 \%$ of the patients had $M R \leq 2+$.

In Chapter 6, the present and the future clinical role of repair techniques vs replacement is presented. Since clinical experience with replacement is really preliminary and all the patients treated with this approach are so far really sick candidates with prohibitive risk, it is really difficult to properly define which patients could benefit most from replacement versus repair. The specific aim of Chapter 6 is to state few important clinical and pathophysiological considerations in order to clarify when and why a repair strategy should be preferred over replacement. In particular, durability, safety and distortion of the physiology remain major concerns regarding replacement as compared to repair.

Chapter 7 focuses on mitral paravalvular leak (PVL) closure. We were the first to compare safety of transcatheter PVL closure through apical access to the standard surgical treatment, showing that transcatheter approach represents a safer option, in term of periprocedural mortality and complications. In particular, surgical treatment was identified as a risk factor for in-hospital death.

\section{Discussions of the results}

In Chapter 8, the different clinical and technical aspects of transcatheter mitral valve interventions are discussed. In particular, in the first section the clinical role of the MitraClip therapy in both degenerative and functional MR are discussed, focusing of proper patient selection and interventional timing in order to optimize the results.

The second section discusses the evolution of the idea of transcatheter direct mitral annuloplasty from preclinical animal testing to the clinical application, describing also the specific features of this type of approach, compared to other mitral repair devices.

The third section focuses on the interventional hot-topic of percutaneous repair vs replacement technique. In particular, it is reported why in my opinion repair should be in the future the preferred option whenever feasible and why repair and replacement will be two complementary rather than competitive approaches. 
Finally, the last section describes the challenging procedure of mitral PVL occlusion, focusing on safety and efficacy of the percutaneous approach compared to the standard surgical treatment. 

Samenvatting (Summary in Dutch) 



\section{Introductie}

De klinische impact van hartklepafwijkingen groeit elk jaar. Vooruitgang in klepchirurgie en, meer recent, in transkatheter interventies, zorgen voor een snelle verschuiving in therapie naar minder invasieve opties. In de afgelopen jaren zijn verschillende nieuwe transkatheter technieken ontwikkeld voor de behandeling van mitralisklepinsufficiëntie (MI) middels een minder invasieve benadering. Verschillende soorten transkatheter technieken zijn beschikbaar gekomen. Momenteel is de MitraClip het device met de breedste klinische toepassing aangezien het geschikt is voor de behandeling van zowel degeneratieve mitralisklepinsufficiëntie (DMR) als functionele mitralisklepinsufficiëntie (FMR). Naast de MitraClip zijn er aanvullende transkatheter technologieën ontwikkeld om de beschikbare instrumentaria uit te breiden voor klepreparatie en klepvervanging.

\section{Belangrijkste resultaten}

In het eerste hoofdstuk worden de epidemiologische en klinische achtergrond van mitralisklep aandoeningen besproken om de noodzaak tot het ontwikkelen van minder invasieve therapieën duidelijk te maken. Het device met momenteel de grootste klinische indicatie (MitraClip) wordt geïntroduceerd, waarbij de gunstige resultaten in hoogrisicopatiënten met zowel degeneratieve als functionele mitralisklepinsufficiënties worden beschreven. De Cardioband, een ander percutaan device dat recentelijk is geïntroduceerd in de klinische praktijk, wordt tevens in dit hoofdstuk beschreven. Op het einde van dit hoofdstuk worden de uitdagingen op het gebied van mitralisklep interventies benoemd.

In hoofdstuk 2 wordt de rol van behandeling met de MitraClip in hoog-risicopatiënten met DMR beschreven. In een centrum met veel ervaring hebben 48 opeenvolgende patiënten met ernstige DMR een MitraClip implantatie gekregen. De procedure was succesvol in $98 \%$ van de patiënten met een in-hospital mortaliteit van $2 \%$. Echocardiografie verricht voor ontslag liet in $91.5 \%$ van de patiënten een reductie van de $\mathrm{MI}$ naar graad $\leq 2+$ zien. Deze studie toont dat implantatie van een MitraClip een waardevolle alternatieve behandeling is vergeleken met chirurgie in hoog-risico en oudere patiënten met DMR, met tevens significant klinische voordelen voor octogenarians.

In hoofdstuk 3 wordt de behandeling met MitraClip implantatie in patiënten met decompensatio cordis en ernstige FMR besproken. Het is nog niet bewezen middels gerandomiseerd onderzoek dat implantatie van de MitraClip on-top-of optimale medicamenteuze therapie bij patiënten met FMR bijdraagt aan een betere overleving. Meer dan 100 opeenvolgende patiënten met FMR ondergingen een MitraClip implantatie. De procedure was succesvol in 99\% van de patiënten met een 30-dagen mortaliteit van $1.8 \%$. Op het moment van ontslag hadden $87 \%$ van de patiënten een $\mathrm{Ml}$ graad $\leq 2+\mathrm{Na}$ 12 maanden was de EF verbeterd van $28 \pm 11 \%$ naar $35 \pm 10 \%$. Tijdens de follow-up na 
één jaar hadden $86 \%$ van de patiënten NYHA-klasse I-II. Een pro-BNP waarde van $\geq 1,600$ $\mathrm{pg} / \mathrm{ml}$ preoperatief was een onafhankelijke risicofactor van mortaliteit gedurende de follow-up.

In hoofdstuk 4 is de veiligheid en haalbaarheid van een nieuwe directe annuloplastiek van de mitralisklep succesvol onderzocht in een diermodel. Dit is de eerste studie die laat zien dat transkatheter directe annuloplastiek haalbaar is met een verstelbaar device vergelijkbaar met devices die worden gebruikt in de chirurgie. Het belangrijkste van deze preklinische studie was het verkrijgen en standaardiseren van de procedurele stappen voordat deze techniek op patiënten toegepast gaat worden.

In hoofdstuk 5 worden de eerste resultaten van de first-in-man Cardioband studie getoond. In 5 verschillende centra in Europa werden 31 hoog-risico decompensatio cordis patiënten met symptomatisch FMR geïncludeerd. Alle patiënten ondergingen de volledige implantatie van een Cardioband. Procedure gerelateerde mortaliteit was nul en in-hospital mortaliteit 6.5\%. Tijdens de 30-dagen follow-up hadden $88 \%$ van de patienten een $\mathrm{Ml}$ graad $\leq 2+$.

In hoofdstuk 6 worden de huidige en toekomstige klinische rol van klepreparatie versus klepvervanging gepresenteerd. Het is nog moeilijk om goed te bepalen welke patiënten het meest baat hebben bij klepreparatie vergeleken met klepvervanging vanwege de beperkte klinische ervaring met klepvervanging en de zieke hoog-risico populatie die tot nu toe met deze techniek is behandeld. Het specifieke doel van hoofdstuk 6 is het benoemen van enkele belangrijke klinische en pathofysiologische overwegingen om duidelijk te maken wanneer en waarom klepreparatie de voorkeur heeft boven klepvervanging.

Hoofdstuk 7 richt zich op het sluiten van paravalvulaire lekkage (PVL) van de mitralisklep. Wij hebben voor de eerste keer de veiligheid van het sluiten van PVL met een transkatheter via een apicale benadering vergeleken met de standaard chirurgische behandeling. De benadering middels transkatheter is een meer veilige optie gekeken naar periprocedurele mortaliteit en complicaties. De chirurgische benadering is met name een risicofactor voor in-hospital overlijden.

\section{Discussie}

In hoofdstuk 8 worden de verschillende klinische en technische aspecten van transkatheter mitralisklep interventie beschreven. De eerste paragraaf richt zich op de klinische rol van de MitraClip in zowel degeneratieve als functionele MI, met als focus het selecteren van geschikte patiënten en timing van interventie zodat de meest optimale resultaten worden verkregen.

De tweede paragraaf bespreekt het ontstaan van directe transkatheter mitralisklep annuloplastiek van de preklinische dierproeven tot klinische applicatie, waarbij tevens 
de specifieke kenmerken van deze benadering worden beschreven in vergelijking met andere devices gebruikt voor de reparatie van de mitralisklep.

In de derde paragraaf wordt het hot-topic onderwerp van percutane klepvervanging versus klepreparatie technieken besproken. Er wordt vermeld waarom, in mijn mening, in de toekomst indien mogelijk klepreparatie moet worden gekozen en waarom klepreparatie en klepvervanging elkaar kunnen aanvullen in plaats van competitief zijn.

In de laatste paragraaf wordt de uitdagende procedure van mitralisklep PVL occlusie beschreven waarbij de focus ligt op veiligheid en effectiviteit van de percutane benadering vergeleken met de standaard chirurgische behandeling. 

Valorisation of research 

My own research over the last years has been focused on heart valve disease. In particular, the main focus was interventional mitral valve therapies. My interest in this regard was the direct consequence of the growing clinical importance of these new types of therapies, which have become progressively available to treat patients who were before denied to conventional surgical treatment, due to the high risk. This was mainly due to the rapid improvement of the technologies and of the imaging procedural guidance.

But the most challenging question are now, once several new devices are available and implantation has been demonstrated to be feasible: which patient really can profit from these new therapies? Which are the best candidates from an anatomical and clinical standpoint? Which is the best procedural timing in order to obtain a prognostic benefit?

I tried to answer to some of these questions with my research, which gave a significant contribution in this regard.

In particular, I started to focus on the MitraClip therapy that nowadays counts more than 40,000 implant worldwide. MitraClip therapy was initially proposed as an alternative to surgery, while now represent the ideal treatment for high risk or inoperable patients with both degenerative and functional mitral regurgitation, as recommended by the European and American Guidelines for the management of heart valve disease. However, there are still several open issues regarding patient selection and optimal timing.

I focused my research on both degenerative and functional disease in this regard.

In the next future, randomized trial should compare the outcome of surgery and MitraClip in high-risk elderly patients with degenerative $\mathrm{MR}$ in order to better define the optimal treatment for this population, which is growing according to the increase of life expectancy.

Regarding functional MR, MitraClip is progressively becoming the first line therapy, due to the fact that most of the patient presenting with this condition have prohibitive surgical risk. In order to obtain a prognostic benefit, MitraClip treatment should not be performed too late. Whether MitraClip can really confer survival benefit in heart failure patients with severe functional MR, has still to be demonstrated. This is the most important challenge of the next future, and the ongoing randomized COAPT trial (which compare optimal medical therapy to MitraClip in patients with severe functional MR) should definitely give an answer to this question.

The second part of my research presented in this text focuses on the Cardioband, which is a device to perform a complete percutaneous direct mitral annuloplasty, by implanting a surgical-like band on the atrial surface of the mitral annulus through a transseptal approach. The main advantages of the Cardioband are the high safety profile, due to the minimal impact on the physiology of the heart, and the fact that it keeps the door open for further interventional or surgical treatments. Our group was involved in the development of this technology from the real initial phase, since the concept was invented by Prof. Maisano. Cardioband obtained CE Mark in October 2015. Today, 
about 100 high-risk patients have been treated. The next future challenges in this field are mainly three: 1 ) define the role of Cardioband as a combined therapy with other device (ie. MitraClip + Cardioband), 2) improve procedural Guidance with multimodality imaging, 3) define subgroup of patients with optimal results.

The last part of the manuscript describes other important aspect of modern mitral valve interventions: transcatheter mitral valve replacement and mitral paravalvular leak occlusion.

At the moment, one of the hottest topics in interventional cardiology is the future role of replacement versus repair technologies. Strongly believing that repair will remain the preferred approach and that the 2 methods will be complementary rather that competitive, in absence of data, we gave our contribution by defining some pathophysiologic and anatomical reasons to support why repair should be the preferred method. Since the experience with transcatheter replacement is at the moment really preliminary, any comparison is now just speculative. The next step will be to define the right therapy for the right patient, and this can be done only with rigorous randomized trials.

Finally, we focused on paravalvular leak occlusion. Traditionally, reoperative surgery to treat paravalvular leak has been associated with high risk of mortality. We were the first group to compare surgical results with transcatheter closure performed through transapical access. Transapical access is an alternative to the transseptal route, which has the advantage of a more direct approaching to the mitral valve. The long-term results of this relatively new approach have still to be defined, but our study was pioneering in this regards. Our results have to be confirmed on a larger bases in order to define the best candidate for transapical approach compared to the less invasive transseptal one. 